BRUNO BARAZANI

INVESTIGAÇÕES SOBRE A SINTERIZAÇÃO DE SÍLICA VÍTREA POR PLASMA PULSADO 
BRUNO BARAZANI

\title{
INVESTIGAÇÕES SOBRE A SINTERIZAÇÃO DE SÍLICA VÍTREA POR PLASMA PULSADO
}

\author{
Dissertação apresentada à Escola \\ Politécnica da Universidade de São Paulo \\ para a obtenção do título de Mestre em \\ Engenharia Mecânica.
}

Área de concentração:

Engenharia de Controle e Automação Mecânica

Orientador:

Prof. Dr. Delson Torikai

São Paulo 
Este exemplar foi revisado e alterado em relação à versão original, sob responsabilidade única do autor e com a anuência de seu orientador.

São Paulo, ....... de agosto de 2011.

Assinatura do autor

Assinatura do orientador

FICHA CATALOGRÁFICA

Barazani, Bruno

Investigações sobre a sinterização de sílica vítrea por plasma pulsado / B. Barazani. - ed.rev. -- São Paulo, 2011.

$98 \mathrm{p}$.

Dissertação (Mestrado) - Escola Politécnica da Universidade de São Paulo. Departamento de Engenharia Mecatrônica e de Sistemas Mecânicos.

1. Física (Processos) 2. Vidro cerâmico 3. Quartzo 4. Nanopartículas I. Universidade de São Paulo. Escola Politécnica. Departamento de Engenharia Mecatrônica e de Sistemas Mecânicos II. t. 


\section{Dedicatória}

Dedico este trabalho à minha família que sempre me apoiou e incentivou os meus estudos. 


\section{Agradecimentos}

Ao Prof. Dr. Delson Torikai pela orientação, ensinamentos, atenção, paciência, conversas instigantes sobre novas tecnologias ou mesmo sobre temas cotidianos e por proporcionar um ambiente de trabalho muito agradável nesses 5 anos já de convívio.

À Escola Politécnica da Universidade de São Paulo (EPUSP) onde tive o privilégio de estudar para me formar Engenheiro e realizar o Mestrado.

À Coordenação de Aperfeiçoamento de Pessoal de Nível Superior (CAPES) pelo apoio financeiro.

Ao Grupo de Pesquisa de Sensores e Atuadores do Departamento de Engenharia Mecatrônica e de Sistemas Mecânicos da Escola Politécnica da USP pelo uso das instalações e principalmente do equipamento SPSS (Spark Plasma Sintering System).

Ao LIQC - Laboratório de Materiais \& Dispositivos Fotônicos (Unicamp) - pelo fornecimento da matéria-prima e pelas caracterizações realizadas.

Ao LabMicro - Microscopia Eletrônica e de Força Atômica (EPUSP) - pela caracterização realizada.

Ao colega e amigo Fausto Kenzo Chinen pelo ensinamento sobre o uso do equipamento SPSS e discussões que contribuíram para este trabalho.

Às pessoas que me acompanharam de perto nesses dois últimos anos pesquisando, discutindo e escrevendo trabalhos juntos, Prof. Dr. Ricardo Cury Ibrahim, Lucas Gonçalves Dias Mendonça e Bruno Butilhão Chaves.

Aos professores, colegas, amigos e familiares que de alguma forma contribuíram para a minha formação e/ou para o desenvolvimento deste trabalho. 


\section{Resumo}

A obtenção da sílica vítrea pelo processo de sinterização por plasma pulsado (SPS), a partir de matérias-primas de diferentes estruturas (cristalina e amorfa) e diferentes granulometrias, foi investigada. Análises de difração de raios $X$, transmitância óptica, microscopia óptica e eletrônica de varredura, e medições de densidade foram realizadas nas amostras sinterizadas. Sílicas vítreas transparentes foram fabricadas a partir de pós de quartzo atingindo-se temperaturas finais entre 1450 e $1600^{\circ} \mathrm{C}$, enquanto que nanopó e pó amorfo de sílica formaram consolidados transparentes com temperaturas máximas próximas de $1200^{\circ} \mathrm{C}$. Taxas de aquecimento entre 40 e $150^{\circ} \mathrm{C} / \mathrm{min}$. foram utilizadas nas sinterizações, com tempos de processo menores que 40 minutos. As maiores taxas de aquecimento exigiram uma maior temperatura final para a fusão completa do material cristalino e causaram, de forma indireta, a presença de aglomerações de micro-bolhas nas amostras obtidas com o nanopó. Um gradiente radial de temperatura (decrescente do centro para as bordas) foi observado nos consolidados fabricados com os pós cristalinos, facilitando o processo de fechamento da porosidade aberta. A presença ou ausência de material não fundido e de bolhas nas amostras foram analisadas por difratogramas de raios $\mathrm{X}$, microscopia óptica e medidas de densidade. A análise da transmitância indicou uma quantidade praticamente nula de grupos $\mathrm{OH}$ nos compactos sinterizados com os pós cristalinos e em torno de $20 \mathrm{ppm}$ no caso dos sólidos fabricados com matéria-prima sol-gel. Amostras de nanopós de sílica dopada com titânia ( $6 \%$ em massa) foram processadas com temperaturas finais de $1200 \mathrm{e}$ $1400^{\circ} \mathrm{C}$ apresentando coloração azulada e negra, respectivamente, e aumento dos clusters de titânia para a temperatura mais elevada. A sinterização a uma temperatura em torno $1200^{\circ} \mathrm{C}$ mantida por apenas 4 minutos resultou na conversão completa da fase anatase para a fase rutilo da titânia.

Palavras-chave: Sinterização por Plasma Pulsado; Parâmetros de Processo; Sílica Vítrea; Quartzo; Nanopó; Caracterização Físico-química. 


\begin{abstract}
The production of vitreous silica by the spark plasma sintering (SPS) process, starting from raw materials of different structures (crystalline and amorphous) and granulometry were investigated. Analysis of X-ray diffraction, optical transmittance, optical and scanning electron microscopy, and density measurements were performed on the sintered compacts. Transparent vitreous silica was fabricated from quartz powder at final temperatures ranging from 1450 and $1600^{\circ} \mathrm{C}$ while silica nanopowder and silica powder formed transparent compacts at temperatures around $1200^{\circ} \mathrm{C}$. Heating rates between 40 and $150^{\circ} \mathrm{C} / \mathrm{min}$. were used in processes with durations smaller than 40 minutes. Higher heating rates demanded higher final temperatures to complete the fusion process and caused, indirectly, the formation of micro-bubbles agglomerations in the samples produced from the nanopowder. A radial gradient of temperature (decreasing from the center to the border) was observed at the compacts fabricated with the crystalline powders favoring the closure of the open porosity. The presence or the absence of non-fused material and bubbles in the samples was analyzed by X-ray diffraction, optical microscopy and density measurements. The transmittance analysis indicated an almost zero quantity of $\mathrm{OH}$ groups in the compacts sintered from crystalline powders and about 20 ppm in the solids fabricated from the sol-gel raw material. Nanopowder samples of silica titania ( 6 wt \% of titania) were processed with final temperatures of $1200^{\circ} \mathrm{C}$ and $1400^{\circ} \mathrm{C}$ presenting blue and black coloration, respectively, and an increase of the titania clusters for the highest temperature. The sintering at temperatures near $1200^{\circ} \mathrm{C}$ with a holding time of just 4 minutes caused the complete anatase-rutile conversion in titania.
\end{abstract}

Keywords: Spark Plasma Sintering; Process Parameters; Vitreous Silica; Quartz; Nanopowder; Physicochemical characterization. 


\section{Lista de Figuras}

Figura 3. 1 - Representação simplificado de uma máquina SPS. 6

Figura 3. 2 - Corrente elétrica passando pelo pó em processo de sinterização SPS [4]........ 7

Figura 3. 3 - Coluna de descarga gerando evaporação e fusão da superfície das partículas. 8

Figura 3. 4 - Densidade de corrente nas amostras de Alumina e Cobre [22]. 9

Figura 3.5 - (a) Distribuição de temperatura no molde para amostra de $\mathrm{Al}_{2} \mathrm{O}_{3}$. (b) Temperatura nas amostras de Cobre e Alumina [22]. 9

Figura 3. 6 - Curva de formação do vidro de sílica comparada a de um sólido cristalino [28].

Figura 3. 7 - Estrutura molecular da sílica cristalina (quartzo) e da sílica amorfa [28]......... 13

Figura 3.8 - Transmitância óptica dos tipos 1,2 e 3 de sílica fundida [30].......................... 17

Figura 3. 9 - Índice de refração da sílica vítrea em função da concentração de dopantes [14].

Figura 3. 10 - Expansão térmica da sílica titânia [13]................................................... 19

Figura 3. 11 - Representação esquemática do processo VAD [52]. 21

Figura 4. 1 - Máquina SPS modelo DR. SINTER® - SPS1050 utilizada nos experimentos.. 25

Figura 4.2 - Representação esquemática do sistema de sinterização SPS........................26

Figura 4.3 - Foto de molde e punções com suas respectivas medidas. ..............................27

Figura 4. 4 - Modelo ilustrativo de molde, punção e pó sendo inserido no molde [3]............28

Figura 4.5 - Balança analítica usada na medição da densidade...................................... 31

Figura 5. 1 - Fios de nicromo formando três anéis e envolvendo o molde particionado. .......34

Figura 5. 2 - Configuração com várias camadas de papel grafite entre molde e amostra. ...34

Figura 6. 1 - Amostras aquecidas a $60^{\circ} \mathrm{C} / \mathrm{min}$. e suas respectivas curvas de temperatura. . 36

Figura 6. 2 - Amostras aquecidas a $140^{\circ} \mathrm{C} / \mathrm{min}$. e suas respectivas curvas de temperatura. 37

Figura 6. 3 - Curva de pressão na câmara indicando três picos de liberação de gás na sinterização do pó cristalino. 
Figura 6. 4 - Amostra com face superior e miolo central fundidos (transparentes) de modo que é possível observar o raio laser incidente no centro atravessando a peça.

Figura 6. 5 - Representação esquemática do comportamento da frente de fusão no material (vista em corte).

Figura 6. 6 - Foto e esquema de amostra com frente de fusão em uma das faces. 40

Figura 6. 7 - Foto e esquema de amostra com frentes de fusão nas duas faces. 41

Figura 6.8 - (a) Corte de amostra com bolhas. (b) Esquema da formação de bolhas pelo encontro de frentes de fusão.

Figura 6. 9 - Foto com aumento aproximado de 200x de amostra com bolhas. 42

Figura 6. 10 - Sílica vítrea obtida a partir de nanopó e a respectiva curva de temperatura. . 44

Figura 6. 11 - Micro-bolhas em foto com ampliação próxima de 200x. 44

Figura 6. 12 - Partes da amostra rompida devido ao esforço aplicado na pré-compactação.

Figura 6. 13 - Amostras obtidas a partir do nanopó e suas respectivas curvas de temperatura.

Figura 6. 14 - (a) Material não densificado por completo. (b) Material completamente consolidado.....

Figura 6. 15 - Curvas de temperatura com e sem patamar depois de terminada a consolidação e as amostras resultantes.....

Figura 6. 16 - Amostra livre de bolhas produzida com o nanopó amorfo. 49

Figura 6. 17 - Parâmetros de processo em experimento que gerou amostra sem bolhas....50

Figura 6. 18 - Variação da temperatura no tempo e amostra obtida com pó amorfo de sílica.

Figura 6. 19 - Contração axial em função da temperatura para os diferentes pós de sílica.. 53

Figura 6. 20 - Efeito da taxa de aquecimento na temperatura de início da consolidação. ....54

Figura 6. 21 - Curva de contração axial para a sinterização do pó de sílica cristalina..........56

Figura 6. 22 - Curva de contração axial para a sinterização do nanopó de sílica.................56

Figura 6. 23 - Contração de 4 pós cristalinos de tamanhos variados sob a mesma temperatura.

Figura 6. 24 - Liberação de gases do nanopó, do pó cristalino e do pó amorfo para temperaturas menores que as de consolidação. 
Figura 6. 25 - Pressão na câmara e contração axial em função da temperatura em experimento com o nanopó realizado com alta taxa de aquecimento

Figura 6. 26 - Experimento com maior "distanciamento" entre o pico de liberação de gás e o início da consolidação que resultou em amostra livre de bolhas. 62

Figura 6. 27 - Temperatura e pressão no processamento de pó mais impuro de sílica. 63

Figura 6. 28 - Difratograma da sílica vítrea obtida a partir do pó cristalino. 64

Figura 6. 29 - Difratograma da sílica vítrea obtida a partir do nanopó amorfo. 64

Figura 6. 30 - Difratograma da sílica vítrea obtida a partir do pó amorfo. 65

Figura 6. 31 - Difratograma comprovando a ausência de cristais em peça com regiões esbranquiçadas devido à presença de bolhas. 66

Figura 6. 32 - Transmitância no UV - VIS - NIR de $\mathrm{SiO}_{2}$ vítreo fabricado com pó cristalino.. 69

Figura 6. 33 - Transmitância no UV - VIS - NIR de $\mathrm{SiO}_{2}$ vítreo fabricado com pó amorfo..... 69

Figura 6. 34 - Aproximação do valor de $T_{b}$ como ponto médio dos pontos $T_{2,52}$ e $T_{2,92 \ldots \ldots \ldots .70}$

Figura 6. 35 - Transmitância de $\mathrm{SiO}_{2}$ vítreo obtido com pó cristalino de baixa pureza. ........ 71

Figura 6. 36 - Transmitância de $\mathrm{SiO}_{2}$ parcialmente fundido fabricado com pó cristalino....... 71

Figura 6. 37 - Curva de temperatura de amostra obtida a partir de sílica dopada titânia anatase. 72

Figura 6. 38 - Amostras de sílica titânia e as respectivas curvas de temperatura. 73

Figura 6. 39 - Superfície da sílica titânia processada a $1220^{\circ} \mathrm{C}$ com ampliação de 1000x...74

Figura 6. 40 - Superfície da sílica titânia processada a $1450^{\circ} \mathrm{C}$ com ampliação de 1000x... 75 


\section{Lista de Tabelas}

Tabela 3. 1 - Intervalos de temperaturas e densidades das formas estáveis da sílica. ........ 11

Tabela 3. 2 - Classificação dos principais vidros comerciais de sílica pura.

Tabela 4. 1 - Características dos tipos de pós utilizados como matérias-primas. 28

Tabela 4. 2 - Condições de processamento testadas para cada pó. 29

Tabela 4. 3 - Especificações do pó de sílica dopada com titânia. 29

Tabela 4. 4 - Parâmetros de processamento do nanopó de sílica dopado com titânia. 29

Tabela 4. 5 - Amostras publicadas neste trabalho e suas condições de processamento. .... 30

Tabela 6. 1 - Fusão completa ou parcial de acordo com parâmetros de processo. 38

Tabela 6. 2 - Aparência das amostras em função dos parâmetros de processo. 50

Tabela 6. 3 - Densificação em função do tipo de pó e das condições da sinterização. 57

Tabela 6. 4 - Características da matéria-prima, do material sinterizado e sua densidade....67 


\section{Sumário}

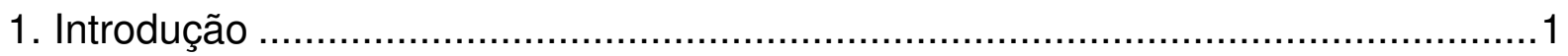

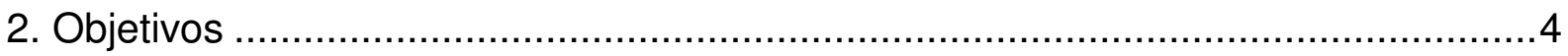

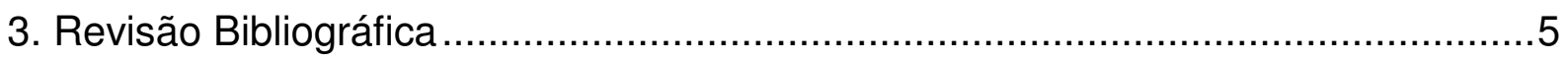

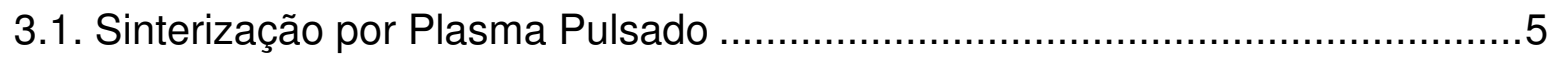

3.1.1. Equipamento e fenômenos da sinterização por plasma pulsado .................5

3.1.2. Distribuição da densidade de corrente e da temperatura ..........................

3.2. Sílica e suas fases ...............................................................................10

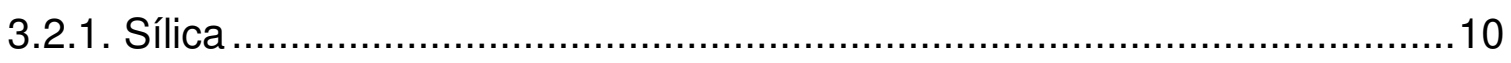

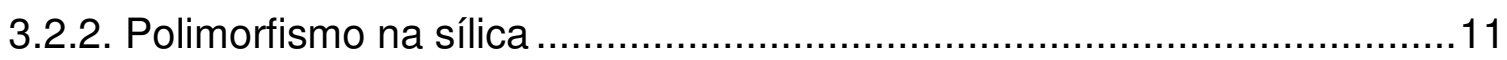

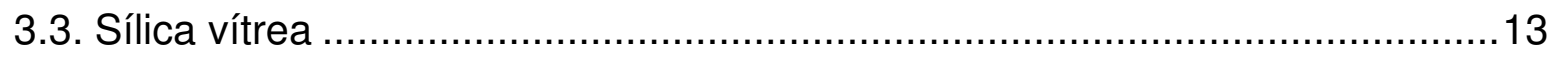

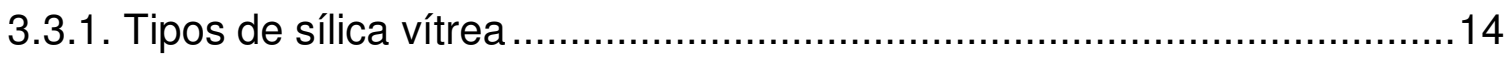

3.3.2. Transmitância óptica da sílica vítrea.....................................................15

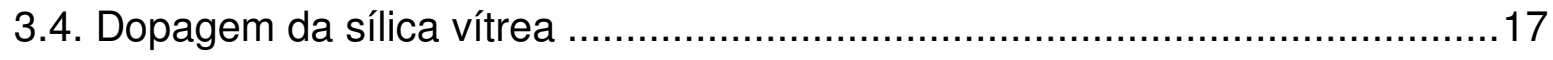

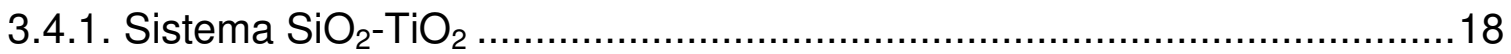

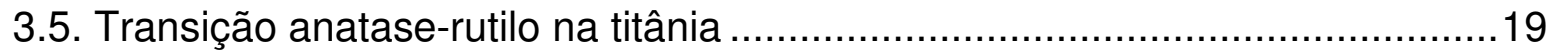

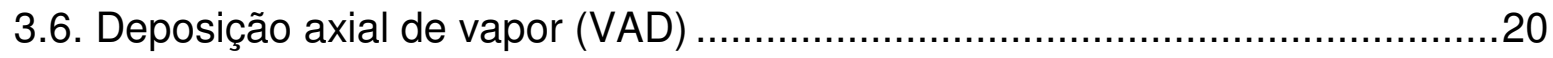

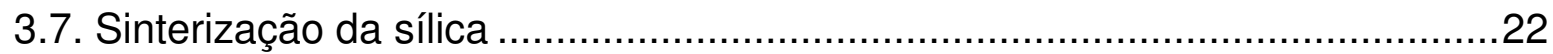

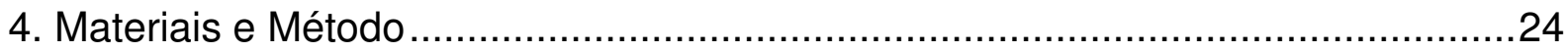

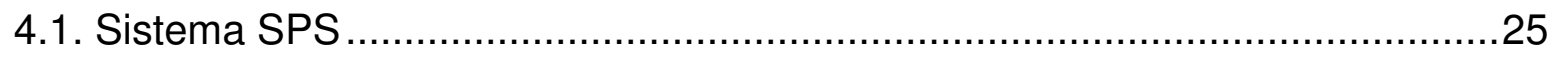

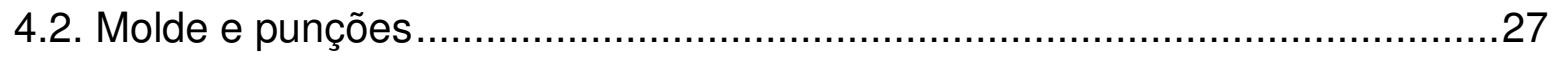

4.3. Matérias-primas e condições de processamento ..........................................28

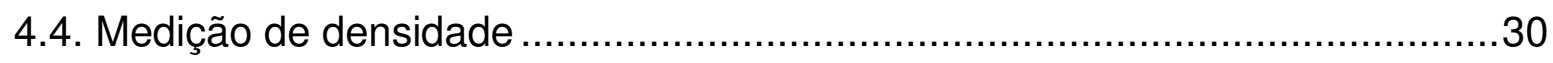

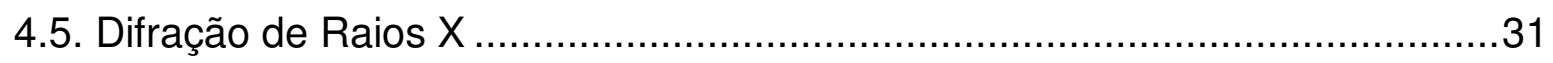

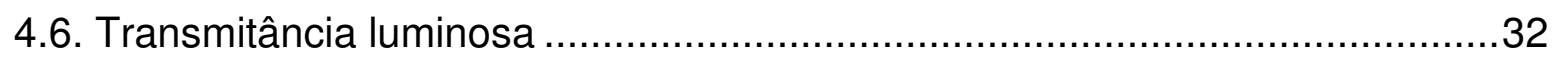


4.7. Microscopia eletrônica de varredura .32

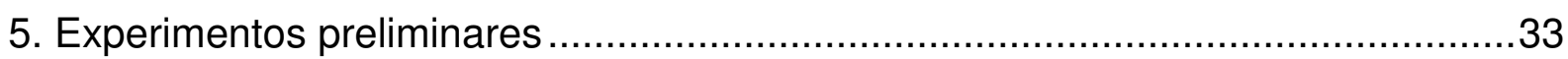

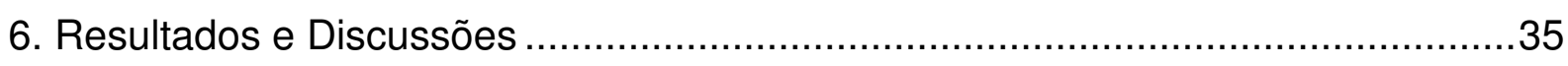

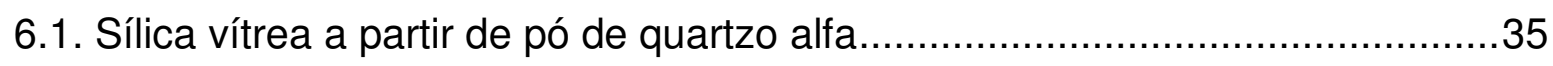

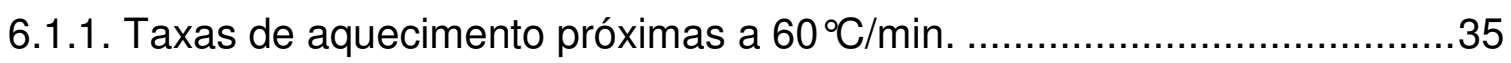

6.1.2. Taxas de aquecimento próximas de $140^{\circ} \mathrm{C} / \mathrm{min}$....................................36

6.1.3. Gradiente de temperatura na amostra ................................................39

6.1.4. Frentes de fusão e formação de bolhas.................................................. 41

6.2. Sílica vítrea a partir de nanopó de $\mathrm{SiO}_{2}$ amorfo ..........................................43

6.2.1. Taxas de aquecimento próximas a $60^{\circ} \mathrm{C} / \mathrm{min}$........................................43

6.2.2. Efeito da pré-compactação com prensa hidráulica ..................................45

6.2.3. Taxas de aquecimento entre 125 e $150^{\circ} \mathrm{C} / \mathrm{min}$.....................................46

6.2.4. Efeito do tempo de patamar na eliminação de bolhas ...............................47

6.2.5. Obtenção de sílica vítrea livre de bolhas ...............................................48

6.3. Sílica vítrea a partir de pó amorfo de sílica ……...........................................51

6.4. Processo de densificação da matéria-prima ..............................................52

6.4.1. Temperatura da contração axial ..........................................................52

6.4.2. Duração e valor da contração axial........................................................54

6.4.3. Efeito da granulometria na densificação dos pós de quartzo.....................57

6.5. Liberação de gases dos pós de sílica no processo SPS.................................58

6.5.1. Liberação de gás do $\mathrm{SiO}_{2}$ e origem da matéria-prima ..............................59

6.5.2. Liberação de gás do $\mathrm{SiO}_{2}$ e taxa de aquecimento ...................................60

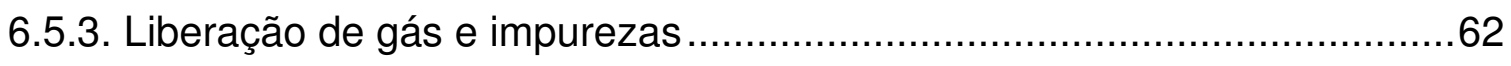

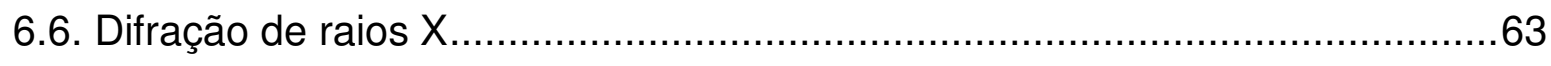

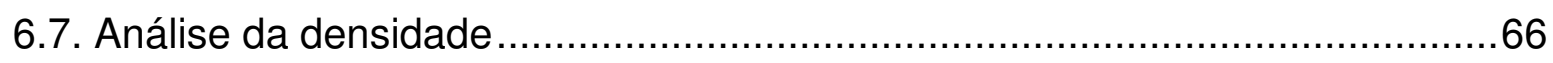

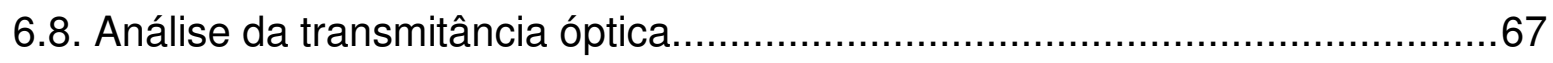

6.9. Fabricação de sílica titânia pela técnica SPS ...........................................72 


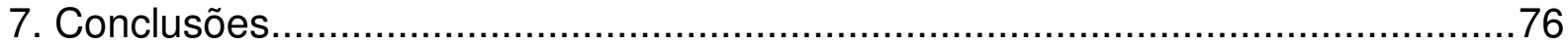

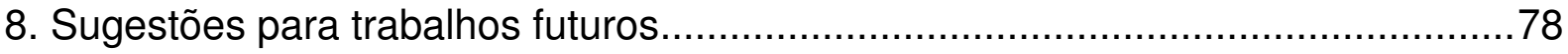

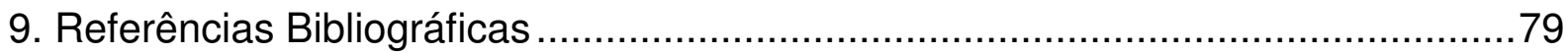




\section{Introdução}

A sinterização é o processo em que partículas finas de um determinado material se unem para diminuir sua energia livre e formar um único sólido. No processo, a matéria-prima é aquecida de modo que seja atingida a energia de ativação de fenômenos de transporte de massa como difusão de superfície e de contorno de grão [1]. Em uma sinterização, geralmente, deseja-se obter materiais de alta densidade e pequeno tamanho de grão, uma vez que essas características melhoram, de maneira geral, as propriedades do material. No entanto, altas temperaturas de tratamento por um longo tempo levam ao aumento do tamanho médio de grão [2] enquanto que baixas taxas de aquecimento podem restringir a densidade final do consolidado [3].

O método convencional de sinterização - sem aplicação de pressão na amostra - é muito utilizado devido a sua viabilidade econômica, contudo ele favorece o crescimento de grão e limita a densidade final do sólido fabricado [1]. Já os métodos HP (hot pressing) e HIP (hot isostatic pressing), que aplicam pressão externa no material particulado, resultam em compostos de maior densidade relativa, uma vez que o esforço de compressão favorece mecanismos de densificação como a difusão de contornos de grão, no caso de materiais policristalinos e o escoamento viscoso no caso de partículas de material amorfo [1].

A sinterização por Plasma Pulsado (SPS) caracteriza-se pela geração de calor por pulsos de alta corrente elétrica aplicados diretamente na amostra e no molde, assim como a aplicação de pressão uniaxial na matéria-prima [3,4]. Esse tipo de sinterização apresenta numerosos benefícios em relação aos métodos tradicionais de sinterização, principalmente pela diminuição dos tempos e das temperaturas de processo, além das propriedades finais diferenciadas que os materiais adquirem como a alta densidade e o pequeno tamanho de grão [4]. A técnica é aplicada na fabricação de materiais com gradação funcional (MGFs), materiais nano-estruturados (através do uso de nanopós), materiais termo-elétricos, cerâmicas avançadas, bio-materiais, além do seu uso para controle de crescimento de grão, melhoria das propriedades mecânicas, entre outros. 
A sílica ou $\mathrm{SiO}_{2}$ é um composto químico encontrado em abundância na natureza e pode se apresentar em variadas formas cristalinas (quartzo, cristobalita, etc) [5]. No entanto, é na forma amorfa solidificada que essa substância recebe o nome sílica vítrea ou sílica fundida e apresenta importantes aplicações em diferentes setores da indústria de tecnologia avançada. Uma das diferentes formas de se obter monólitos de sílica vítrea é através da sinterização de pós de sílica cristalina ou amorfa. A sílica fundida possui características diferenciadas como a elevada transparência e os baixos coeficientes de dilatação e condutividade térmica [6]. Além disso, uma grande variabilidade das propriedades da sílica vítrea pode ser obtida pela simples mudança de processamento, assim como em dopagens específicas. Essas características, entre outras, justificam o emprego do material como, por exemplo, na composição de fibras ópticas - comunicadoras, sensoras [7] e amplificadoras [8]; em aplicações de microlitografia [9]; na fabricação de cadinhos para crescimento de cristais de silício [10], lentes especiais [11] e separadores de feixes [12]; além de outras funções como o isolamento térmico e elétrico.

Dentre os sistemas formados por sílica fundida dopada com diferentes substâncias, a sílica titânia $\left(\mathrm{SiO}_{2}-\mathrm{TiO}_{2}\right)$ é de especial interesse devido seu ultra-baixo coeficiente de expansão térmica [13] (podendo ser negativo ou nulo) e seu elevado índice de refração [14]. Essas duas propriedades podem ser controladas através da quantidade de titânia no composto, geralmente menor que 10\% da massa total. Uma das principais aplicações da sílica titânia é como material formador de núcleos de fibras ópticas em razão do expressivo aumento na refringência que a titânia causa na sílica vítrea [7].

A crescente necessidade dos vidros de sílica para a indústria de semicondutores, fillers para microchips, e em especial no processamento de células solares, têm provocado forte demanda do quartzo de elevada pureza, onde 0 quartzo extraído e processado nos EUA, conhecido como lota Quartz detém o monopólio mundial para tais aplicações de alta tecnologia. Recentemente, com o aparente esgotamento na homogeneidade das reservas de quartzito em Spruce Pine nos EUA para produção do lota Quartz e a conseqüente dificuldade em manter os atuais níveis de produção além da demanda crescente por vidros de sílica, o quartzo brasileiro tornou-se novamente o principal foco de interesse internacional. Particularmente, esta questão tornou-se ainda mais estratégica em virtude do 
aumento explosivo da produção de células fotovoltaicas na China, que além de se tornar o maior fabricante mundial, tem crescido a uma taxa anual próximo a 30\% [15, 16]. Para o Brasil, revelado como principal detentor de reservas quartíferas do planeta [17], é interessante investir em técnicas avançadas de fabricação de sílica vítrea e/ou de vidros especiais a base de sílica a partir de cristais de quartzo, podendo atuar, então, como exportador de produtos com maior valor agregado ao invés de se limitar à exportação de matérias-primas. 


\section{Objetivos}

O objetivo deste trabalho é explorar o processamento da sílica vítrea pela técnica de sinterização por plasma pulsado. Deseja-se, primeiramente, estudar a viabilidade da produção de monólitos de sílica vítrea transparente de alta pureza pela técnica SPS. Este estudo também se propõe a determinar como variações das condições do processo SPS afetam as propriedades finais do material sinterizado, bem como entender quais são os mecanismos e parâmetros de processamento adequados para diferentes tipos de matérias-primas de sílica. Para isso, serão caracterizadas algumas propriedades das sílicas produzidas. 


\section{Revisão Bibliográfica}

\subsection{Sinterização por Plasma Pulsado}

A sinterização por plasma pulsado ou Spark Plasma Sintering (SPS) é um método com numerosos benefícios em relação às técnicas convencionais de sinterização como a sinterização sem pressão e a prensagem a quente ou hot pressing (HP). Dentre as vantagens do método estão a maior rapidez e controle do processo, maior pureza e alta densidade relativa do material produzido $[4,18]$. No entanto, a técnica tornou-se mais conhecida pela sua aplicação na produção de materiais com gradação funcional (MGF).

Na década de 1960, K. Inoue patenteou o método SPS [19, 20], porém devido à falta de tecnologia para sua aplicação e limitações de custos, equipamentos e eficiência, a importância do método demorou a ser reconhecida. Poucas máquinas foram vendidas nos EUA e Japão. Somente nos anos 80 , juntamente com a quebra da patente, várias companhias começaram a fabricar equipamentos SPS baseados na tecnologia original. Recentemente, com a chegada da terceira geração SPS, mais evoluída (compressão mecânica de 10 a 100 toneladas e pulsos de corrente de 2.000 a 20.000 A), o método ganhou reputação no processamento de materiais com gradação e de materiais compósitos e atraiu a atenção de engenheiros e pesquisadores de materiais $[4,21]$.

\subsubsection{Equipamento e fenômenos da sinterização por plasma pulsado}

Basicamente o sistema SPS é composto por dois eletrodos verticais de compressão mecânica, uma câmara de atmosfera controlada (vácuo, ar ou argônio), um gerador de pulsos de corrente contínua e uma unidade de controle [4]. Uma representação simplificada do sistema SPS pode ser visualizada no esquema da figura 3.1 a seguir. 


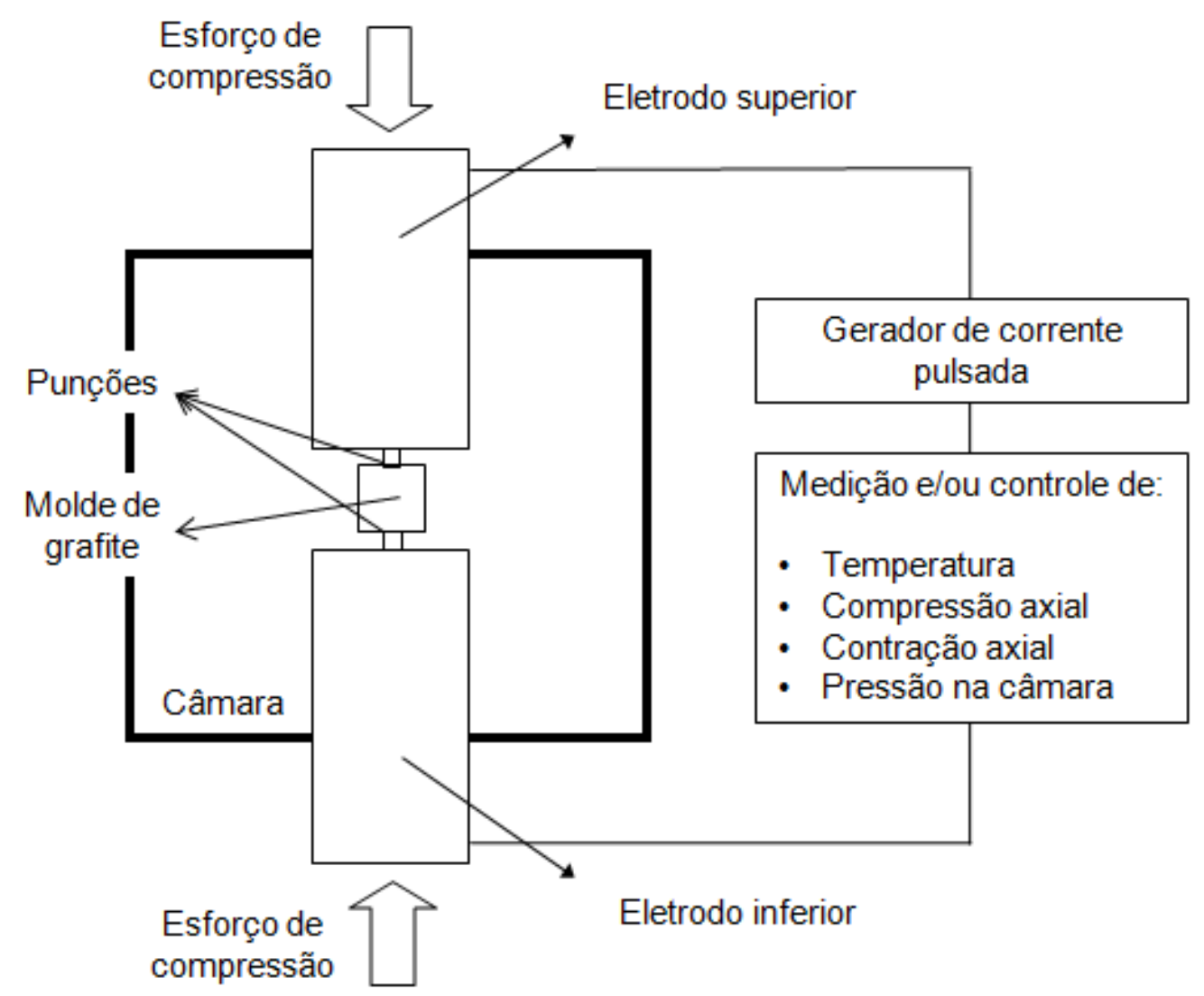

Figura 3. 1 - Representação simplificado de uma máquina SPS.

O pó do material a ser processado é estocado dentro do molde de grafite (sintering die) e entre os punções pressurizadores (upper punch e lower punch). Os eletrodos, então, submetem a matéria-prima (pó) a um esforço de compressão mecânica e a pulsos de corrente elétrica que aquecem o material. A baixa capacidade térmica e alta condutividade térmica do grafite, além do fato dele ser diretamente aquecido pela corrente elétrica, aumentam a eficiência do tratamento térmico em razão do rápido aquecimento e resfriamento [4, 22].

A sinterização por plasma pulsado é um processo baseado em descargas elétricas de alta corrente originada de pulsos elétricos de corrente contínua ou PECS (pulsed electric current sintering) que melhoram a eficiência do aquecimento [1]. A elevação da temperatura ocorre devido ao efeito Joule (Figura 3.2) - no molde, punções e eventualmente entre as partículas do pó quando estas estão em contato e ao faiscamento gerado nos espaços vazios entre as partículas da matéria-prima processada $[1,4,23]$. Como o calor é gerado no volume do molde e da amostra (para amostra eletricamente condutiva), $\mathrm{o}$ gradiente de temperatura durante $\mathrm{O}$ aquecimento é mínimo evitando os problemas de tensões térmicas, e permitindo 
altas taxas de aquecimento, tipicamente entre 100 e $600^{\circ} \mathrm{C} / \mathrm{min}$, que levam a amostra rapidamente a altas temperaturas favorecendo os mecanismos de densificação, como difusão de contorno de grão, em detrimento dos mecanismos não densificadores, como difusão de superfície [3,24]. Além disso, a compressão mecânica do material particulado é outro fator que acelera a densificação do material $[1]$.

Como resultado, o processo de sinterização por plasma pulsado gera materiais sinterizados compactos de alta qualidade, mais densos, com menores tempos de processamento e temperaturas mais baixas.

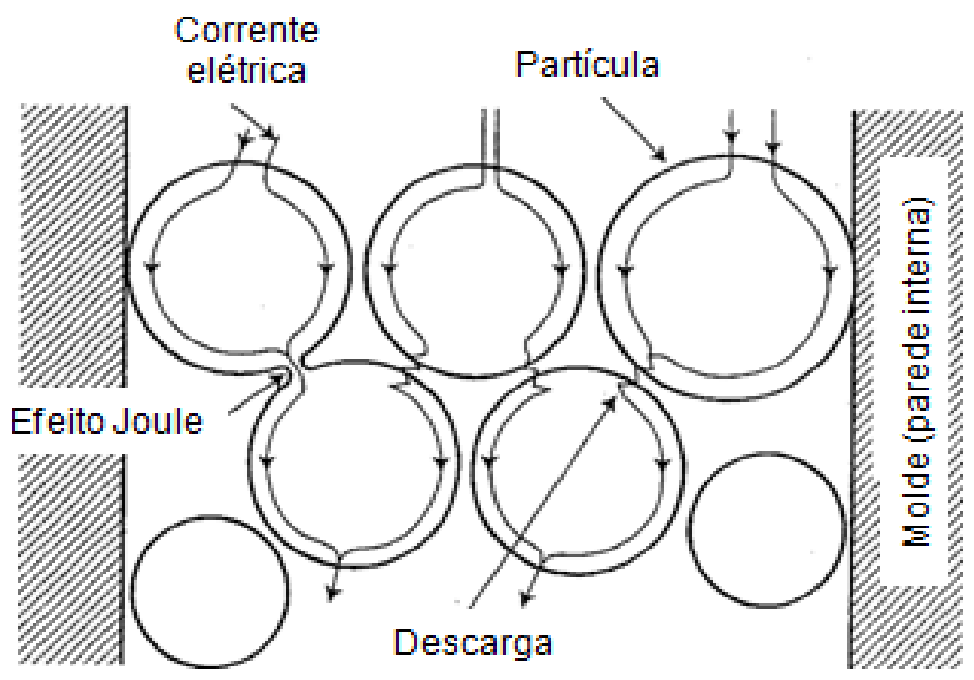

Figura 3. 2 - Corrente elétrica passando pelo pó em processo de sinterização SPS [4].

Quando a descarga elétrica ocorre entre partículas do pó - separadas por distâncias da ordem de nanômetros - um estado local (coluna de descarga ou plasma) de altíssima temperatura (chegando a dezenas de milhares de graus celsius) é gerado momentaneamente [23]. Isso causa a evaporação, eliminando impurezas e gases adsorvidos, e a fusão das superfícies das partículas levando à formação de "pescoços" (Figura 3.3) em torno da área de contato entre elas [4, 23]. Esse fenômeno acelera a consolidação do material devido à altíssima temperatura local atingida. 


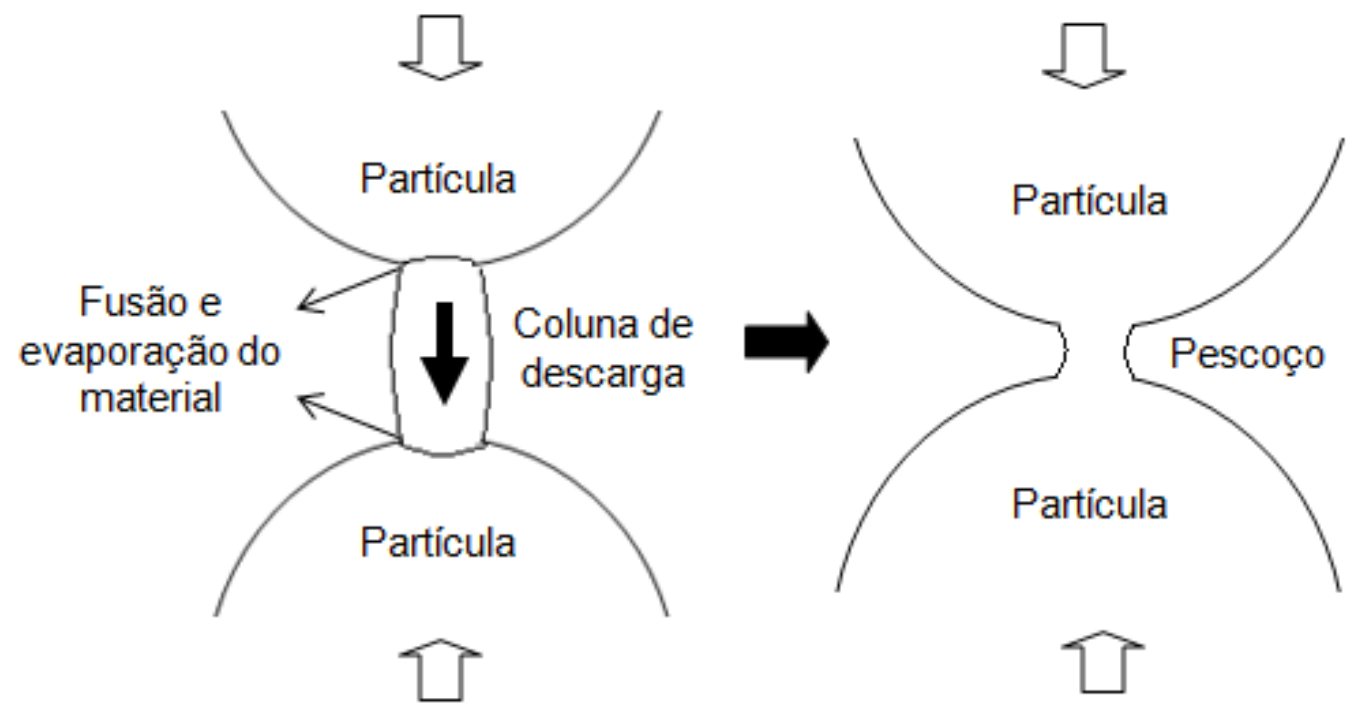

Figura 3. 3 - Coluna de descarga gerando evaporação e fusão da superfície das partículas.

\subsubsection{Distribuição da densidade de corrente e da temperatura}

A distribuição da densidade de corrente no processo SPS depende principalmente da geometria e das condutividades térmicas e elétricas do grafite e da amostra e influencia a distribuição dos locais da geração de aquecimento e outros efeitos como o transporte de massa.

Simulações numéricas foram realizadas com matérias-primas (pós) de um material condutor (Cobre) e de um material isolante (Alumina) [22]. Ambas as amostras com mesma geometria, mas diferentes condutividades térmicas e elétricas. A aplicação de uma ddp de $5 \mathrm{~V}$ entre os eletrodos a temperatura ambiente indicou a não formação de corrente elétrica no material não condutor. Ou seja, o aquecimento da amostra isolante não ocorre devido ao efeito Joule no interior do material. No entanto, para o Cobre, a elevação da temperatura por efeito Joule ocorre de maneira direta, já que as linhas de corrente atravessam a amostra conforme mostra a figura 3.4. Em ambos os casos, porém, a região de maior densidade de corrente é a dos punções, região de menor seção transversal. 


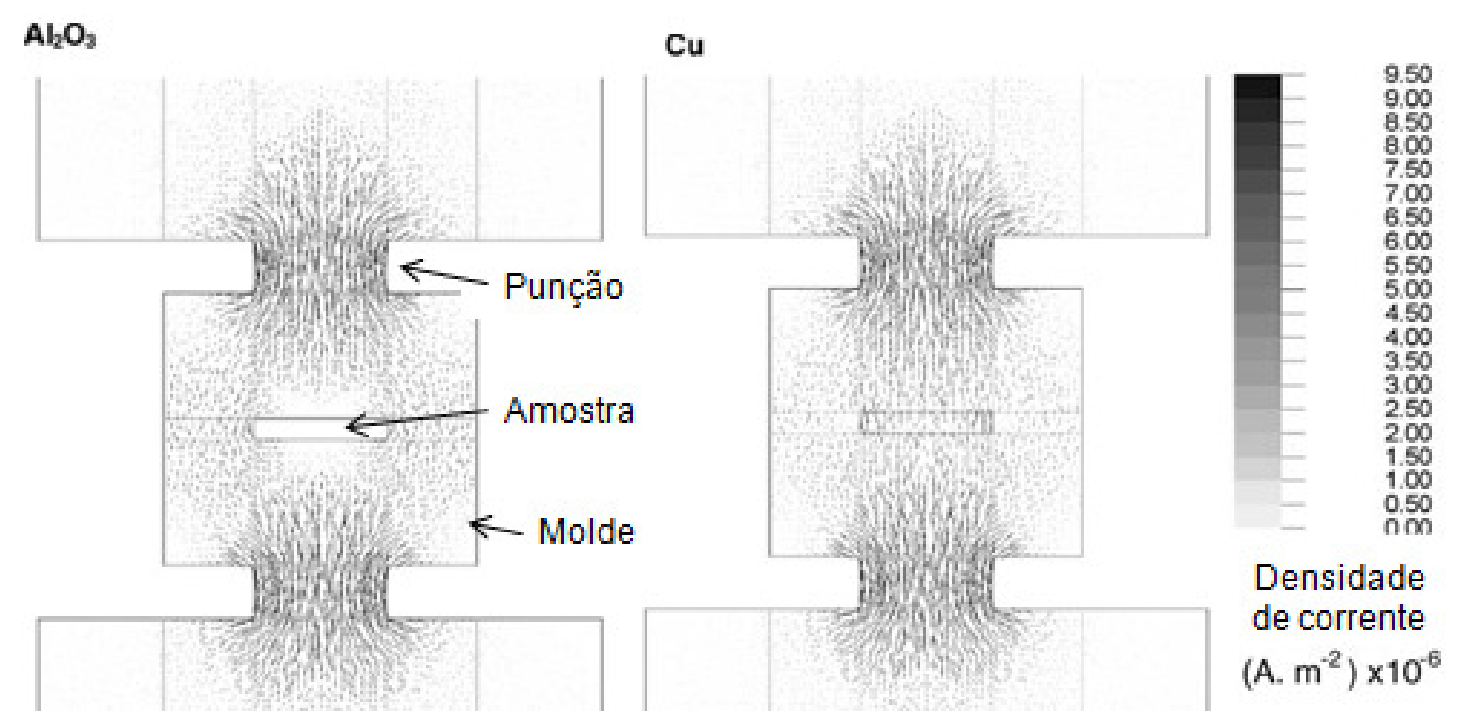

Figura 3. 4 - Densidade de corrente nas amostras de Alumina e Cobre [22].

O mesmo estudo também analisou a distribuição de temperatura no sistema e concluiu que os punções - locais de maior densidade de corrente - possuem as temperaturas mais elevadas e funcionam como fontes de calor para o aquecimento da amostra, como pode ser observado na figura 3.5 (a). Além disso, sugeriu-se que a distribuição de temperaturas em amostras condutoras e não condutoras é semelhante, com maior temperatura no centro e decrescendo radialmente, porém com maior gradiente entre o centro e a extremidade da amostra no caso do material isolante (Figura 3.5 (b)).
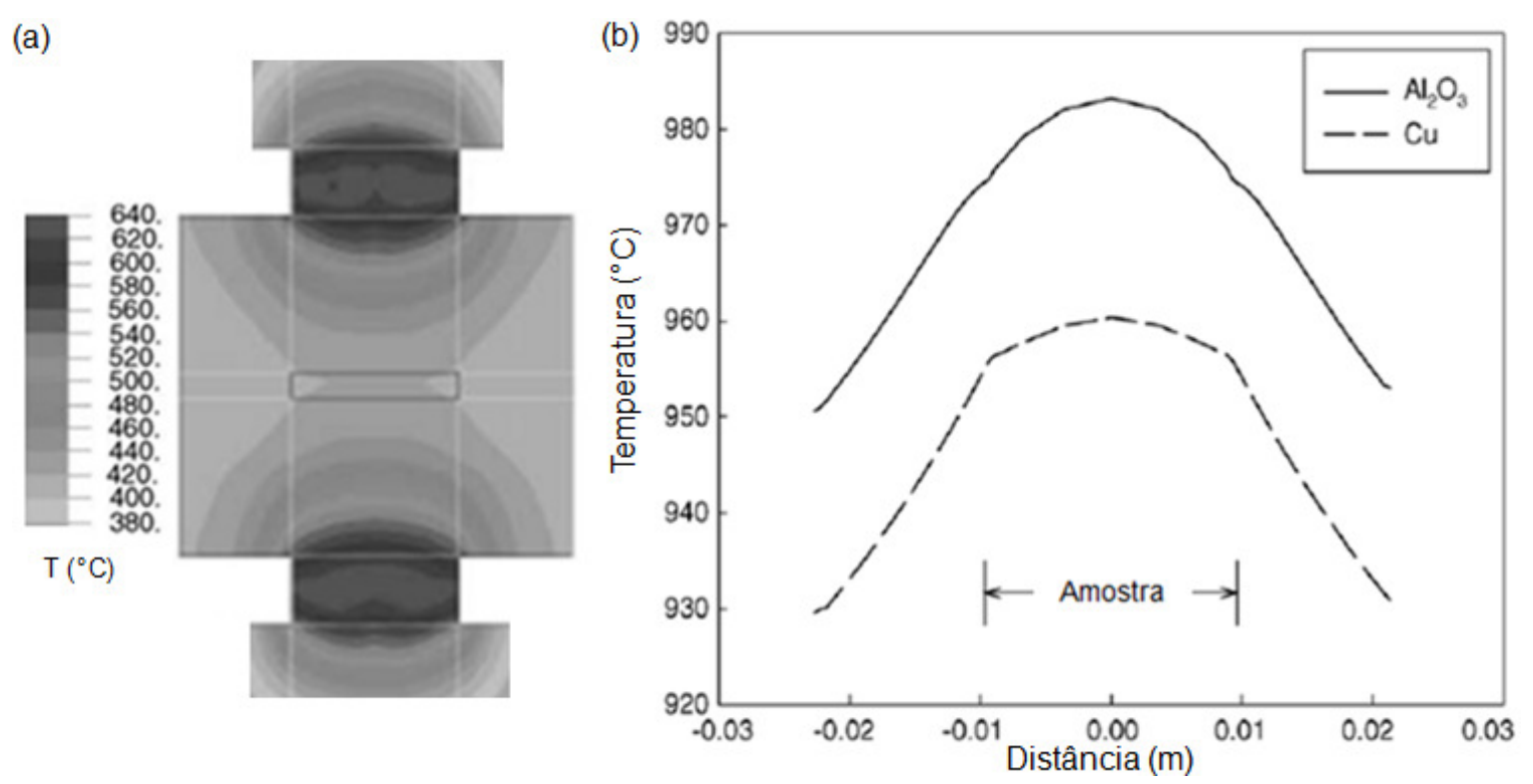

Figura 3.5 - (a) Distribuição de temperatura no molde para amostra de $\mathrm{Al}_{2} \mathrm{O}_{3}$. (b) Temperatura nas amostras de Cobre e Alumina [22]. 
Além deste, muitos outros estudos vêm sendo realizados com o intuito de prever a distribuição de grandezas como temperatura e tensão no molde e na amostra durante o processo SPS [25, 26, 27].

\subsection{Sílica e suas fases}

\subsubsection{Sílica}

O dióxido de silício $\left(\mathrm{SiO}_{2}\right)$ ou sílica pode ser encontrado na natureza (sílica natural) ou sintetizado em laboratório através de processos químicos. Considerada um material cerâmico, a sílica tem $51 \%$ de suas ligações interatômicas de caráter iônico e $49 \%$ de caráter covalente [28]. Sua estrutura atômica caracteriza-se por um átomo de silício envolvido por quatro átomos de oxigênio formando um tetraedro de diferentes arranjos dependendo da fase polimórfica em que o material se encontra. A sílica também é considerada uma cerâmica refratária e como tal caracteriza-se pela elevada temperatura de fusão e capacidade de não reagir (permanecer inerte) quando exposta a ambientes severos [28]. É possível ainda citar as propriedades mais marcantes de algumas das formas polimórficas específicas da sílica como, por exemplo, a propriedade piezelétrica do quartzo [29] ou o baixo coeficiente de expansão térmica da sílica vítrea e sua isotropia [6]. A transparência óptica é outra propriedade presente em todas as fases do material.

Devido a essas propriedades, o $\mathrm{SiO}_{2}$ apresenta uma grande variedade de aplicações na indústria como na fabricação de fornos de alta temperatura devido à sua capacidade de isolamento térmico [5], na confecção de relógios em razão da propriedade piezelétrica do cristal de quartzo e como principal composto na produção de vidros para recipientes, janelas, lentes, fibras ópticas entre outros. 


\subsubsection{Polimorfismo na sílica}

$\mathrm{O} \mathrm{SiO}_{2}$ possui mais de 20 fases sendo a maior parte delas cristalinas e 0 restante delas amorfa [5]. No entanto, as formas estáveis da sílica, ou seja, as formas em que fixadas temperatura e pressão o material possui propriedades constantes no tempo, são apenas quatro. Estas formas são: quartzo; tridimita; cristobalita e líquido. As três primeiras fases têm estrutura cristalina e somente a fase líquida é considerada amorfa. Porém, estudos verificaram que a fase tridimita só é estável na presença de aditivos como óxidos e que, portanto, ela não deveria estar no diagrama de equilíbrio da sílica pura. Constatou-se, então, que o ponto de equilíbrio entre o quartzo e a cristobalita estaria entre 1050 e $1100^{\circ} \mathrm{C}$ [5].

A tabela 3.1 mostra as principais fases da sílica e os intervalos de temperatura nos quais estas fases são as formas mais estáveis do material. A mesma tabela agrega os valores das densidades correspondentes a cada fase [5]. A transformação de uma fase para a outra segundo as temperaturas indicadas na tabela ocorre somente para processos lentos de longa duração. No caso de tratamentos rápidos a mudança de fase no material ocorre a temperaturas diferentes das apresentadas na tabela 3.1.

Tabela 3. 1 - Intervalos de temperaturas e densidades das formas estáveis da sílica.

\begin{tabular}{ccc}
\hline & Temperatura $\left({ }^{\circ} \mathrm{C}\right)$ & Densidade $\left(\mathrm{g} / \mathrm{cm}^{3}\right)$ \\
\hline Quartzo & -273 a 867 & 2,65 \\
Tridimita & 867 a 1470 & 2,26 \\
Cristobalita & 1470 a 1723 & 2,33 \\
Líquido & $>1723$ & 2,20 \\
\hline
\end{tabular}

Toda forma cristalina da sílica pode ser convertida para sua fase amorfa processo de fusão do material cristalino - se for aquecida a uma temperatura específica com uma taxa de aquecimento suficientemente grande. Trata-se de um processo metastável e que exige temperaturas menores ou iguais a $1700^{\circ} \mathrm{C}$. $\mathrm{O}$ quartzo, por exemplo, funde a aproximadamente $1400^{\circ} \mathrm{C}[5,6]$.

Independentemente de qual foi a temperatura de fusão do cristal de sílica, o resfriamento do $\mathrm{SiO}_{2}$ líquido dá origem à sílica vítrea ou quando se ultrapassa a temperatura de transição vítrea $\left(T_{v}\right)$ do material, que está entre 1000 e $1450^{\circ} \mathrm{C}[30$, 
31]. A sílica vítrea será descrita mais detalhadamente na seção a seguir, mas vale dizer que, como todo material vítreo ela possui estrutura amorfa e características de um sólido. A figura 3.6 mostra a curva de formação de sílica vítrea em contraste com a da formação de um sólido cristalino puro, um metal, por exemplo. Durante a cristalização do material, o seu volume específico sofre uma redução brusca, ou seja, sua densidade aumenta repentinamente. Esse fenômeno não ocorre no caso da transformação vítrea [28].

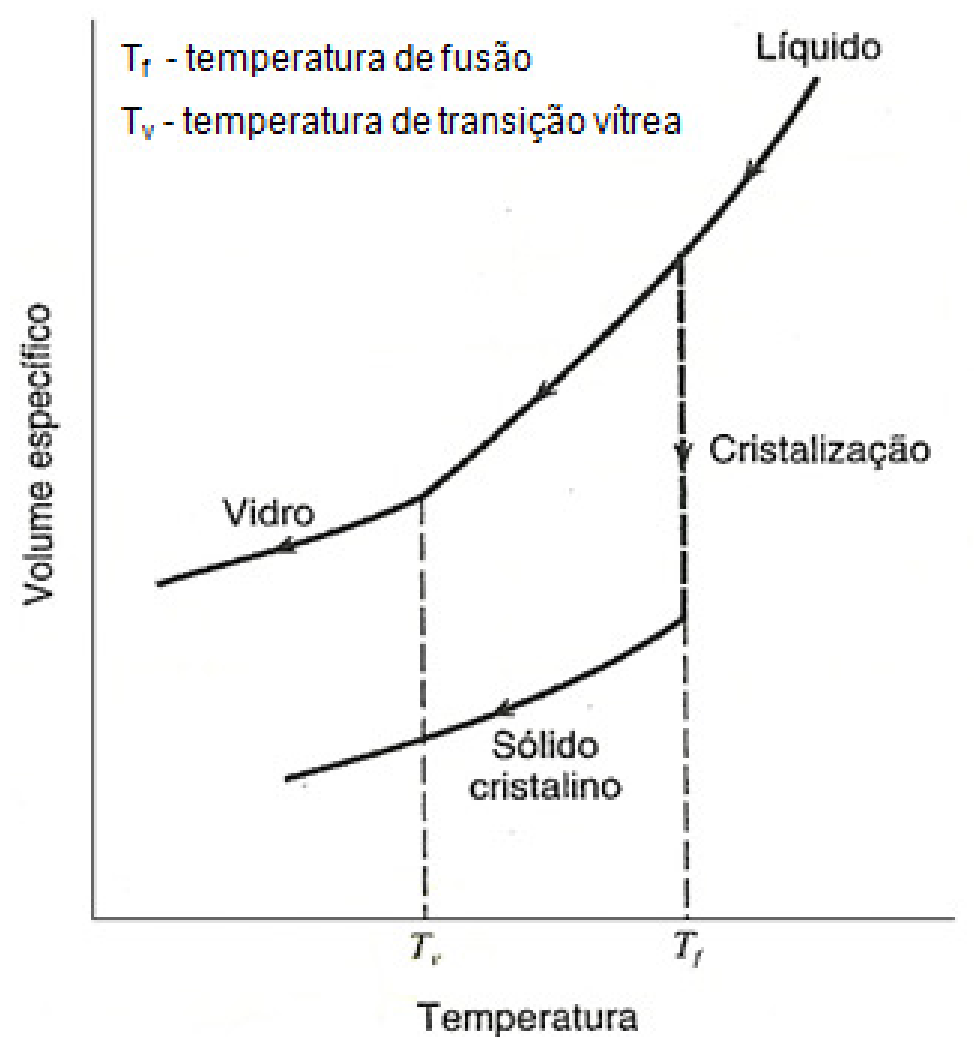

Figura 3. 6 - Curva de formação do vidro de sílica comparada a de um sólido cristalino [28].

Outra transformação é a cristalização ou a desvitrificação da sílica vítrea. 0 processo mais comum nesse caso é a conversão da fase amorfa para a forma cristalina da cristobalita. Esse fenômeno pode ocorrer a temperaturas abaixo de $1470^{\circ} \mathrm{C}$ (metaestável) e caracteriza-se por iniciar-se na superfície do material [5] principalmente se esta se encontra em contato com alguma substância estranha que pode agir como agente de nucleação [6]. Portanto, amostras de sílica vítrea com maior porosidade ou com muitas bolhas têm seu processo de desvitrificação acelerado devido à grande área superficial existente [5] . 
As transformações citadas são apenas alguns exemplos das transições possíveis e as de maior interesse para este estudo.

\subsection{Sílica vítrea}

Como dito anteriormente, das quatro principais formas polimórficas da sílica, apenas a fase líquida é considerada amorfa e como tal não apresenta uma repetição de padrão ao longo de sua estrutura molecular como ocorre com o quartzo (Figura 3.7) e as outras fases cristalinas do $\mathrm{SiO}_{2}$. A fase líquida da sílica quando resfriada dá origem à sílica vítrea que, portanto, possui a mesma estrutura amorfa da fase líquida, porém passa a ter características de um sólido, sendo a viscosidade a única diferença entre os dois estados [32].

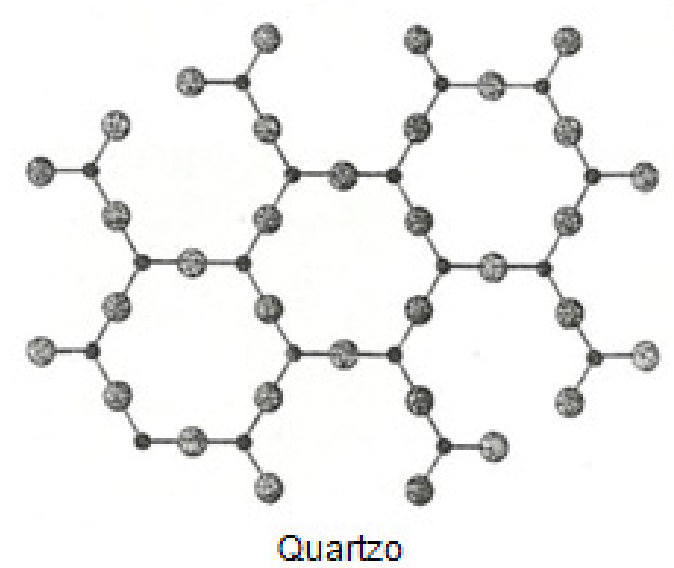

Quartzo
- Átomo de silício

(2) Átomo de oxigênio

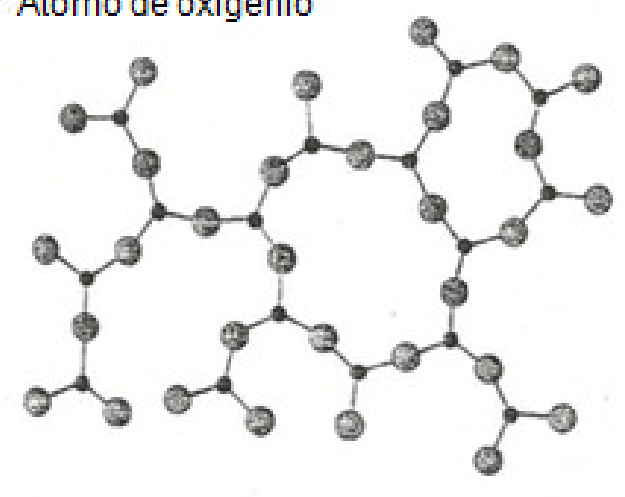

Sílica fundida

Figura 3. 7 - Estrutura molecular da sílica cristalina (quartzo) e da sílica amorfa [28].

A sílica vítrea é um material de muitas aplicações na indústria de tecnologia avançada, uma vez que possui propriedades diferenciadas, tais como: baixo coeficiente de dilatação térmica, baixo coeficiente de condutividade térmica, alta durabilidade química, estabilidade a altas temperaturas e a alta transparência óptica em um longo intervalo do espectro luminoso [6]. Além disso, a sílica fundida, diferentemente das outras fases principais do $\mathrm{SiO}_{2}$, é isotrópica e portanto suas propriedades não variam com a mudança da direção de medição. Como exemplo de 
aplicação, sabe-se que a transparência óptica da sílica vítrea associada a sua resistência mecânica e características dielétricas e refratárias fazem com que ela seja o material base para a fabricação de fibras ópticas. Normalmente, o núcleo da fibra óptica é composto por $\mathrm{SiO}_{2}$ vítreo dopado com outros óxidos como $\mathrm{GeO}_{2}$ e $\mathrm{TiO}_{2}$, enquanto que o revestimento é composto somente por $\mathrm{SiO}_{2}$ vítreo de alta pureza [7].

Outro exemplo de aplicação são os vidros comuns, uma mistura de sílica fundida (geralmente o material predominante) e outros óxidos, como o $\mathrm{Na}_{2} \mathrm{O}$ e $\mathrm{O}$ $\mathrm{CaO}$. Do mesmo modo, lentes de precisão e separadores de feixes utilizam como componente básico a sílica vítrea. Na micro e optoeletrônica ela é usada como material dielétrico, na fabricação de guias de onda, em máscaras de projeção para litografia, em sistemas de proteção térmica, entre outros.

\subsubsection{Tipos de sílica vítrea}

Existem diferentes processos de obtenção de sílica vítrea [30, 33, 34, 35], os quais influenciam as propriedades finais do material vítreo fabricado, como, por exemplo, sua viscosidade. Isso ocorre, pois estes diferentes processos causam mudanças nas características da rede estrutural do $\mathrm{SiO}_{2}$ vítreo [30]. A tabela 3.2 apresenta uma forma de classificação dos principais vidros comerciais de sílica pura [30] de acordo com seu meio de produção. A sílica vítrea classificada como tipo 1 é produzida a partir de quartzo natural por fusão elétrica em atmosfera de vácuo ou de

gás inerte. Possui baixa quantidade de grupos $\mathrm{OH}$, por volta de 5 ppm, mas costuma ter quantidade de impurezas metálicas relativamente grande, da ordem de centenas de ppm, quando comparada aos outros tipos de sílica vítrea [30].

A sílica vítrea tipo 2 é produzida a partir do pó de cristal de quartzo por fusão em chama - processo de Verneuil. Ela contém menos impurezas metálicas, porém grande quantidade de grupos $\mathrm{OH}$, cerca de 150 a 400 ppm, devido à atmosfera de $\mathrm{H}_{2}$ e $\mathrm{O}_{2}$ utilizada na produção da chama por este processo [30, 35].

O material de tipo 3 é sintetizado com base na reação de hidrolização de $\mathrm{SiCl}_{4}$ também sob uma atmosfera de $\mathrm{H}_{2}$ e $\mathrm{O}_{2}$. A sílica vítrea produzida praticamente não 
contém impurezas metálicas (ordem de ppb), mas possui grande quantidade de íons $\mathrm{OH}$, da ordem de 1000 ppm, e também Cl em razão do tetracloreto utilizado na reação [30].

Os grupos hidroxila afetam a viscosidade do material, de modo que menores quantidades de $\mathrm{OH}$ deixam a sílica vítrea mais viscosa [36], aumentando sua vida útil dependendo da aplicação. Além disso, uma maior presença de íons hidroxila na sílica fundida diminui sua temperatura de transição vítrea [37]

As propriedades ópticas também são influenciadas pela quantidade de grupos $\mathrm{OH}$ e pelas impurezas metálicas presentes na sílica vítrea - dependência que será abordada na seção seguinte.

Tabela 3. 2 - Classificação dos principais vidros comerciais de sílica pura.

\begin{tabular}{|c|c|c|c|}
\hline Tipo & $\begin{array}{l}\text { Processo de } \\
\text { fabricação }\end{array}$ & $\begin{array}{c}\text { Quantidade de } \\
\text { grupos } \mathrm{OH}\end{array}$ & $\begin{array}{c}\text { Quantidade } \\
\text { de Cl }\end{array}$ \\
\hline 1 & $\begin{array}{l}\text { Fusão elétrica de } \\
\text { quartzo natural }\end{array}$ & $\leq 5 \mathrm{ppm}$ & - \\
\hline 2 & $\begin{array}{c}\text { Fusão de pó de } \\
\text { quartzo em chama } \\
\text { (Verneuil) }\end{array}$ & $150-400$ ppm & - \\
\hline 3 & $\begin{array}{l}\text { Hidrólise de } \mathrm{SiCl}_{4} \\
\text { (sintético) }\end{array}$ & $\begin{array}{l}\text { Da ordem de } \\
1000 \text { ppm }\end{array}$ & $\begin{array}{c}\text { Da ordem de } \\
100 \text { ppm }\end{array}$ \\
\hline
\end{tabular}

\subsubsection{Transmitância óptica da sílica vítrea}

As propriedades ópticas da sílica vítrea, como índice de refração e absorção (oposto da transmitância óptica), podem variar significativamente de acordo com o processo de manufatura do vidro, a cristalinidade, o comprimento de onda e a temperatura. Além disso, propriedades ópticas são fortemente influenciadas pela presença de impurezas, defeitos, inclusões e bolhas [38].

A transmitância óptica de um material mede a sua capacidade de transmissão da radiação luminosa para um determinado comprimento de onda.

Apesar das diferenças existentes nos espectros de absorção dos distintos tipos de sílica, a sílica vítrea possui, de maneira geral, elevada absorção em comprimentos de onda menores que $160 \mathrm{~nm}$ devido à interação com elétrons, 
absorção por impurezas, presença de grupos $\mathrm{OH}$ (hidroxila) e pontos de defeito. Além disso, fortes bandas de absorção são observadas entre 2,73 e 2,85 $\mu$ m e a 4,3 $\mu \mathrm{m}$ causadas pelos grupos $\mathrm{OH}$ e entre 9 e $9,5 \mu \mathrm{m}$ e de 21 a $23 \mu \mathrm{m}$ devido à ressonância aos modos de vibração do Si-O—Si [38]. O gráfico da figura 3.8 mostra como se comporta a transmitância óptica de diferentes tipos de sílica vítrea [30] em uma faixa de comprimento de onda desde o ultravioleta até o infravermelho próximo (UV-Vis-NIR) do espectro da radiação luminosa.

Embora ocorra uma diminuição da transmitância em torno de 2,72 $\mu \mathrm{m}$ para os três tipos de sílica analisados, essa redução é mais acentuada para os materiais de tipos 2 e 3 (Figura 3.8) uma vez que eles possuem maior quantidade de grupos hidroxila (Tabela 3.2). A concentração (em ppm) de $\mathrm{OH}$ na sílica fundida pode ser estimada através da relação [39]:

$$
[O H]=\frac{1000}{t} \log \left(\frac{T_{b}}{T_{2,72}}\right)
$$

Onde 't' é a espessura da amostra em 'mm', ' $T_{2,72}$ ' é a transmitância óptica em 2,72 $\mu \mathrm{m}$ e ' $\mathrm{T}_{\mathrm{b}}$ ' é a transmitância óptica na linha de base - transmitância estimada em 2,72 $\mu \mathrm{m}$ caso a quantidade de $\mathrm{OH}$ fosse nula.

Além dos grupos hidroxila, imperfeições na rede e outras impurezas como as impurezas metálicas também causam diminuição da transmitância da sílica vítrea. Porém, nesse caso, a redução ocorre em torno de 0,24 $\mu \mathrm{m}$ de comprimento de onda [30]. As sílicas vítreas tipos 1 e 2 têm maior absorção próximo deste valor, já que possuem maiores quantidades de impurezas metálicas (Tabela 3.2). Por outro lado, o material tipo 3 não sofre aumento de absorção em 0,24 $\mu$ m (Figura 3.8) uma vez que apresenta uma quantidade quase nula dessas impurezas devido ao processo sintético de fabricação [30]. 


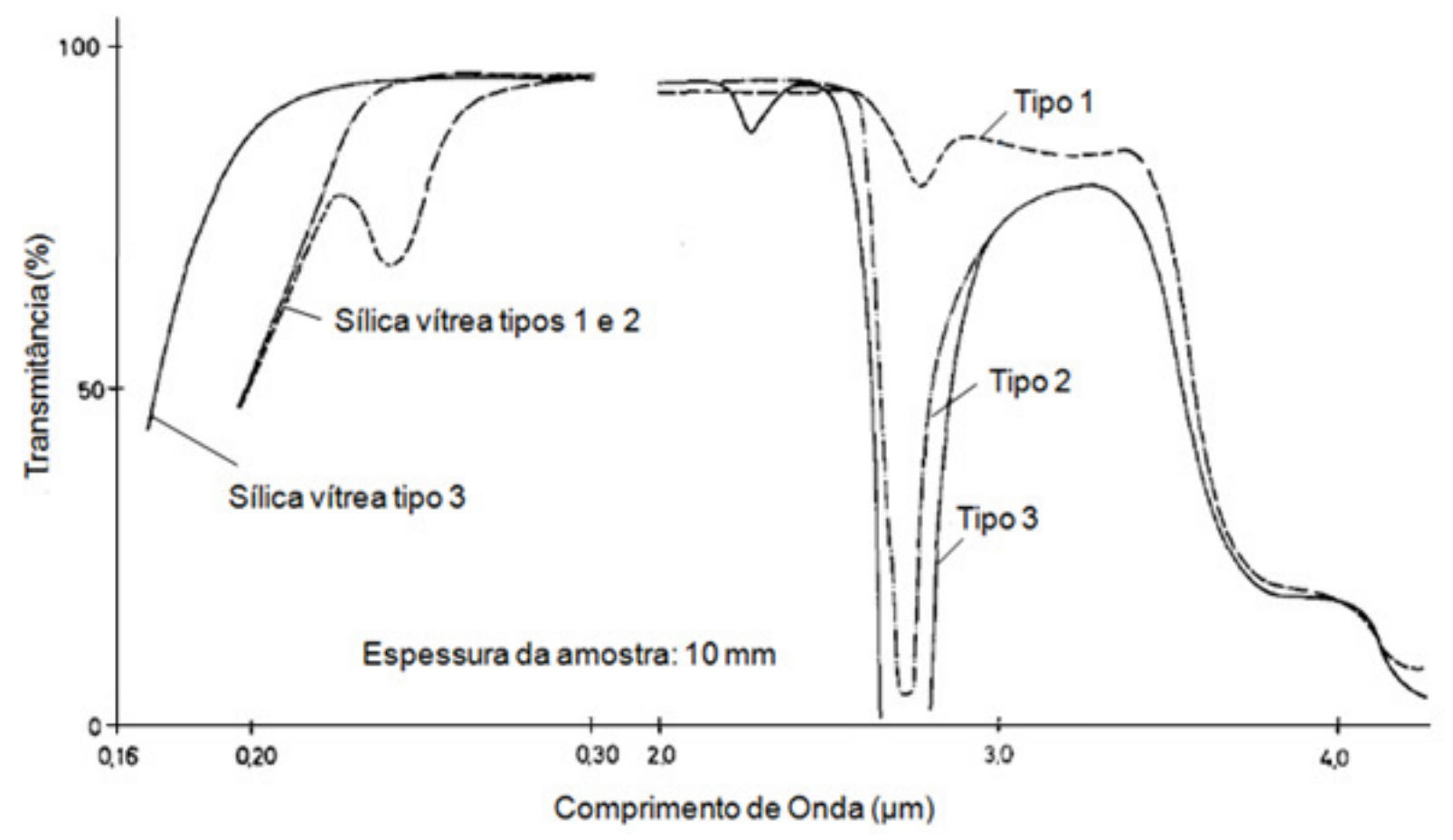

Figura 3. 8 - Transmitância óptica dos tipos 1,2 e 3 de sílica fundida [30].

\subsection{Dopagem da sílica vítrea}

Muitas vezes, para que a sílica fundida adquira determinada característica de projeto (expansão térmica, condutividade, índice de refração, etc) realiza-se a dopagem do material puro com outros compostos como óxidos e/ou íons [38].

$A$ adição de óxidos alcalinos $\left(\mathrm{Na}_{2} \mathrm{O}, \mathrm{K}_{2} \mathrm{O}, \mathrm{Li}_{2} \mathrm{O}\right)$, por exemplo, aumenta $\mathrm{o}$ coeficiente de expansão térmica da sílica vítrea [38]. Já os dopantes $\mathrm{TiO}_{2}, \mathrm{Al}_{2} \mathrm{O}_{3}$, $\mathrm{GeO}_{2}$ e $\mathrm{P}_{2} \mathrm{O}_{5}$ aumentam índice de refração do material, ao passo que $\mathrm{B}_{2} \mathrm{O}_{3}$ e $\mathrm{F}$ o reduzem (Figura 3.9). Dentre estes óxidos que aumentam a refringência da sílica fundida, o $\mathrm{TiO}_{2}$ é o mais eficiente. 


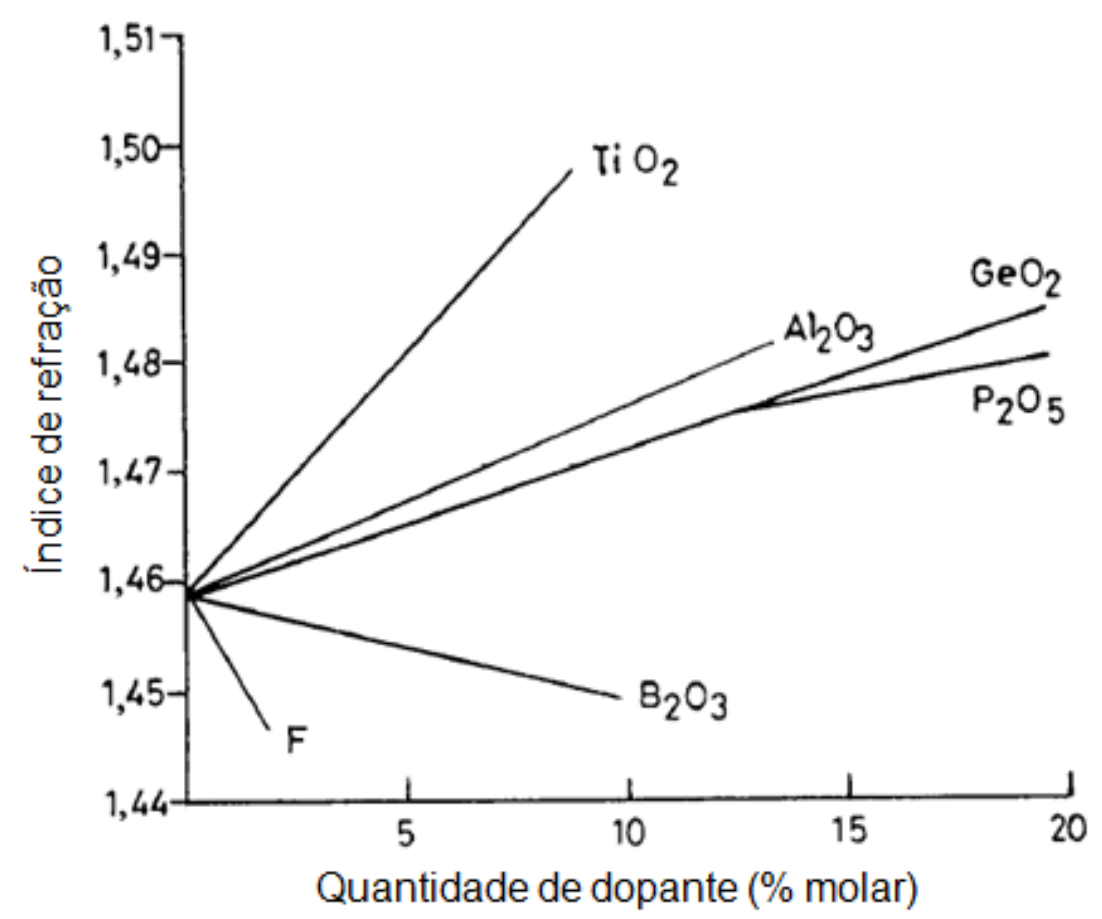

Figura 3. 9 - Índice de refração da sílica vítrea em função da concentração de dopantes [14].

Com exceção do sistema $\mathrm{SiO}_{2}-\mathrm{TiO}_{2}$ (sílica vítrea dopada com titânia), as outras formas de dopagem da sílica fundida não serão abordadas neste estudo.

\subsubsection{Sistema $\mathrm{SiO}_{2}-\mathrm{TiO}_{2}$}

Dentre os sistemas vítreos compostos por sílica e materiais dopantes, a sílica dopada com titânia é de grande interesse comercial devido, principalmente, ao seu ultra-baixo coeficiente de expansão térmica (podendo ser nulo ou negativo) [13, 40, 41] e ao seu elevado do índice de refração comparado ao de outros vidros de $\mathrm{SiO}_{2}$ dopado (Figura 3.9).

Estas duas propriedades podem ser controladas através da quantidade de titânia adicionada ao composto. A figura 3.10 mostra como varia o coeficiente de expansão térmica da sílica titânia com diferentes porcentagens de $\mathrm{TiO}_{2}$ na composição do material em função da temperatura. 


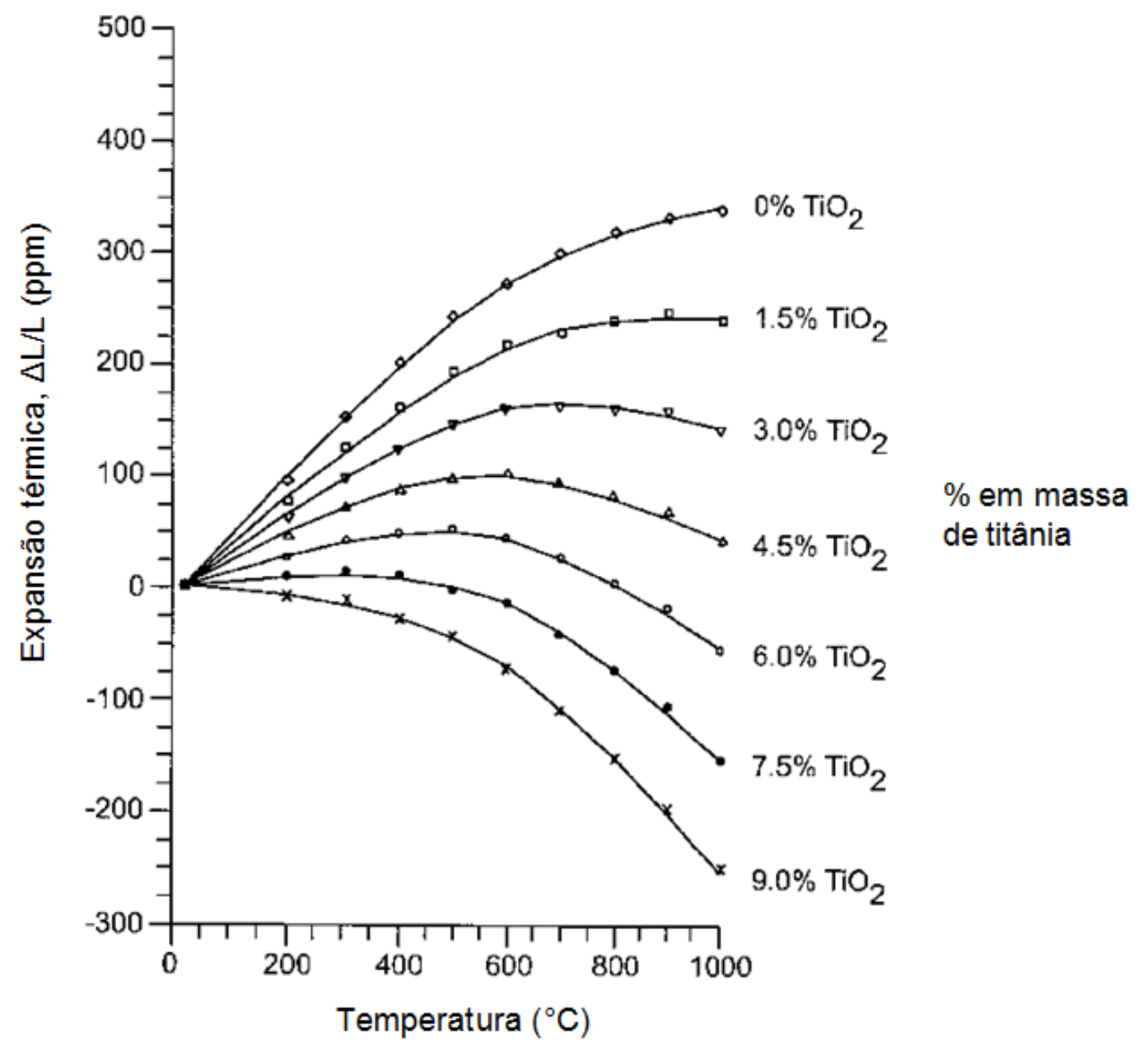

Figura 3. 10 - Expansão térmica da sílica titânia [13].

\subsection{Transição anatase-rutilo na titânia}

Anatase e rutilo são os dois principais polimorfos da titânia $\left(\mathrm{TiO}_{2}\right)$. A transição da forma metaestável anatase para a forma estável rutilo é considerada irreversível e não ocorre em uma temperatura definida, tendo sido observada entre $400 \mathrm{e}$ $1000^{\circ} \mathrm{C}[42,43,44]$. Tanto a temperatura, como a taxa dessa transformação dependem de vários fatores como impurezas, tamanho de partícula, atmosfera entre outros $[45,46]$

Impurezas catiônicas de valência maior ou igual a 4+, por exemplo, retardam a transição anatase-rutilo [47]. Esse fenômeno foi observado, entre outros estudos, em pesquisa recente na qual o aquecimento de um composto formado por uma 
matriz de sílica com adições de titânia (15\% da massa total) a $1050^{\circ} \mathrm{C}$ não apresentou formação de rutilo em mais de 25 horas de tratamento [48].

Por outro lado, atmosferas quimicamente redutoras favorecem a transição anatase-rutilo, uma vez que a formação de vacâncias de oxigênio na estrutura anatase facilita a quebra de ligações e a difusão de matéria $[49,50]$.

\subsection{Deposição axial de vapor (VAD)}

Uma das maneiras mais eficientes e com boa relação custo/benefício de se produzir preformas de fibra óptica é o processo de deposição axial de vapor ou VAD (Vapour-phase Axial Deposition). Métodos similares ao VAD, tais como: CVD (Chemical Vapour-phase Deposition), MCVD (Modified Chemical Vapour-phase Deposition), OVD (Outside Vapour-phase Deposition) também podem ser utilizados para esse fim [33].

O processo VAD depende das seguintes reações [51]:

$$
\begin{aligned}
& \mathrm{H}_{2}+\mathrm{O}_{2} \rightarrow \mathrm{H}_{2} \mathrm{O} \\
& \mathrm{SiCl}_{4}+2 \mathrm{H}_{2} \mathrm{O} \rightarrow \mathrm{SiO}_{2}+4 \mathrm{HCl}
\end{aligned}
$$

Nesta segunda reação (reação de hidrólise), o gás tetracloreto de silício $\left(\mathrm{SiCl}_{4}\right)$ reage com vapor d'água para formar partículas nanométricas de sílica amorfa de alta pureza [33]. As nano partículas de $\mathrm{SiO}_{2}$ amorfo formadas na reação são depositadas na superfície inferior de um alvo central que gira em torno do seu eixo e se desloca verticalmente para cima de modo que as nano partículas acumuladas formem algo similar a um cilindro (Figura 3.11) de cor branca que recebe o nome de preforma porosa de fibra óptica [52]. Para que ocorra a reação química descrita anteriormente um ou mais queimadores são responsáveis pela injeção dos gases $\mathrm{SiCl}_{4}, \mathrm{H}_{2}$ e $\mathrm{O}_{2}$ na câmara onde ocorre a combustão do hidrogênio formando vapor d'água para as reações de hidrólise. 


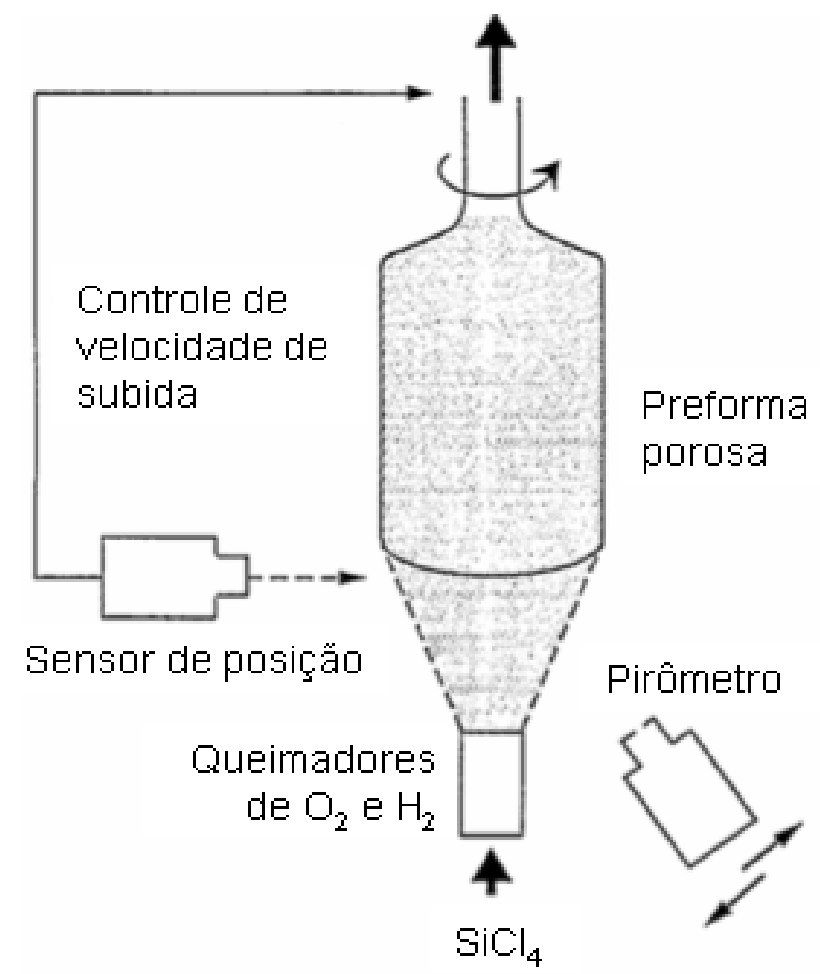

Figura 3. 11 - Representação esquemática do processo VAD [52].

Uma vez obtida a pré-forma porosa de sílica vítrea, é realizado um tratamento térmico para que ocorra a desidratação e posterior consolidação do material formando, então, a preforma vítrea (consolidado de sílica vítrea transparente) em um processo no qual ocorre considerável redução de volume. Uma das maneiras de realizar esse tratamento é aquecer a preforma porosa em um forno elétrico com atmosfera controlada. Nestas condições obteve-se a preforma vítrea a uma temperatura de $1400^{\circ} \mathrm{C}$ mantida por 3 horas em uma atmosfera de Hélio [33]. Outra maneira é a pulverização da preforma porosa para se obter nanopó amorfo de sílica e então produzir consolidados de sílica vítrea por meio da sinterização deste pó.

$\mathrm{Na}$ etapa de aquecimento da preforma porosa para que ocorra o coalescimento e posterior colapsamento entre as partículas vítreas é comum o aparecimento de bolhas que permanecem presas na estrutura final do vidro. Um estudo realizado sobre o assunto [53], concluiu que altas taxas de aquecimento, nessa etapa de consolidação, provocam o rápido crescimento do volume de bolhas em um curto espaço de tempo. Em consequência disso, o mesmo trabalho sugeriu que baixas taxas de aquecimento são mais adequadas para essa etapa de obtenção do material vítreo consolidado. 
Uma desvantagem do processo VAD é a elevada quantidade de grupos $\mathrm{OH}$ que a preforma vítrea apresenta [30,38]. Isso ocorre devido à grande liberação de vapor d'água na chama de $\mathrm{H}_{2}$ e $\mathrm{O}_{2}$.

\subsection{Sinterização da sílica}

A sinterização é um dos processos utilizados para a obtenção de consolidados de sílica fundida, seja a partir de pó de sílica cristalina ou a partir de pó de sílica amorfa.

Em um determinado estudo [54], concluiu-se que a temperatura ótima para obtenção da sílica vítrea pela sinterização de corpos pré-compactados de pó amorfo de $\mathrm{SiO}_{2}-0,4 \mu \mathrm{m}$ de tamanho médio de partícula - é acima de $1400^{\circ} \mathrm{C}$ em atmosfera de alto vácuo $\left(10^{-4} \mathrm{~Pa}\right)$ e tempo de patamar de aproximadamente 17 minutos.

Em outro estudo [55], envolvendo a mistura de matérias-primas de $\mathrm{SiO}_{2}$, pós de quartzo e de sílica pirogênica (nanopó amorfo) foram sinterizados em forno elétrico mantido à temperatura de $1550^{\circ} \mathrm{C}$ por uma hora utilizando-se uma taxa de aquecimento de $5^{\circ} \mathrm{C} / \mathrm{min}$.. Quando processados separadamente, ambas amostras resultantes sofreram cristalização na forma de cristobalita, enquanto que na sinterização do pó de quartzo com adições de mais de 10\% de sílica pirogênica verificou-se a presença de cristais de cristobalita e de quartzo no produto final.

Sílica vítrea foi, também, obtida a partir de pó cristalino (quartzo, com 100 $\mu \mathrm{m}$ de diâmetro médio) pela técnica SPS [56] - a mesma utilizada neste trabalho -, onde consolidados vítreos livres de bolhas foram fabricados para uma taxa de aquecimento de $50^{\circ} \mathrm{C} / \mathrm{min}$. com temperaturas máximas de processo entre $1500 \mathrm{e}$ $1600^{\circ} \mathrm{C}$, sem tempo de patamar, e um esforço de compressão de $20 \mathrm{MPa}$ exercido sobre a matéria-prima. Este mesmo trabalho sugeriu que partes brancas presentes na superfície da amostra seriam cristais não fundidos devido ao gradiente de temperatura existente no molde quando utilizada uma taxa de aquecimento de $100^{\circ} \mathrm{C} / \mathrm{min}$. Além disso, o aumento da temperatura a essa taxa de aquecimento causou a formação de numerosas bolhas devido, segundo o estudo, à difusão de carbono na sílica. 
Nanopó amorfo de $\mathrm{SiO}_{2}$ com tamanho de partícula menor que $10 \mathrm{~nm}$ foi consolidado pelo processo SPS à temperatura mínima de $1000^{\circ} \mathrm{C}$ mantida por 5 minutos com aplicação de $100 \mathrm{MPa}$ de compressão na amostra [57]. No entanto, o vidro obtido apresentou uma transmitância de apenas $63 \%$ no UV-Vis do espectro luminoso devido à presença de grupos $\mathrm{OH}$ em quantidade 40 vezes maior do que na sílica fundida comum. 


\section{Materiais e Método}

O planejamento utilizado para se obter consolidados de sílica vítrea e de sílica titânia a partir de diferentes matérias-primas por intermédio da técnica de sinterização por plasma pulsado (SPS) organizou-se resumidamente nas seguintes etapas descritas abaixo:

1) Aquisição dos materiais para pesquisa (pós de sílica pura com diferentes estruturas e granulometrias): pós de quartzo alfa de granulometria média de $100 \mu \mathrm{m}$; pó de sílica amorfa de granulometria média de $100 \mu \mathrm{m}$; nanopó amorfo de sílica; e nanopó amorfo de sílica dopada com titânia.

2) Determinação das condições de processamento ótimo para obtenção de sílica vítrea transparente a partir dos diferentes tipos de matérias-primas de $\mathrm{SiO}_{2}$. Nesta etapa, para cada teste, parâmetros como temperatura, velocidade de aquecimento, tempo de processamento, entre outros, foram modificados e o resultado final analisado. Assim, foi possível verificar como cada um desses fatores influencia nas características finais da peça e determinar as condições de processamento ótimo da máquina SPS para a obtenção da sílica vítrea transparente.

3) Caracterização das amostras sinterizadas por: i) transmitância óptica no UVVis-NIR; ii) difratometria de raios $\mathrm{X}$; iii) medidas de densidade; iv) microscopia óptica e v) microscopia eletrônica de varredura.

4) Obtenção de consolidados de sílica titânia, tomando como base os parâmetros de processo estabelecidos para consolidar a sílica vítrea pura (o $\mathrm{SiO}_{2}$ compõe mais de $90 \%$ da matéria-prima trabalhada neste caso). 


\subsection{Sistema SPS}

O equipamento SPS em uso é o modelo DR. SINTER® - SPS1050, fabricado por SPS Syntex Inc., Japão, e locado no Departamento de Engenharia Mecatrônica da Escola Politécnica da Universidade de São Paulo. A figura 4.1 mostra a foto da máquina utilizada nos experimentos.

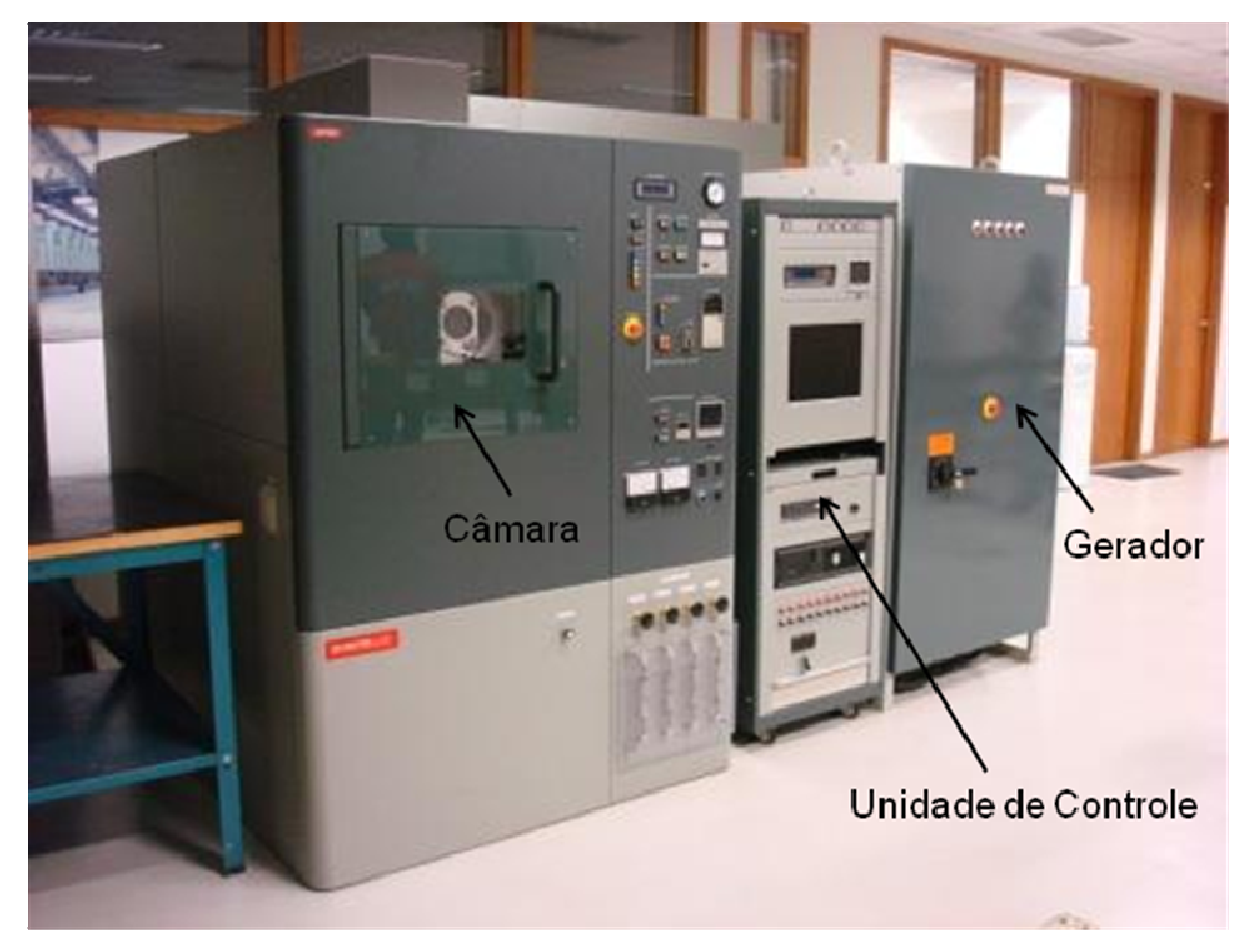

Figura 4. 1 - Máquina SPS modelo DR. SINTER® - SPS1050 utilizada nos experimentos.

O SPS é formado por um eixo vertical composto por dois eletrodos; uma câmara de sinterização; um mecanismo de controle da atmosfera da câmara (vácuo, ar ou argônio); um gerador de pulsos de corrente contínua; e uma unidade de controle. A compressão mecânica é realizada pelos dois eletrodos verticais por onde também passam os pulsos de corrente. $O$ molde é posicionado entre os eletrodos (resfriados com água corrente), dentro da câmara com atmosfera controlada. Uma representação esquemática do sistema SPS é apresentada na figura 4.2.

A medição da temperatura do processo pode ser realizada por um termopar que é inserido em um pequeno orifício na parede externa do molde ou através de um pirômetro óptico que mede a temperatura da superfície externa do molde para 
onde ele aponta. O termopar disponível e utilizado pela equipe do laboratório é do tipo $\mathrm{K}$ que é recomendado para temperaturas de até $1200^{\circ} \mathrm{C}$, enquanto que o pirômetro óptico instalado pode ser utilizado até a temperatura de $2500^{\circ} \mathrm{C}$, porém não sendo sensível a temperaturas menores que $570^{\circ} \mathrm{C}$. Neste trabalho, devido às temperaturas máximas atingidas da ordem de $1600^{\circ} \mathrm{C}$, fez-se uso do pirômetro óptico para a medição da temperatura.

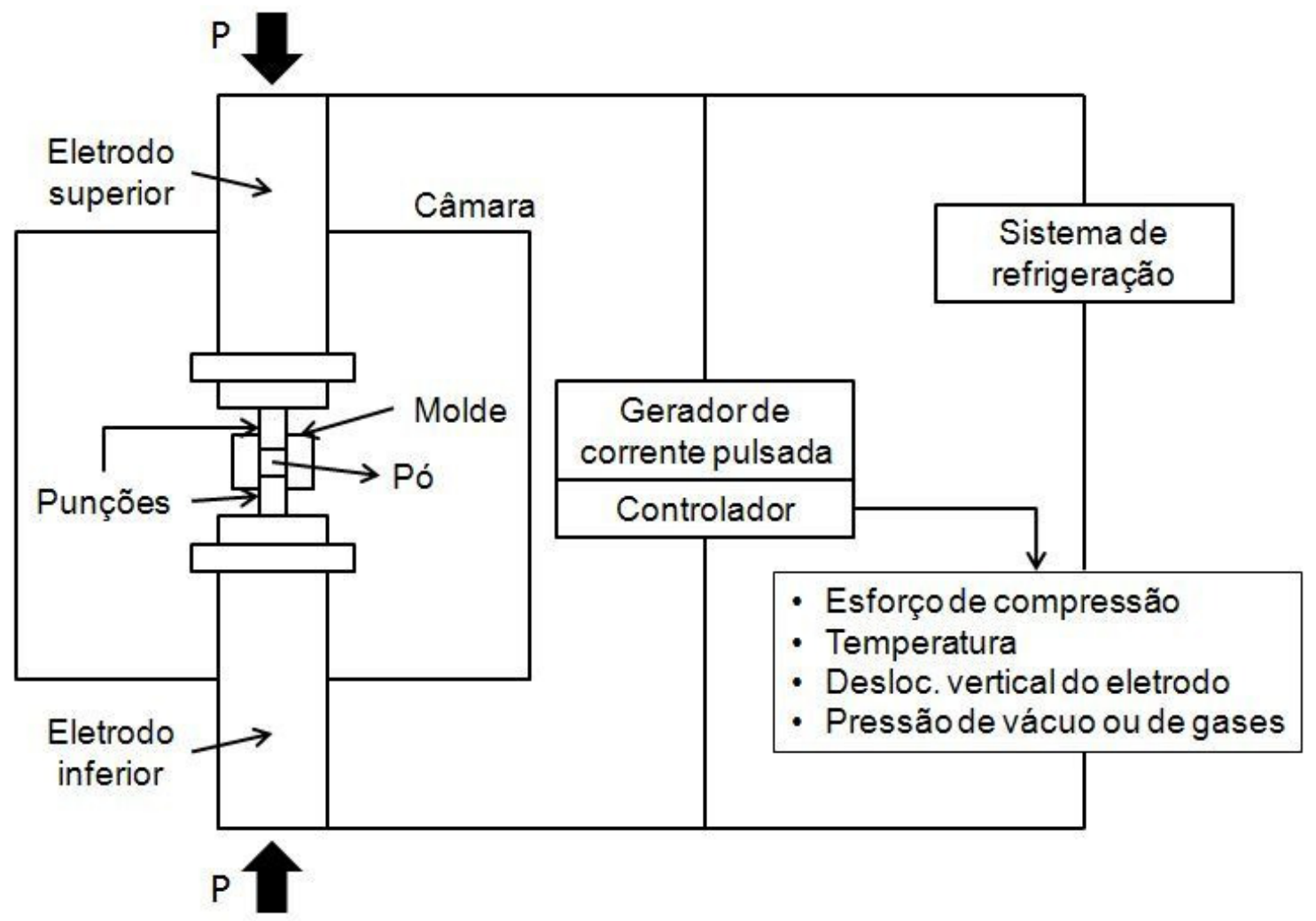

Figura 4. 2 - Representação esquemática do sistema de sinterização SPS.

Durante todo o processo, a temperatura e o esforço de compressão axial eram controlados por um sistema PID retro-alimentado, enquanto que a contração axial da amostra (deslocamento vertical para cima do pino inferior durante a densificação), a pressão atmosférica na câmara (somente atmosfera de baixa pressão foi utilizada) e os outros indicadores eram simplesmente monitorados. Todos os parâmetros de processo (voltagem, corrente elétrica, temperatura, pressão mecânica, deslocamento, taxa de deslocamento e pressão na câmara) eram visualizados em tempo real em um monitor conectado ao equipamento, e gravados para análise posterior. 


\subsection{Molde e punções}

Em todos os experimentos realizados, os pós a serem sinterizados eram inseridos em um molde cilíndrico de grafite de alta densidade, de diâmetro interno de $20 \mathrm{~mm}$, diâmetro externo de $40 \mathrm{~mm}$ e altura de $40 \mathrm{~mm}$. Dois punções cilíndricos, do mesmo material do molde, de dimensões de $20 \mathrm{~mm}$ de diâmetro por $20 \mathrm{~mm}$ de altura, serviam para restringir o pó dentro do molde e transmitir a ele o esforço de compressão, além de fechar o circuito elétrico entre os eletrodos. Durante o depósito do pó no molde realizava-se a pré-prensagem do mesmo de forma manual ou com o auxílio de uma prensa hidráulica. As figuras 4.3 e 4.4 mostram, respectivamente, foto e modelo ilustrativo do molde e dos punções utilizados.

Para evitar o gradiente do esforço de compressão aplicado na amostra devido ao atrito entre o punção e o molde [58] e, também, para facilitar a retirada da peça após o processo, utilizou-se papel grafite de aproximadamente $0,5 \mathrm{~mm}$ de espessura na parede interna do molde. Além de funcionar como lubrificante, a folha de papel grafite possibilita uma distribuição de corrente elétrica mais uniforme e também foi colocada entre a amostra e as faces dos punções.

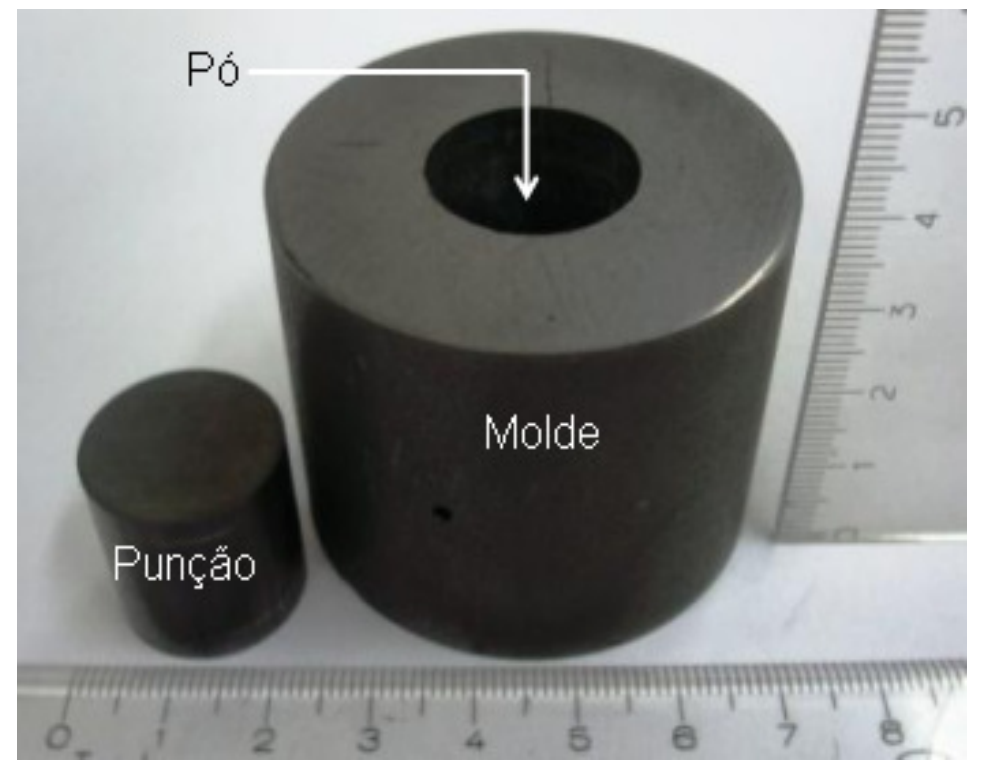

Figura 4. 3 - Foto de molde e punções com suas respectivas medidas. 


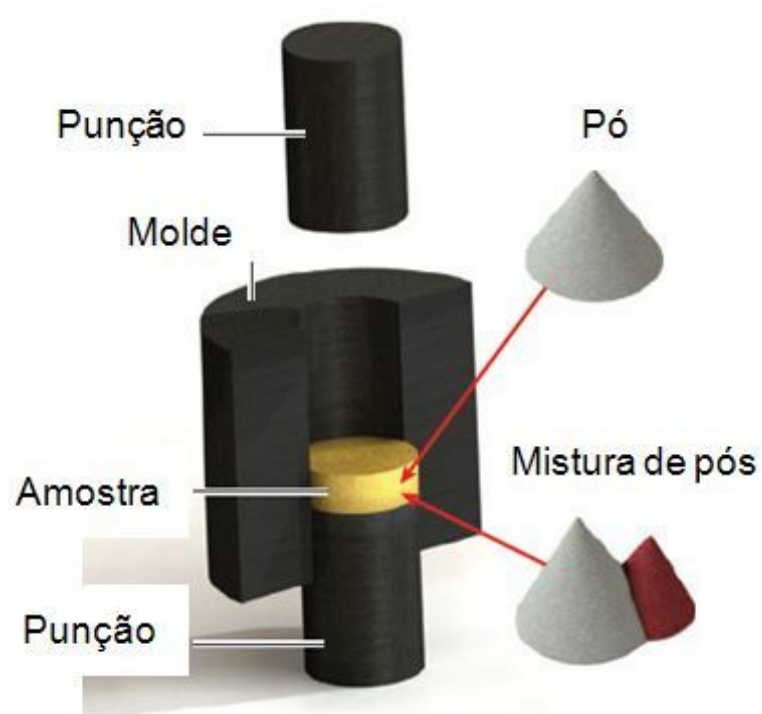

Figura 4. 4 - Modelo ilustrativo de molde, punção e pó sendo inserido no molde [3].

\subsection{Matérias-primas e condições de processamento}

A tabela 4.1, a seguir, descreve os tipos de matérias-primas de sílica utilizadas neste trabalho e a tabela 4.2 apresenta as condições de processamento utilizadas no trabalho.

Tabela 4. 1 - Características dos tipos de pós utilizados como matérias-primas.

\begin{tabular}{cccccc}
\hline $\begin{array}{c}\text { Tipo de } \\
\text { pó }\end{array}$ & $\begin{array}{c}\text { Estrutura } \\
\text { cristalina }\end{array}$ & $\begin{array}{c}\text { Tamanho } \\
\text { de } \\
\text { partícula }\end{array}$ & $\begin{array}{c}\text { Origem } \\
\text { da } \\
\text { matéria- } \\
\text { prima }\end{array}$ & $\begin{array}{c}\text { Pureza } \\
(\%)\end{array}$ & $\begin{array}{c}\text { Laboratório/Empresa } \\
\text { fornecedora }\end{array}$ \\
\hline Cristalino & $\begin{array}{c}\text { Quartzo } \\
\text { alfa }\end{array}$ & $\sim 100 \mu \mathrm{m}$ & Natural & 99,99 & Kyushu Ceramics \\
Cristalino & $\begin{array}{c}\text { Quartzo } \\
\text { alfa }\end{array}$ & $\sim 100 \mu \mathrm{m}$ & Natural & - & lota \\
Cristalino & $\begin{array}{c}\text { Quartzo } \\
\text { alfa }\end{array}$ & $\begin{array}{c}\text { De } 140 \mathrm{a} \\
500 \mu \mathrm{m} \\
\text { De } 30 \mathrm{a}\end{array}$ & $\begin{array}{c}\text { Natural } \\
\text { Nantética: }\end{array}$ \\
amorfo & - & 99,9999 & LIQC - Unicamp \\
Amorfo & - & $\begin{array}{c}\text { Processo } \\
\text { VAD }\end{array}$ & & LIQC - Unicamp \\
& $\sim 100 \mu \mathrm{m}$ & $\begin{array}{c}\text { Sintética: } \\
\text { Processo } \\
\text { Sol-Gel }\end{array}$ & 99,9999 & MKC \\
\hline
\end{tabular}


Tabela 4. 2 - Condições de processamento testadas para cada pó.

\begin{tabular}{cccccc}
\hline $\begin{array}{c}\text { Tipo de } \\
\text { pó }\end{array}$ & $\begin{array}{c}\text { Massa } \\
(\mathrm{g})\end{array}$ & $\begin{array}{c}\text { Compressão } \\
\text { Mecânica } \\
(\mathrm{MPa})\end{array}$ & $\begin{array}{c}\text { Taxa de } \\
\text { aquecimento } \\
\left({ }^{\circ} \mathrm{C} / \mathrm{min}\right)\end{array}$ & $\begin{array}{c}\text { Pré- } \\
\text { prensagem }\end{array}$ & $\begin{array}{c}\text { Temperatura } \\
\text { final }\left({ }^{\circ} \mathrm{C}\right)\end{array}$ \\
\hline Cristal & 5,7 & $\sim 6,4$ & Entre 50 e 140 & Manual & $\begin{array}{c}\text { Entre } 1400 \text { e } \\
1600\end{array}$ \\
$\begin{array}{c}\text { Nanopó } \\
\text { amorfo }\end{array}$ & 2,5 & $\sim 6,4$ & Entre 40 e 150 & $\begin{array}{c}\text { Manual ou } \\
\text { prensa } \\
\text { hidráulica } \\
\text { Manual }\end{array}$ & $\begin{array}{c}\text { Entre } 1200 \text { e } \\
1450\end{array}$ \\
Amorfo & 5,7 & $\sim 6,4$ & Entre 40 e 100 & $\begin{array}{c}\text { Entre } 1200 \text { e } \\
1300\end{array}$ \\
\hline
\end{tabular}

A tabela 4.3 apresenta as características dos pós de sílica dopados com titânia e a tabela 4.4 indica as condições de processamento utilizadas para estes pós.

Tabela 4. 3 - Especificações do pó de sílica dopada com titânia.

\begin{tabular}{ccccc}
\hline Tipo de pó & $\begin{array}{c}\text { Origem da } \\
\text { sílica }\end{array}$ & $\begin{array}{c}\text { Microestrutura da } \\
\text { titânia }\end{array}$ & $\begin{array}{c}\text { Processo de } \\
\text { dopagem }\end{array}$ & $\begin{array}{c}\text { Porcentagem } \\
\text { em massa } \\
\text { de titânia }\end{array}$ \\
\hline $\begin{array}{c}\text { Nanopó de sílica } \\
\text { amorfa dopada } \\
\text { com nanocristais } \\
\text { de titânia }\end{array}$ & $\begin{array}{c}\text { Sintética: } \\
\text { processo } \\
\text { VAD }\end{array}$ & $\begin{array}{c}\text { Cristalina - anatase; } \\
\text { ou }\end{array}$ & $\begin{array}{c}\text { ALD - } \\
\text { cristalina - rutilo } \\
\text { camadcana de }\end{array}$ & $\begin{array}{c}\sim 6 \% \\
\text { atômica }\end{array}$ \\
\hline
\end{tabular}

Tabela 4. 4 - Parâmetros de processamento do nanopó de sílica dopado com titânia.

\begin{tabular}{ccccc}
\hline $\begin{array}{c}\text { Massa } \\
(\mathrm{g})\end{array}$ & $\begin{array}{c}\text { Compressão } \\
\text { Mecânica } \\
(\mathrm{MPa})\end{array}$ & $\begin{array}{c}\text { Taxa de } \\
\text { aquecimento } \\
\left({ }^{\circ} \mathrm{C} / \mathrm{min} .\right)\end{array}$ & $\begin{array}{c}\text { Pré- } \\
\text { prensagem }\end{array}$ & $\begin{array}{c}\text { Temperatura final } \\
\left({ }^{\circ} \mathrm{C}\right)\end{array}$ \\
\hline 2,5 & $\sim 6,4$ & Entre 40 e 100 & Manual & Entre 1200 e 1450 \\
\hline
\end{tabular}

Para que o leitor saiba exatamente as condições de processamento de cada amostra produzida e publicada neste trabalho através de fotografias, foi criada a tabela 4.5 que associa cada uma das amostras apresentadas na seção de resultados deste texto com seus respectivos parâmetros de processo por meio de uma letra do alfabeto. 
Tabela 4. 5- Amostras publicadas neste trabalho e suas condições de processamento.

\begin{tabular}{|c|c|c|c|c|}
\hline Amostra & $\begin{array}{l}\text { Matéria-prima } \\
\text { (tipo de pó) }\end{array}$ & $\begin{array}{c}\text { Taxa de } \\
\text { aquecimento } \\
\text { aproximada } \\
\left({ }^{\circ} \mathrm{C} / \mathrm{min} .\right)\end{array}$ & $\begin{array}{l}\text { Temperatura } \\
\text { final } \\
\text { aproximada } \\
\left({ }^{\circ} \mathrm{C}\right)\end{array}$ & $\begin{array}{c}\text { Tempo de } \\
\text { patamar } \\
\text { (min.) }\end{array}$ \\
\hline$A$ & Cristalino $\left(\mathrm{SiO}_{2}\right)$ & 60 & 1450 & 3 \\
\hline$B$ & Cristalino $\left(\mathrm{SiO}_{2}\right)$ & 60 & 1400 & 4 \\
\hline $\mathrm{C}$ & Cristalino $\left(\mathrm{SiO}_{2}\right)$ & 140 & 1600 & 0 \\
\hline $\mathrm{D}$ & Cristalino $\left(\mathrm{SiO}_{2}\right)$ & 140 & 1500 & 0 \\
\hline$E$ & Cristalino $\left(\mathrm{SiO}_{2}\right)$ & 60 & 1400 & 4 \\
\hline $\mathrm{F}$ & Cristalino $\left(\mathrm{SiO}_{2}\right)$ & 150 & 1620 & 0 \\
\hline G & Nanopó amorfo $\left(\mathrm{SiO}_{2}\right)$ & 60 & 1350 & 1 \\
\hline $\mathrm{H}$ & Nanopó amorfo $\left(\mathrm{SiO}_{2}\right)$ & 60 & 1350 & 1 \\
\hline 1 & Nanopó amorfo $\left(\mathrm{SiO}_{2}\right)$ & 60 & 1450 & 0 \\
\hline J & Nanopó amorfo $\left(\mathrm{SiO}_{2}\right)$ & 150 & 1360 & 0 \\
\hline $\mathrm{K}$ & Nanopó amorfo $\left(\mathrm{SiO}_{2}\right)$ & 150 & 1240 & 0 \\
\hline $\mathrm{L}$ & Nanopó amorfo $\left(\mathrm{SiO}_{2}\right)$ & 125 & 1120 & 2 \\
\hline M & Nanopó amorfo $\left(\mathrm{SiO}_{2}\right)$ & 150 & 1430 & 4 \\
\hline$N$ & Nanopó amorfo $\left(\mathrm{SiO}_{2}\right)$ & 150 & 1410 & 0 \\
\hline $\mathrm{O}$ & Nanopó amorfo $\left(\mathrm{SiO}_{2}\right)$ & $\begin{array}{l}40 \text { até } 840^{\circ} \mathrm{C} ; \\
95 \text { após } 840^{\circ} \mathrm{C}\end{array}$ & 1220 & 4 \\
\hline$P$ & Amorfo $\left(\mathrm{SiO}_{2}\right)$ & $\begin{array}{l}40 \text { até } 840^{\circ} \mathrm{C} ; \\
95 \text { após } 840^{\circ} \mathrm{C}\end{array}$ & 1220 & 4 \\
\hline$Q$ & Cristalino $\left(\mathrm{SiO}_{2}\right)$ & 60 & 1420 & 5 \\
\hline $\mathrm{R}$ & Nanopó amorfo $\left(\mathrm{SiO}_{2}\right)$ & 60 & 1350 & 1 \\
\hline$S$ & Nanopó $\left(\mathrm{SiO}_{2}-\mathrm{TiO}_{2}\right)$ & $\begin{array}{l}40 \text { até } 840^{\circ} \mathrm{C} ; \\
95 \text { após } 840^{\circ} \mathrm{C}\end{array}$ & 1220 & 4 \\
\hline $\mathrm{T}$ & Nanopó $\left(\mathrm{SiO}_{2}-\mathrm{TiO}_{2}\right)$ & $\begin{array}{l}40 \text { até } 840^{\circ} \mathrm{C} ; \\
95 \text { após } 840^{\circ} \mathrm{C}\end{array}$ & 1220 & 2 \\
\hline$U$ & Nanopó $\left(\mathrm{SiO}_{2}-\mathrm{TiO}_{2}\right)$ & $\begin{array}{l}40 \text { até } 840^{\circ} \mathrm{C} ; \\
95 \text { após } 840^{\circ} \mathrm{C}\end{array}$ & 1450 & 2 \\
\hline
\end{tabular}

\subsection{Medição de densidade}

A medição da densidade das amostras foi realizada com base no princípio de Arquimedes com o auxílio de uma balança analítica com precisão na terceira casa decimal, modelo AL200C (Marte Balanças e Aparelhos de Precisão). Inicialmente, foram medidas as massas das amostras separadamente e, em seguida, um pequeno recipiente de plástico foi preenchido com água deionizada e colocado na balança que, então, foi zerada. Uma das extremidades de uma linha de pesca de 0,20 $\mathrm{mm}$ de diâmetro foi amarrada na amostra enquanto que a extremidade livre foi 
pendurada na parte superior da balança de modo que a amostra ficasse completamente submersa no líquido (Figura 4.5).

Com essa configuração, a balança mede a massa de água deslocada pela amostra, conforme sugere o conceito de esforço de empuxo. Sabendo-se, também, a densidade da água na temperatura em que a medição foi realizada é possível calcular a densidade da amostra $\left(\mathrm{d}_{\mathrm{a}}\right)$ com boa precisão através da relação:

$$
d_{a}=m_{a}\left(\frac{d_{a g}}{m_{a d}}\right)
$$

Onde, ' $m_{a}$ ' é a massa da amostra, ' $d_{a g}$ ' a densidade da água para a temperatura em que a medição foi feita e ' $m_{a d}$ ' a massa de água deslocada. $O$ método de Archimedes permite a medição da densidade de corpos com superfícies regulares e irregulares.

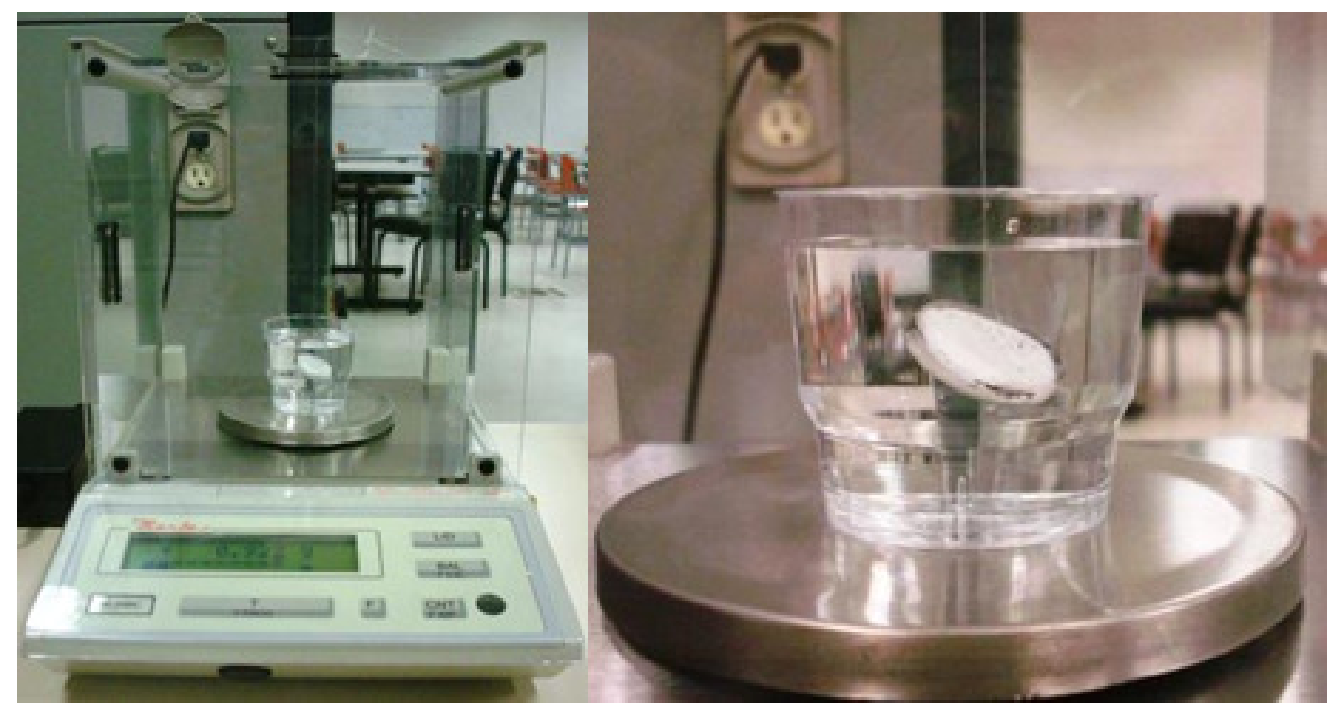

Figura 4. 5 - Balança analítica usada na medição da densidade.

\subsection{Difração de Raios $X$}

Difrações de raios $X$ foram realizadas em amostras nas suas formas consolidadas - não pulverizadas. O equipamento utilizado foi o DMax2200 Rigaku Xray diffractometer equipado com tubo de CuKa e filtro de $\mathrm{Ni}$, e operado em $40 \mathrm{kV}$ e $20 \mathrm{~mA}$, arranjo $\theta-2 \theta$ no intervalo $10^{\circ}<2 \theta<65^{\circ}$ e passo de varredura de $0,01^{\circ}$, 
pertencente ao laboratório de Materiais \& Dispositivos Fotônicos (LIQC) da Faculdade de Engenharia Mecânica - Unicamp, laboratório parceiro neste estudo.

\subsection{Transmitância luminosa}

Realizou-se a análise da transmitância de algumas amostras produzidas pela técnica de espectrofotometria de absorção óptica. Foi utilizado para isso o espectrofotômetro Perkin-EImer UV-Vis-NIR modelo Lambda 9, instalado no Instituto de Física (IFGW) da Unicamp. Mediu-se a transmitância óptica no intervalo de 190 $\mathrm{nm}$ a $3200 \mathrm{~nm}$ de comprimento de onda, com fenda de aproximadamente $3 \times 7 \mathrm{~mm}$ posicionada no centro de cada amostra, todas com espessuras próximas de $6 \mathrm{~mm}$. As medições foram possíveis devido à parceria com o LIQC - Unicamp.

\subsection{Microscopia eletrônica de varredura}

Alguns dos consolidados produzidos foram analisados por microscopia eletrônica de varredura (MEV) no equipamento Philips modelo XL30 do LabMicro Microscopia Eletrônica e de Força Atômica - pertencente ao Departamento de Engenharia Metalúrgica e de Materiais da Escola Politécnica da USP.

Sendo a sílica um material não condutor, uma fina camada de ouro foi depositada sobre uma das faces destas amostras. Fotografias das superfícies das peças com ampliações entre 100 e 5000x foram tiradas. As imagens foram observadas por elétron retro-espalhado (BSE) e a análise química realizada por EDX. 


\section{Experimentos preliminares}

Para os primeiros testes de sinterização de sílica vítrea, utilizou-se o pó de sílica cristalina natural purificada, fornecido pela Kyushu Ceramics. Para definir os parâmetros de processamento como máxima temperatura, taxa de aquecimento e etc., foram seguidas as recomendações de Koide M., et al. [56] em trabalho no qual sílica vítrea transparente foi obtida com taxas de aquecimento moderadas, em torno de $50^{\circ} \mathrm{C} / \mathrm{min}$., temperatura máxima entre 1500 e $1600^{\circ} \mathrm{C}$ e pressão uniaxial de 20 $\mathrm{MPa}$.

No primeiro teste, e nos dois subsequentes, ocorreu a quebra do molde durante o resfriamento em virtude do baixo coeficiente de expansão térmica da sílica vítrea em relação ao do grafite, material do molde. A maior contração térmica do grafite fazia com que o molde comprimisse o consolidado de sílica que por sua vez aplicava um esforço de tração na parede interna do molde que acabava se rompendo.

Como avaliações teóricas de mudança das dimensões físicas do molde não mostraram solução para o problema, foram realizadas algumas tentativas de utilizar moldes separados em partes e unidos por anéis de arame metálico resistente a altas temperaturas (fio de nicromo), mas sem sucesso (Figura 5.1). Outra tentativa para contornar o problema foi a utilização de um molde de diâmetro interno bem maior que o dos punções, e preencher a folga com papel grafite de modo que a diferença de contrações térmicas fosse compensada pelo esmagamento do papel grafite (Figura 5.2), também sem êxito, pois o baixo contato elétrico entre os punções, papel grafite e molde provocaram um aquecimento localizado nas folhas de grafite. 

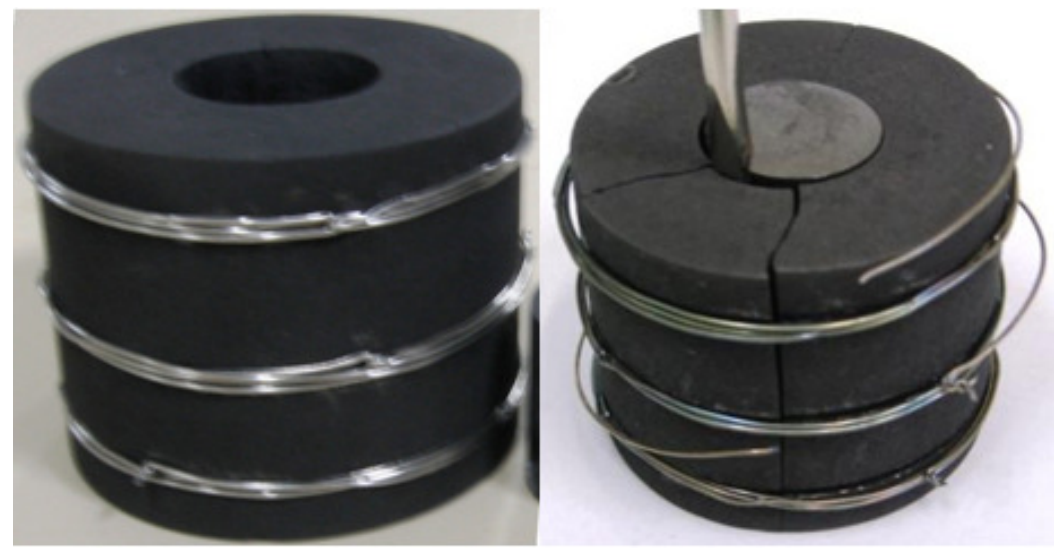

Figura 5. 1 - Fios de nicromo formando três anéis e envolvendo o molde particionado.

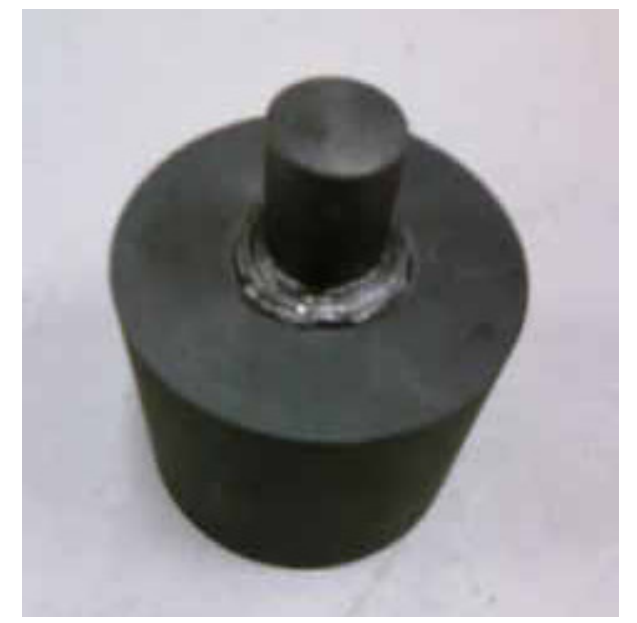

Figura 5. 2 - Configuração com várias camadas de papel grafite entre molde e amostra.

Após outras tentativas, sem sucesso, a solução foi obtida com uma configuração intermediária, com uso de papel grafite para compensar a diferença de expansão térmica. O mesmo molde foi, então, utilizado nos diferentes experimentos sem que ocorressem rachaduras ou trincas no mesmo. 


\section{Resultados e Discussões}

Os itens a seguir, mostram quais são e como foram determinados os parâmetros de fabricação de sílica vítrea através da técnica SPS para diferentes tipos de pó de sílica utilizados como matéria-prima. Neste capítulo é discutido como a alteração de parâmetros de processamento influencia nas características finais do material vítreo e também quais os parâmetros mais adequados em função do tipo de pó utilizado. Fenômenos como gradiente de temperatura na amostra, contração axial da matéria-prima, e liberação de gases da amostra são analisados. Além disso, resultados dos ensaios de caracterização realizados nas amostras obtidas são apresentados e discutidos.

O estudo base da influência dos parâmetros operacionais do equipamento SPS para sinterização da sílica foi realizado para dois tipos de matérias-primas: o pó cristalino (quartzo alfa) fornecido pela Kyocera e o nanopó amorfo de sílica VAD fornecido pelo LIQC-UNICAMP, ambos de alta pureza. Essas duas matérias-primas possuem características distintas que permitem extrapolar as condições ótimas de processamento para os outros tipos de pó de sílica em estudo.

Nos experimentos a seguir, caso nada seja especificado sobre o tamanho de grão e a pureza do pó utilizado, ficará subentendido se tratar de pó de quartzo alfa Kyocera, de tamanho de grão médio de $100 \mu$ m e pureza da ordem de 99,99\%.

\subsection{Sílica vítrea a partir de pó de quartzo alfa}

Nos experimentos realizados com o pó de quartzo obteve-se sílica vítrea transparente para taxas de aquecimento próximas a $60^{\circ} \mathrm{C} / \mathrm{min}$. e a $140^{\circ} \mathrm{C} / \mathrm{min}$.

\subsubsection{Taxas de aquecimento próximas a $60^{\circ} \mathrm{C} / \mathrm{min}$.}


O gráfico da figura 6.1 mostra as curvas de temperatura medida na superfície do molde para dois experimentos com temperaturas finais diferentes, porém ambos com taxas de aquecimento próximas a $60^{\circ} \mathrm{C} / \mathrm{min}$. No experimento em que a temperatura máxima atingida foi de $1400^{\circ} \mathrm{C}$, a amostra obtida apresentou regiões com coloração branca e superfície lateral porosa indicando que o processo de fusão do pó de quartzo alfa foi incompleto, pois a temperatura máxima atingida foi inferior à temperatura de fusão do quartzo. No experimento em que a temperatura final foi de $1450^{\circ} \mathrm{C}$ o consolidado se mostrou completamente transparente devido à fusão de todo o material cristalino e eliminação completa da porosidade aberta.

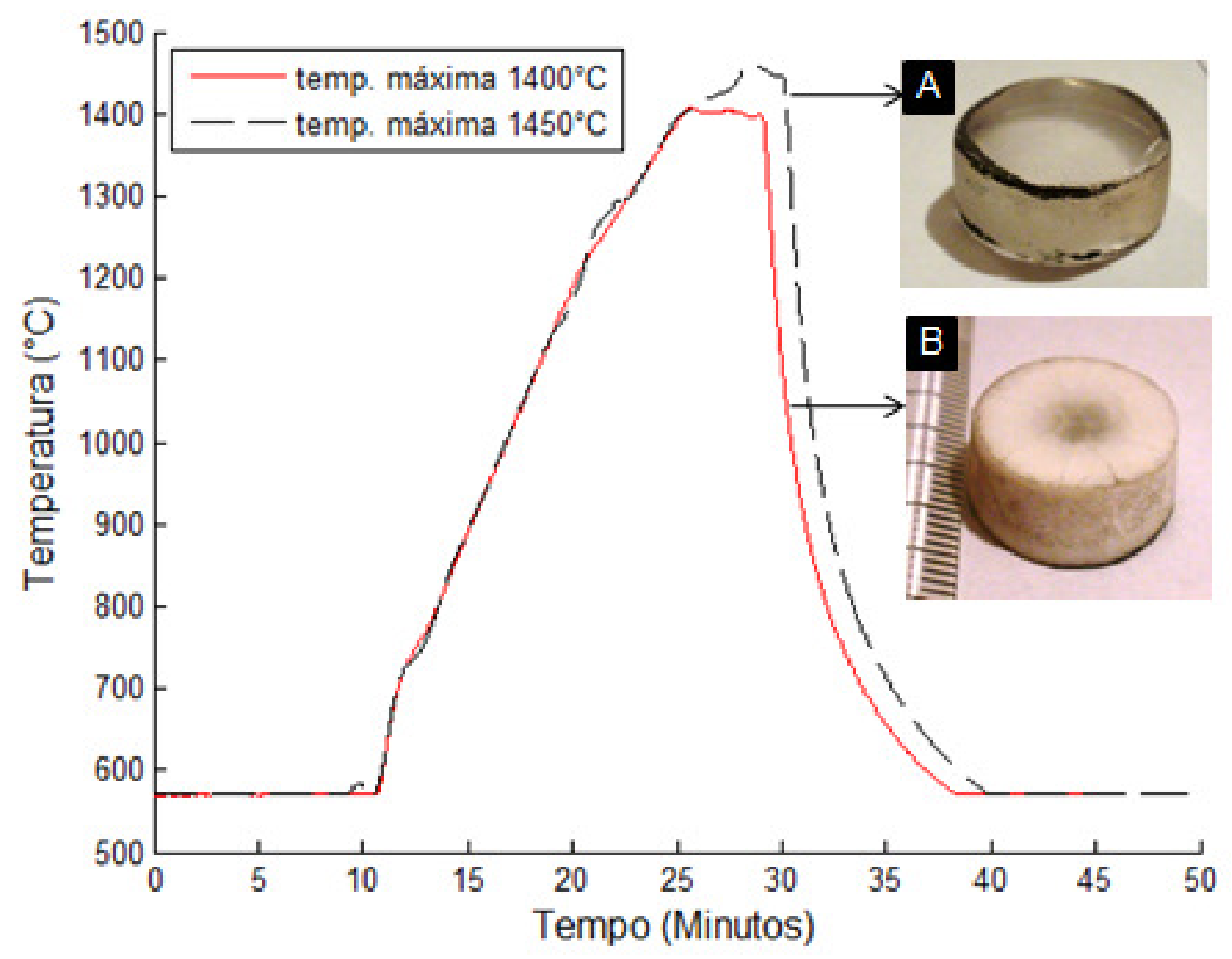

Figura 6. 1 - Amostras aquecidas a $60^{\circ} \mathrm{C} / \mathrm{min}$. e suas respectivas curvas de temperatura.

\subsubsection{Taxas de aquecimento próximas de $140^{\circ} \mathrm{C} / \mathrm{min}$.}

Aumentando a taxa de aquecimento para $140^{\circ} \mathrm{C} / \mathrm{min}$. (Figura 6.2), foi necessário utilizar maior temperatura final de sinterização para obter um material 
completamente fundido. Esse aumento na temperatura foi de cerca de 100 a $150^{\circ} \mathrm{C}$ acima do que o utilizado com taxa de $60^{\circ} \mathrm{C} / \mathrm{min}$. Isso decorre da baixa condutividade térmica da sílica que dificulta a transmissão de calor da superfície do grão para o seu interior, tornando lento o processo de homogeneização da temperatura nas partículas de quartzo. Uma maneira de compensar esse efeito e aumentar mais rapidamente a temperatura interna dos grãos cristalinos de sílica é aumentar as temperaturas máximas do experimento, impondo um maior gradiente de temperatura entre a superfície do grão e seu interior.

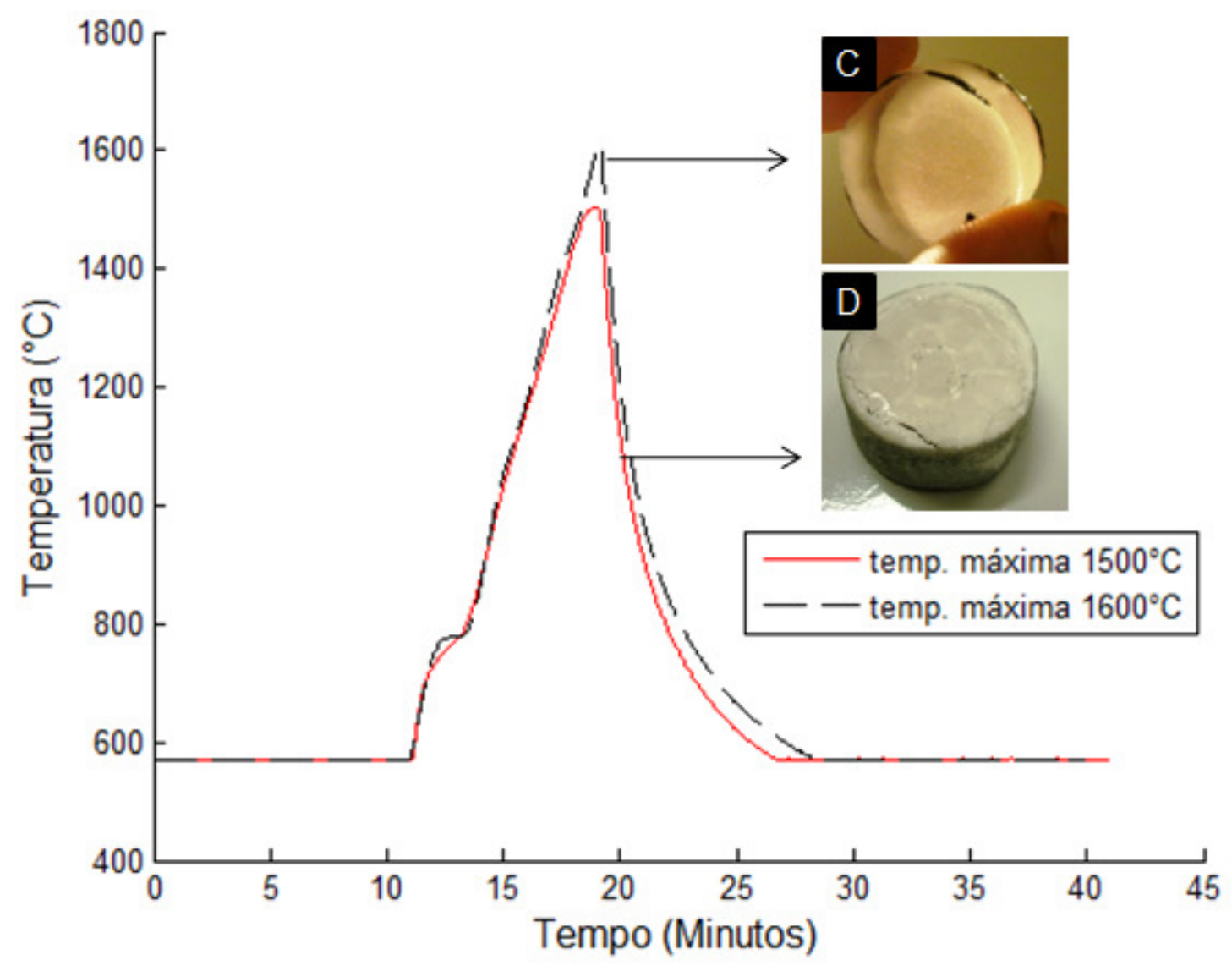

Figura 6. 2 - Amostras aquecidas a $140^{\circ} \mathrm{C} / \mathrm{min}$. e suas respectivas curvas de temperatura.

A tabela 6.1 apresenta os valores das temperaturas correspondentes à fusão parcial e completa de diferentes tipos de matérias-primas de quartzo para diferentes taxas de aquecimento. A partir desses dados, observa-se que para altas taxas de aquecimento $\left(\sim 140^{\circ} \mathrm{C} / \mathrm{min}\right.$.) a temperatura necessária para a obtenção do material transparente deve ser maior, permitindo uma redução no tempo de processamento. No entanto, as amostras obtidas com altas taxas de aquecimento apresentaram 
menor grau de transparência devido à presença de bolhas. Isso ocorre em razão do menor tempo de atuação da bomba de vácuo na retirada dos gases do material antes que se inicie a densificação do mesmo.

Tabela 6. 1 - Fusão completa ou parcial de acordo com parâmetros de processo.

\begin{tabular}{cccccc}
\hline $\begin{array}{c}\text { Fornecedor } \\
\text { do pó }\end{array}$ & $\begin{array}{c}\text { Tamanho } \\
\text { de } \\
\text { partícula }\end{array}$ & $\begin{array}{c}\text { Taxa de } \\
\text { aquec. } \\
\text { aproximada }\end{array}$ & $\begin{array}{c}\text { Temperatura } \\
\text { final - Fusão } \\
\text { incompleta }\end{array}$ & $\begin{array}{c}\text { Temperatura } \\
\text { final - Fusão } \\
\text { completa }\end{array}$ & $\begin{array}{c}\text { Tempo } \\
\text { total de } \\
\text { processo } \\
\text { (min.) }\end{array}$ \\
\hline Kyocera & $100 \mu \mathrm{m}$ & $60^{\circ} \mathrm{C} / \mathrm{min}$. & $1400^{\circ} \mathrm{C}$ & $1450^{\circ} \mathrm{C}$ & $\sim 30$ \\
Kyocera & $100 \mu \mathrm{m}$ & $140^{\circ} \mathrm{C} / \mathrm{min}$. & $1500^{\circ} \mathrm{C}$ & $1610^{\circ} \mathrm{C}$ & $\sim 20$ \\
LIQC & $100 \mu \mathrm{m}$ & $50^{\circ} \mathrm{C} / \mathrm{min}$. & $1450^{\circ} \mathrm{C}$ & $1550^{\circ} \mathrm{C}$ & $\sim 40$ \\
LIQC & $500 \mu \mathrm{m}$ & $50^{\circ} \mathrm{C} / \mathrm{min}$. & $1550^{\circ} \mathrm{C}$ & - & $\sim 40$ \\
lota & $100 \mu \mathrm{m}$ & $60^{\circ} \mathrm{C} / \mathrm{min}$. & $1450^{\circ} \mathrm{C}$ & $1500^{\circ} \mathrm{C}$ & $\sim 30$ \\
\hline
\end{tabular}

Analisando as curvas de pressão interna da câmara de sinterização, observamos a presença de três picos de aumento da pressão durante a fase de aquecimento: o primeiro pico aparecendo em temperaturas entre 100 e $150^{\circ} \mathrm{C}$, atribuído à evaporação da umidade aderida na superfície dos grãos; um segundo pico de pressão que aparece quando a temperatura da amostra atinge cerca de $700^{\circ} \mathrm{C}$; e um terceiro pico de aumento de pressão aparece em temperaturas acima de $1200^{\circ} \mathrm{C}$ quando a sílica começa a se densificar fechando a porosidade aberta. $\mathrm{O}$ aumento da pressão na câmara provém da liberação de gases da matéria-prima, uma vez que experimentos realizados sem amostra, só com o molde, não apresentaram variações da pressão na câmara indicando que não ocorre liberação de gases significativa do molde, punções ou paredes da câmara. O gráfico da figura 6.3 mostra como variou a pressão no interior da câmara para um dos experimentos realizados com o pó cristalino.

Uma análise mais detalhada sobre a pressão na câmara durante a sinterização dos pós de sílica será feita em uma seção mais adiante. 


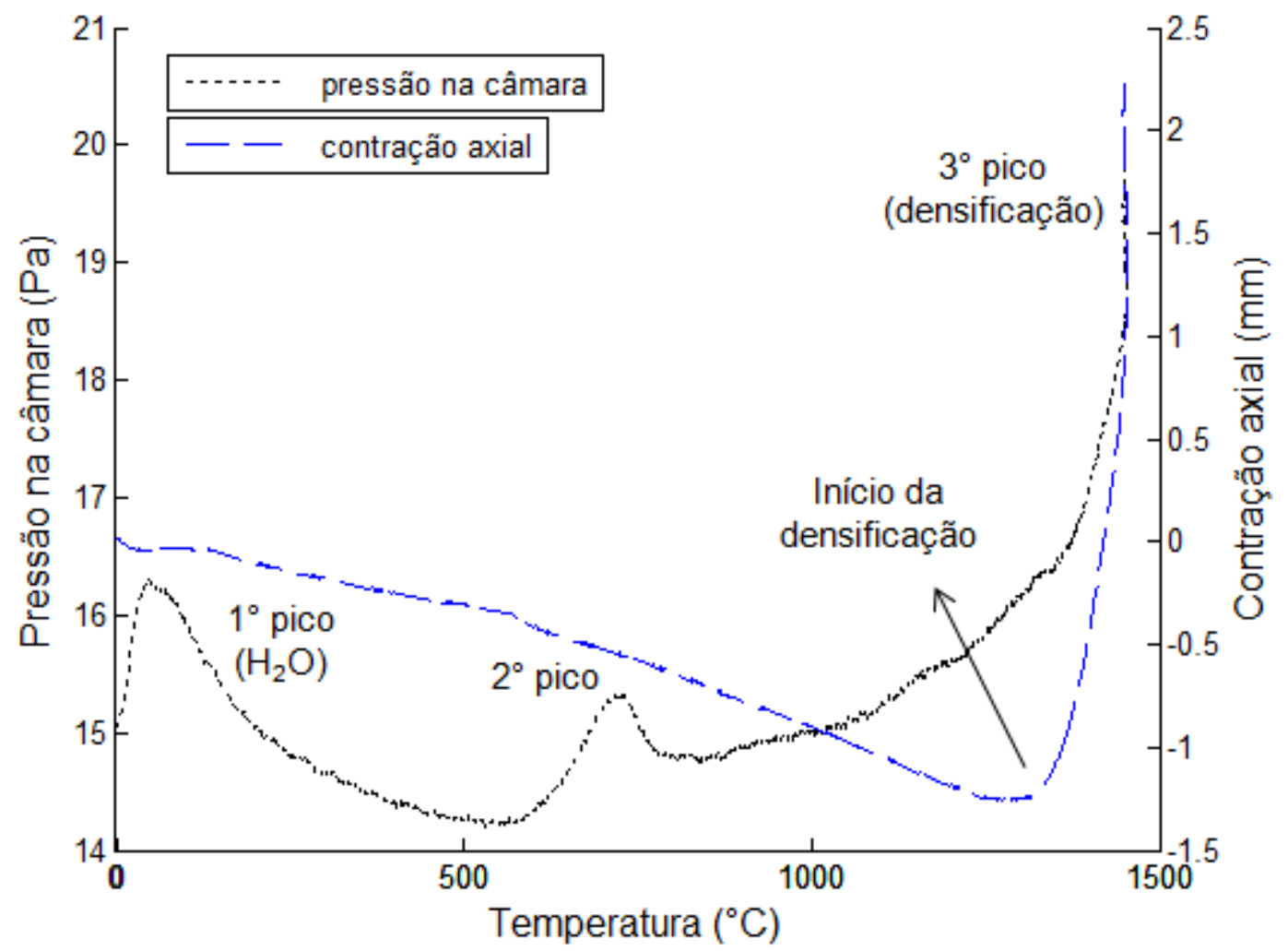

Figura 6. 3 - Curva de pressão na câmara indicando três picos de liberação de gás na sinterização do pó cristalino.

\subsubsection{Gradiente de temperatura na amostra}

A confecção de sílica vítrea a partir de pó de quartzo permitiu a observação de certas características da distribuição da temperatura na amostra de $\mathrm{SiO}_{2}$ durante o processo SPS. A análise da forma geométrica da região vítrea e transparente das amostras parcialmente fundidas (Tabela 6.1) foi que possibilitou inferir sobre 0 gradiente radial e axial de temperatura no material, mostrando como a frente de fusão caminha ao longo da amostra.

A amostra da figura 6.4 - pó Kyocera aquecido a $60^{\circ} \mathrm{C} / \mathrm{min}$. -, por exemplo, não se tornou completamente transparente, mas a região do miolo central e uma de suas faces vitrificaram, conferindo uma geometria côncava à frente de fusão que penetrou no material. Esse fato indica que a temperatura do centro da amostra foi maior que nas bordas e, portanto, sugere uma distribuição radial de temperatura 
crescente no sentido das bordas laterais para o centro da amostra, como esquematizado na figura 6.5 .

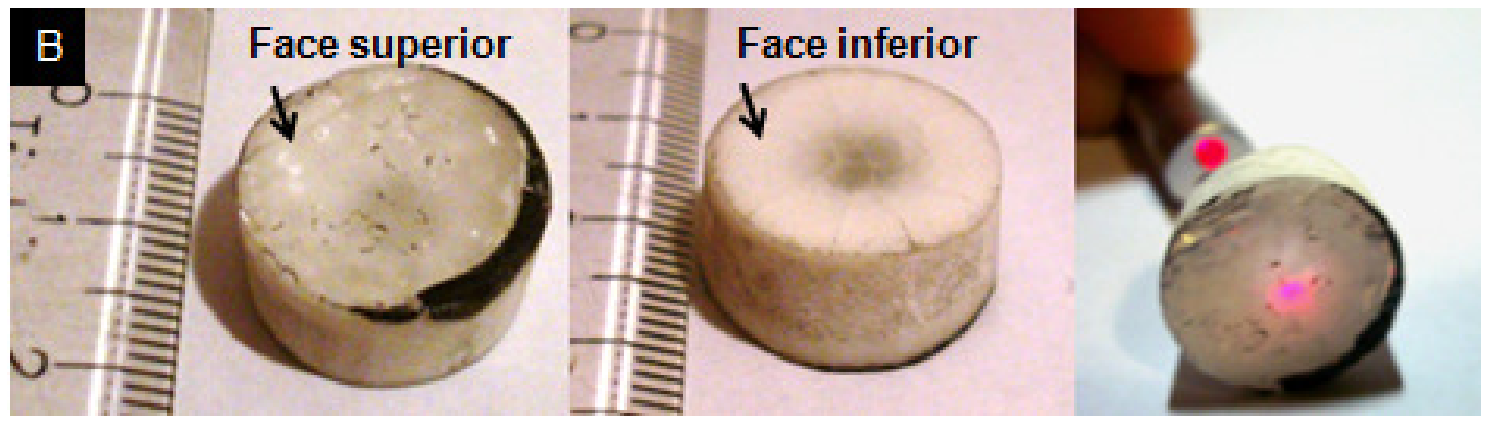

Figura 6. 4 - Amostra com face superior e miolo central fundidos (transparentes) de modo que é possível observar o raio laser incidente no centro atravessando a peça.

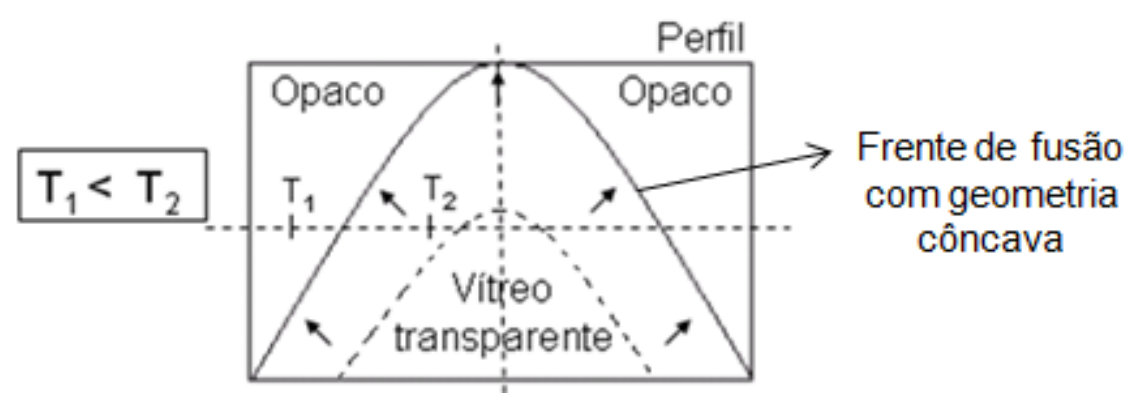

Figura 6. 5 - Representação esquemática do comportamento da frente de fusão no material (vista em corte).

Esse mesmo perfil côncavo da frente de fusão também foi observado em várias outras amostras, como por exemplo, na a sinterização do pó da lota Quartz (Figura 6.6) e do pó da Kyocera aquecido a $140^{\circ} \mathrm{C} / \mathrm{min}$. No entanto, nesse último caso, diferentemente dos exemplos anteriores, a amostra apresentou duas frentes de fusão, uma com origem na face superior e outra com origem na face inferior, conforme esquematizado na figura 6.7.

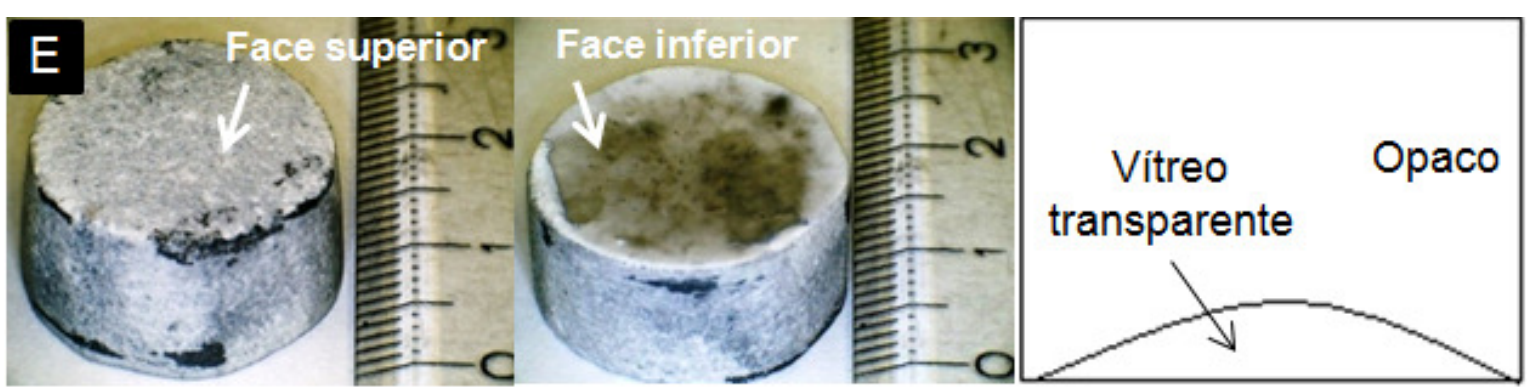

Figura 6. 6 - Foto e esquema de amostra com frente de fusão em uma das faces. 


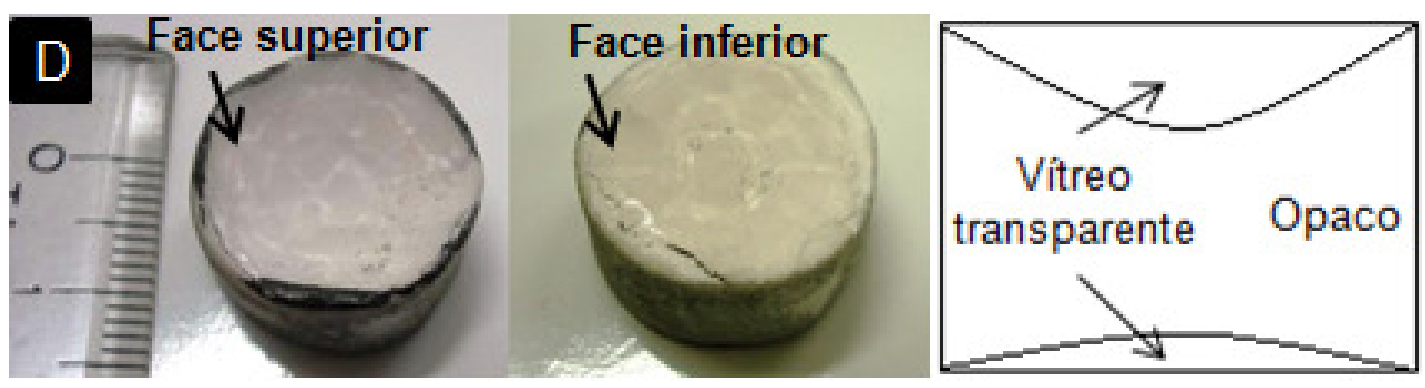

Figura 6. 7 - Foto e esquema de amostra com frentes de fusão nas duas faces.

A geometria da frente de fusão observada facilita a eliminação de gases do consolidado, uma vez que a porosidade vai sendo fechada no sentido do centro para as bordas da peça, possibilitando a saída dos gases pela superfície lateral.

O fato de a temperatura ser maior nas faces das amostras está de acordo com os estudos que indicam os punções como maiores fontes de calor no sistema molde/amostra da sinterização por Plasma Pulsado. A explicação para isso seria a menor área transversal dos punções que causa o aumento da resistência elétrica e, consequentemente, da potência dissipada nos mesmos. Além disso, a dissipação de calor pelas paredes laterais externas do molde resfria a superfície lateral da amostra.

\subsubsection{Frentes de fusão e formação de bolhas}

Outro efeito observado nas amostras obtidas a partir do pó de quartzo foi a formação de bolhas devido ao encontro de frentes de fusão quando utilizadas altas taxas de aquecimento. Conforme a frente de fusão penetra no material ela fecha os poros presentes no seu caminho, 'empurrando' os gases pela porosidade ainda aberta. No encontro de duas frentes de fusão os gases não têm por onde escapar, formando bolhas. Esse efeito pode ser visualizado em uma fatia tirada de uma das amostras (Figura 6.8) obtidas com taxa de aquecimento de $140^{\circ} \mathrm{C} / \mathrm{min}$. 


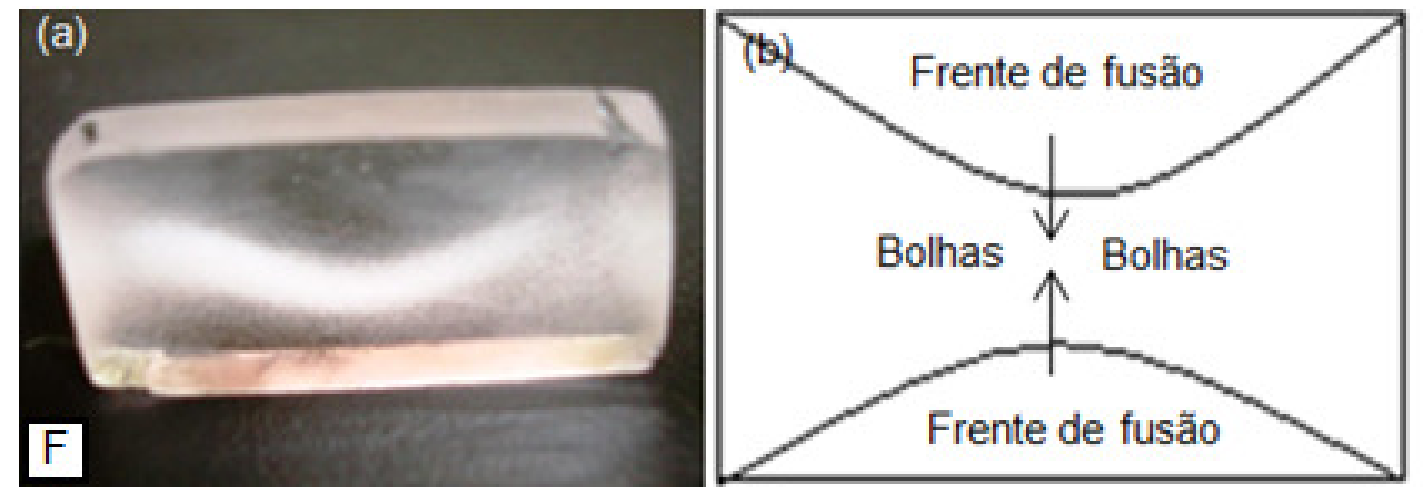

Figura 6.8 - (a) Corte de amostra com bolhas. (b) Esquema da formação de bolhas pelo encontro de frentes de fusão.

A microscopia óptica revelou a presença de bolhas de dimensões micrométricas, mostradas na figura 6.9, com aumento aproximado de 200x.

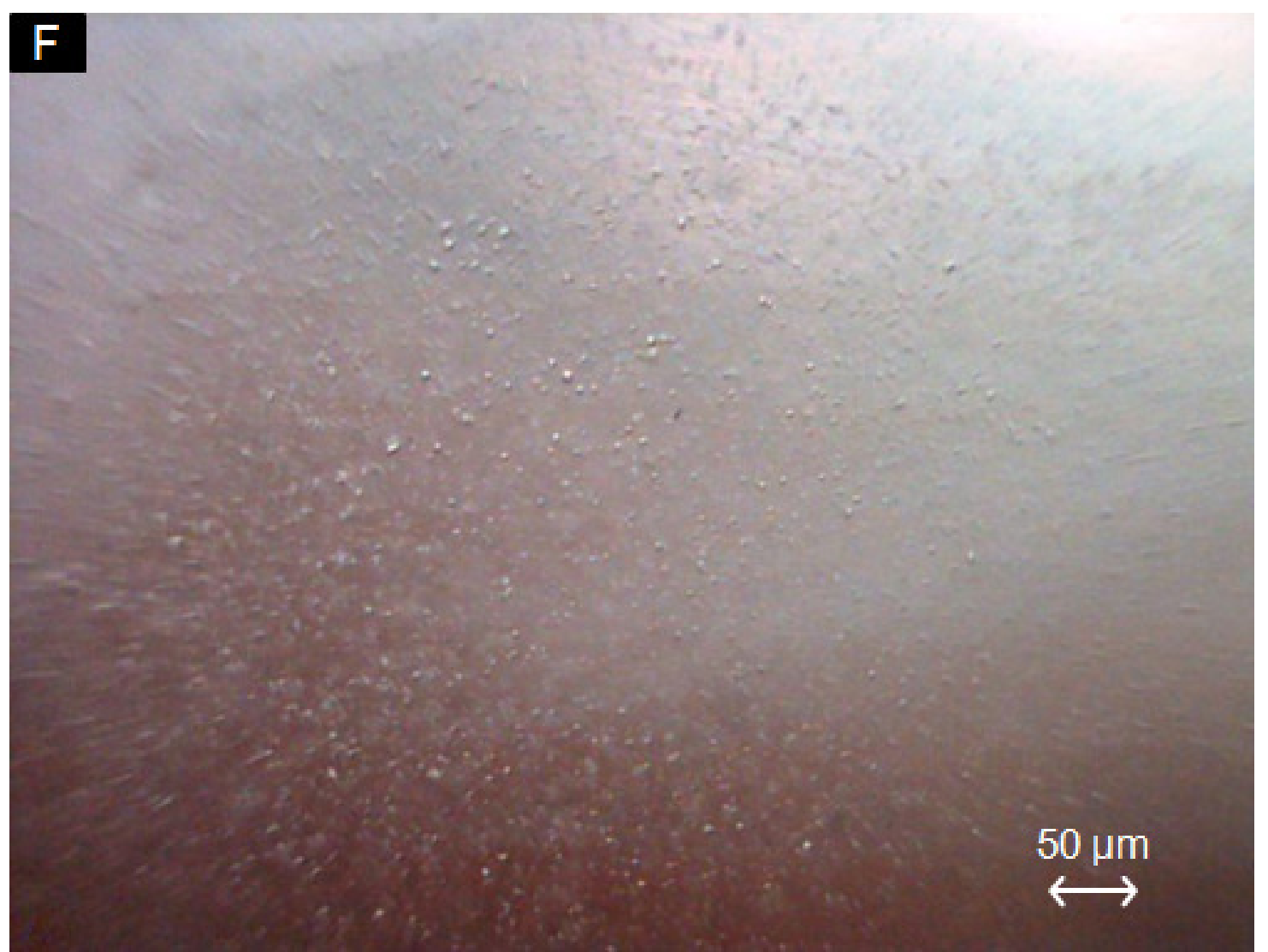

Figura 6. 9 - Foto com aumento aproximado de 200x de amostra com bolhas. 


\subsection{Sílica vítrea a partir de nanopó de $\mathrm{SiO}_{2}$ amorfo}

A obtenção de sílica vítrea transparente a partir de nanopó amorfo de sílica, soot de sílica ou sílica pirogênica não ocorreu de maneira tão imediata como aconteceu com o pó cristalino. A facilidade que esse tipo de matéria-prima demonstrou ter no aprisionamento de bolhas nos materiais sinterizados dificultou a obtenção de uma curva de temperatura adequada à fabricação de amostras completamente transparentes.

Além disso, a considerável redução do tamanho de partícula em relação ao pó de quartzo e o fato da sílica pirogênica já se encontrar em fase amorfa levaram a uma alteração nos parâmetros de processo para a fabricação do material vítreo transparente. Uma vez que essa matéria-prima possui estrutura amorfa, a temperatura de processo para a obtenção do sólido vítreo é pouco acima da temperatura de transição vítrea, o suficiente para que ocorra a densificação ou consolidação - colapsamento entre as partículas do pó - do material particulado.

\subsubsection{Taxas de aquecimento próximas a $60^{\circ} \mathrm{C} / \mathrm{min}$.}

O Gráfico da figura 6.10 mostra a curva de temperatura utilizada para a fabricação de sílica vítrea com taxa de aquecimento próxima a $60^{\circ} \mathrm{C} / \mathrm{min}$. As amostras obtidas com esta programação de temperatura, cuja temperatura final foi em torno de $1350^{\circ} \mathrm{C}$, apresentaram camadas leitosas que, depois de algumas caracterizações, foram identificadas como aglomerações de micro-bolhas. $\mathrm{Na}$ figura 6.11 - foto com ampliação aproximada de 200x -, é possível visualizar o contorno de algumas micro-bolhas presentes nestas amostras. 


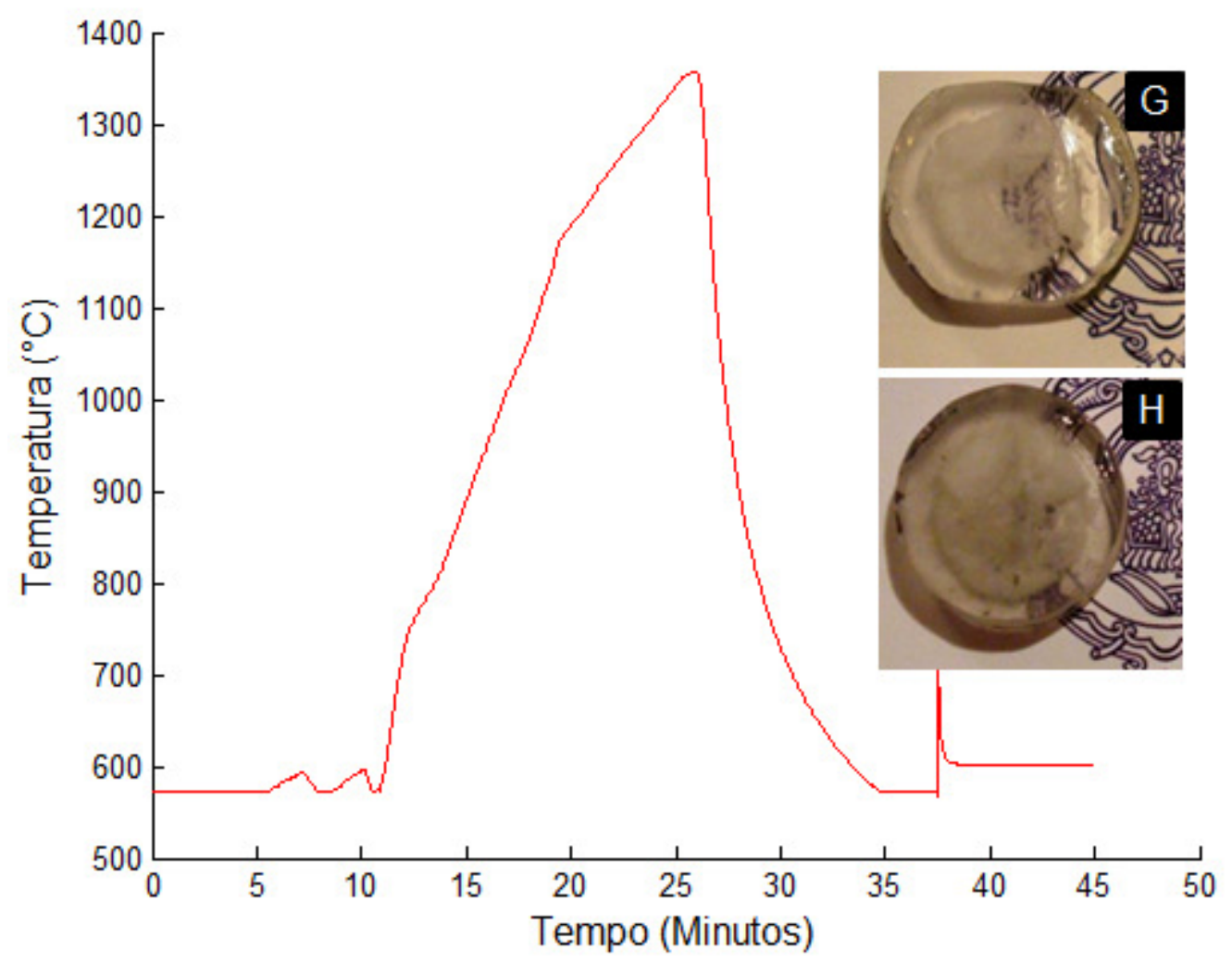

Figura 6. 10 - Sílica vítrea obtida a partir de nanopó e a respectiva curva de temperatura.

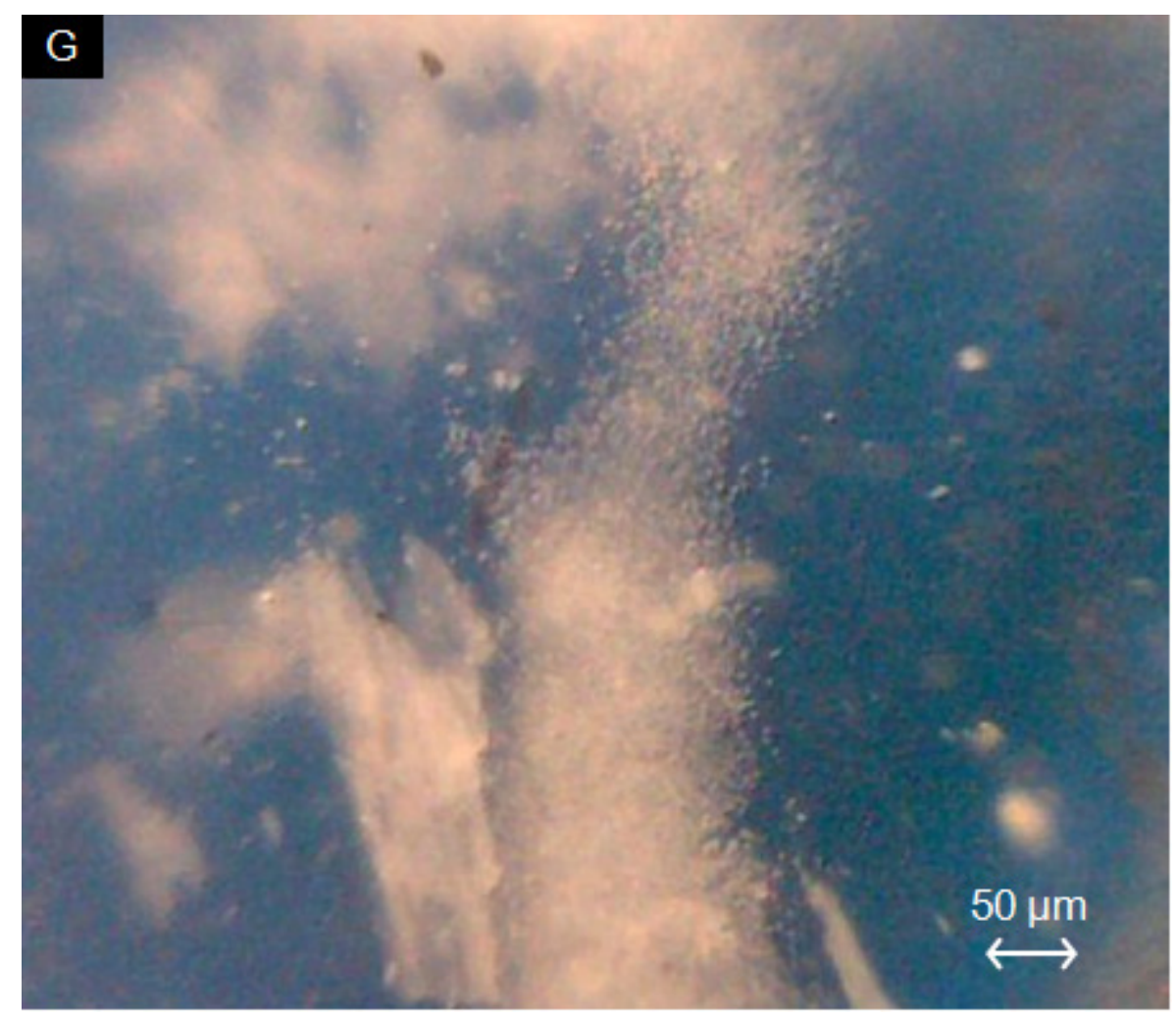

Figura 6. 11 - Micro-bolhas em foto com ampliação próxima de 200x. 


\subsubsection{Efeito da pré-compactação com prensa hidráulica}

Em razão da dimensão das partículas desta matéria-prima ser da ordem de nanômetros, estas se aglomeram com facilidade [58] apresentando uma densidade muito baixa devido à grande quantidade de espaços vazios entre as partículas de pó. Em uma das sinterizações realizadas com o nanopó, a matéria-prima foi préprensada com uma prensa hidráulica (esforço de aproximadamente $5 \mathrm{KN}$ ) com a finalidade de se eliminar a maior quantidade possível de espaços vazios, e, consequentemente aumentar a massa de pó inserida no molde.

A pré-prensagem foi realizada em três oportunidades durante a colocação do pó no molde de grafite e, em seguida, o material foi sinterizado. O resultado foi a quebra transversal da amostra em três partes (Figura 6.12) devido a não uniformidade da pressão interna imposta pela pré-compactação - efeito previsto por Hamanan, M. N. [58] na sinterização de materiais cerâmicos. Além disso, ocorreu o aprisionamento de bolhas como nos testes anteriores.

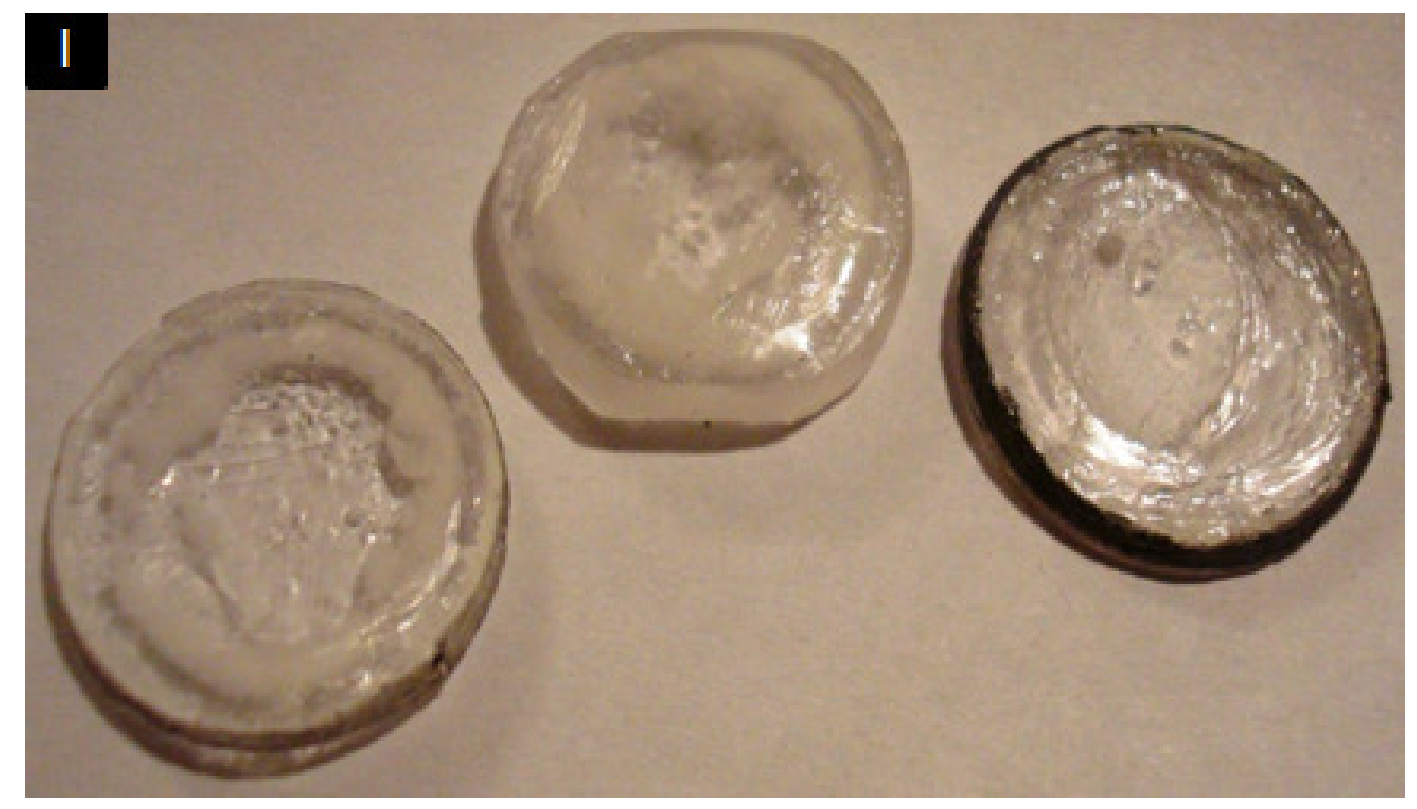

Figura 6. 12 - Partes da amostra rompida devido ao esforço aplicado na pré-compactação. 


\subsubsection{Taxas de aquecimento entre 125 e $150^{\circ} \mathrm{C} / \mathrm{min}$.}

Nanopó amorfo foi, também, processado com taxas de aquecimento superiores a $120^{\circ} \mathrm{C} / \mathrm{min}$., levando a um ganho de tempo de mais de 15 minutos comparado com os experimentos com aquecimento mais lento. No entanto, as amostras resultantes apresentaram uma maior quantidade de bolhas, chegando, algumas delas a se tornarem completamente opacas com coloração esbranquiçada.

Nos experimentos realizados a essas taxas foram atingidas temperaturas máximas entre 1120 e $1450^{\circ} \mathrm{C}$, de modo que a temperatura de $1120^{\circ} \mathrm{C}$ se mostrou insuficiente para concluir o processo de densificação do material vítreo devido à alta porosidade apresentada por essas peças. Temperaturas cerca de $100^{\circ} \mathrm{C}$ maiores foram suficientes para a obtenção do material completamente consolidado apesar das bolhas (Figura 6.13). Na figura 6.14 é possível notar a diferença entre o material não densificado e o material todo compactado.

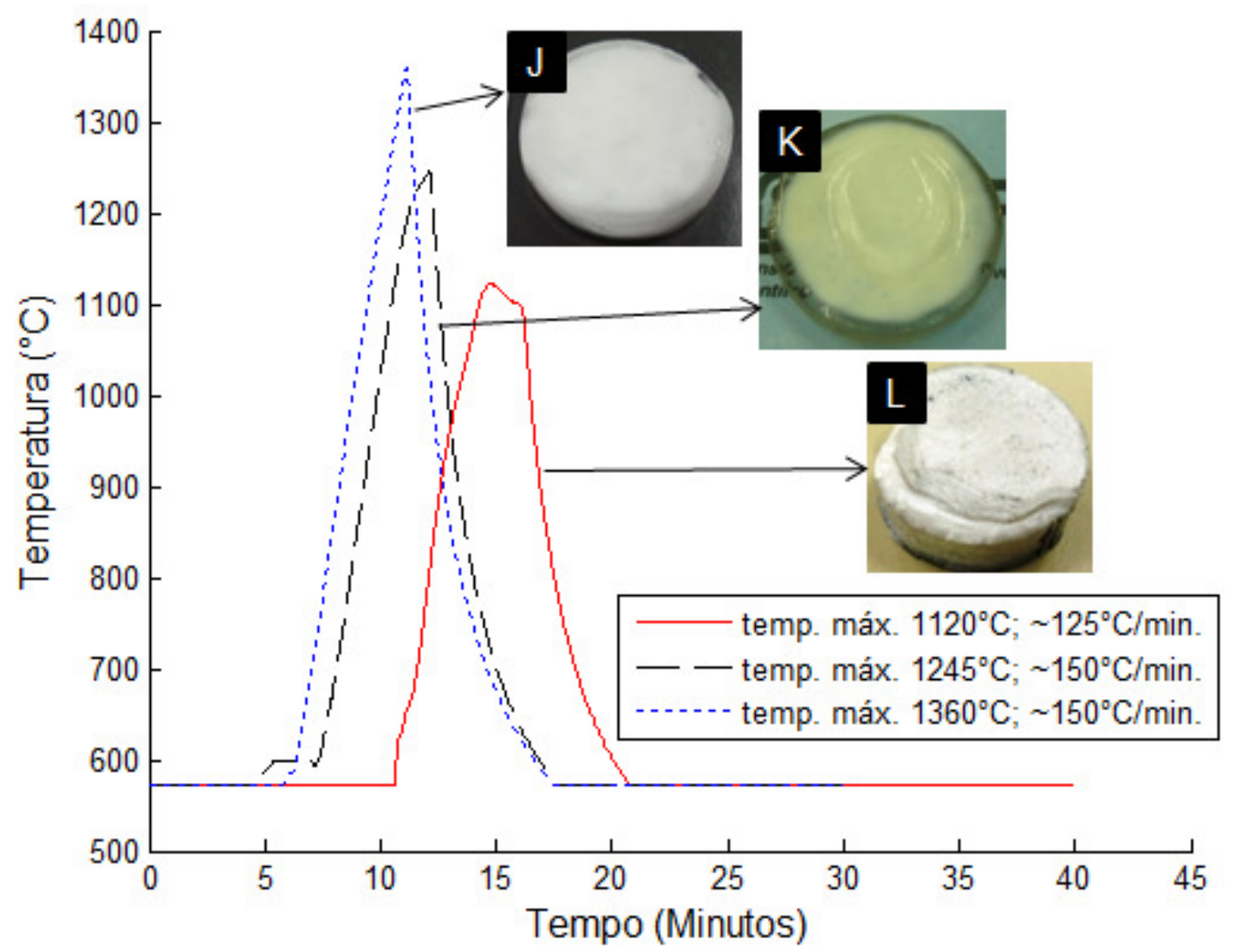

Figura 6. 13 - Amostras obtidas a partir do nanopó e suas respectivas curvas de temperatura. 


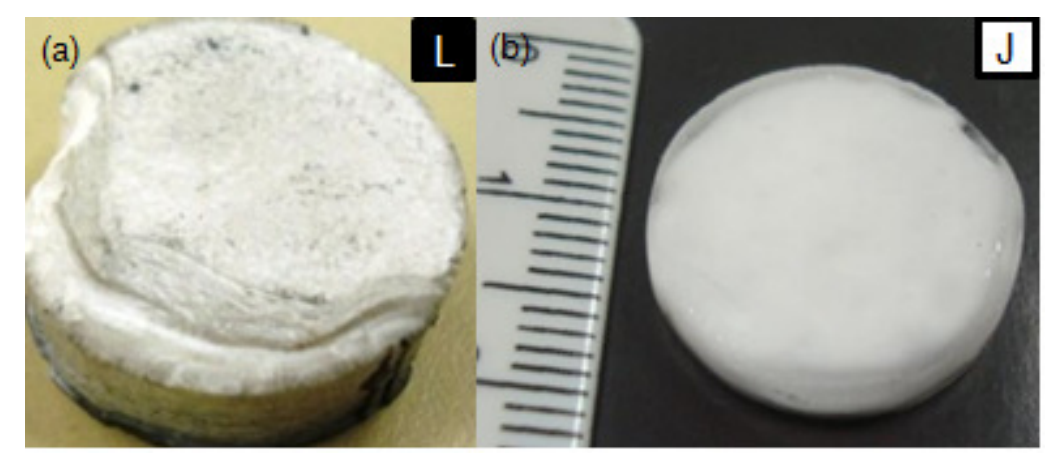

Figura 6. 14 - (a) Material não densificado por completo. (b) Material completamente consolidado.

\subsubsection{Efeito do tempo de patamar na eliminação de bolhas}

Como visto nas seções anteriores, o aparecimento de aglomerados de bolhas ocorre nos materiais sinterizados com todas as taxas de aquecimento testadas no intervalo de 60 a $150^{\circ} \mathrm{C} / \mathrm{min}$., sendo que a quantidade de bolhas aumenta para as maiores taxas.

Contudo, observou-se que a manutenção da temperatura final do processo por mais alguns minutos (patamar de temperatura), diminui consideravelmente a quantidade de bolhas na amostra como é possível observar na figura 6.15. Isso ocorre, pois uma vez terminada a consolidação, se a temperatura permanecer elevada, a agitação térmica dos gases e a menor viscosidade da sílica podem facilitar a saída dos gases do material. O gráfico da figura 6.15 mostra que durante o patamar de temperatura imposto, a contração do material já havia terminado, porém a temperatura elevada permitiu que mais gases escapassem do consolidado.

$\mathrm{Na}$ análise da contração é importante lembrar que como o eletrodo superior do equipamento é fixo, o movimento vertical do eletrodo inferior é todo transferido ao punção inferior, cuja posição (curva azul tracejada no gráfico) é igual a zero no início do processo e aumenta conforme ele sobe devido à contração da amostra. 


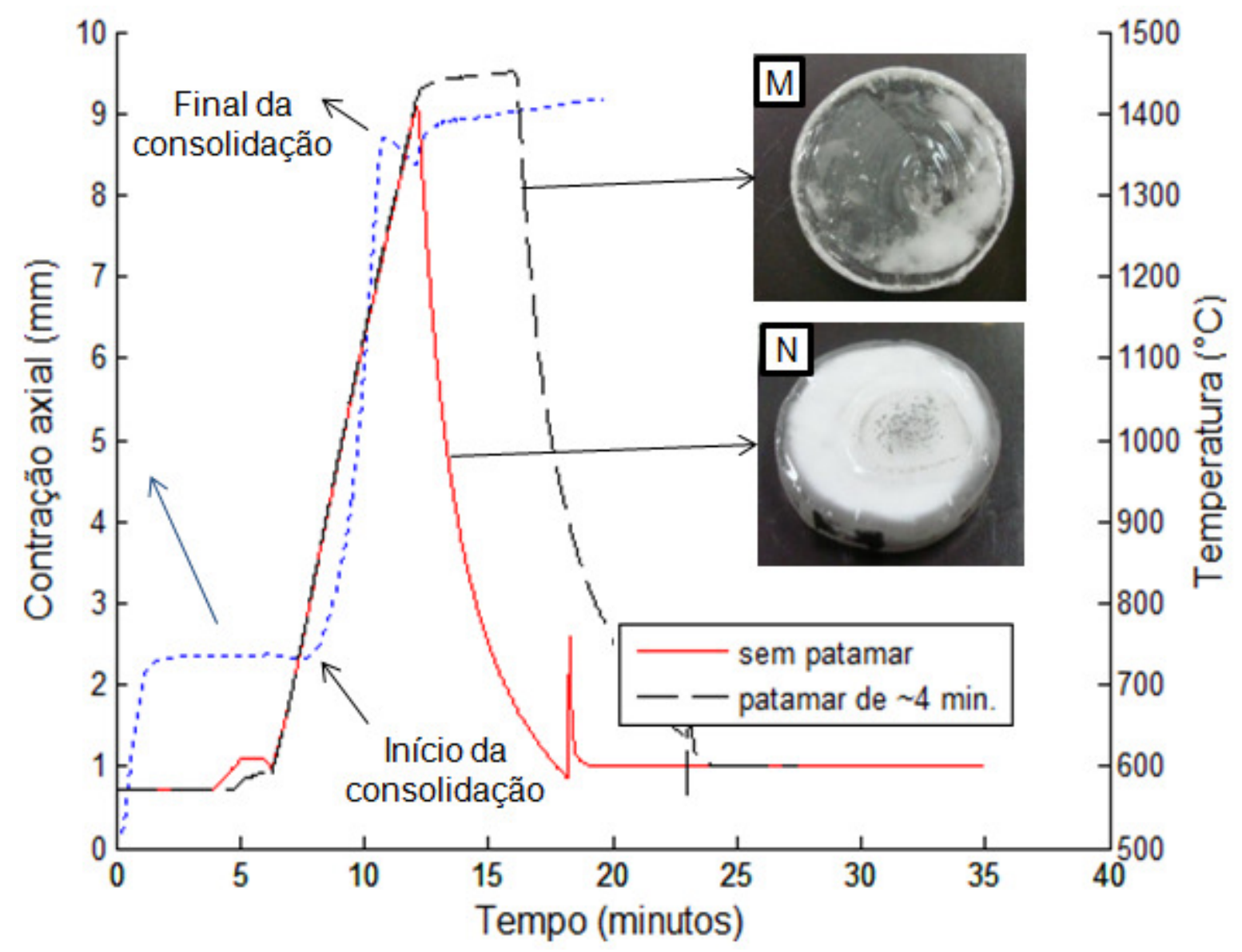

Figura 6. 15 - Curvas de temperatura com e sem patamar depois de terminada a consolidação e as amostras resultantes.

\subsubsection{Obtenção de sílica vítrea livre de bolhas}

Apesar da manutenção da temperatura final de processo por mais alguns minutos ter diminuído consideravelmente a quantidade de bolhas na amostra final, essa medida não foi suficiente para eliminar todas as bolhas. Isso porque algumas delas acabam englobando outras bolhas menores e se tornam maiores. Essas bolhas maiores são mais difíceis de serem colapsadas devido à baixa mobilidade $\mathrm{e}$ permanecem presas no material mesmo com longos tempos de patamares a temperaturas elevadas. Verificou-se, então, a necessidade de eliminação dos gases antes que se iniciasse a consolidação do nanopó evitando assim que esses gases se tornassem bolhas na estrutura sólida. 
Segundo estudo realizado por Morimoto et al [59], a sílica vítrea sintética tipo 3 - tipo de pó utilizado nesta subseção - teria dois picos de liberação de gás, um a temperaturas próximas de $500^{\circ} \mathrm{C}$ e o outro em torno de $700^{\circ} \mathrm{C}$. Dois picos de liberação de gases também foram observados nos experimentos realizados, detectados pelo aumento da pressão no forno, como será mostrado e discutido com mais detalhe em seção mais adiante. $O$ segundo pico, que se inicia a aproximadamente $700^{\circ} \mathrm{C}$, ocorre pouco antes do início da consolidação e, portanto é grande a probabilidade que esses gases liberados fiquem presos na estrutura do consolidado gerando bolhas na amostra.

Em experimento realizado com taxa de aquecimento de $40^{\circ} \mathrm{C} / \mathrm{min}$. entre $20^{\circ} \mathrm{C}$ e $840^{\circ} \mathrm{C}$ e aproximadamente $100^{\circ} \mathrm{C} / \mathrm{min}$. entre $840^{\circ} \mathrm{C}$ e $1220^{\circ} \mathrm{C}$, com tempo de patamar de 4 minutos na temperatura final, obteve-se sílica vítrea livre de bolhas. Isso ocorreu, pois houve um "distanciamento" entre o segundo pico de liberação de gases e o início do processo de consolidação, devido à menor taxa de aquecimento utilizada, dando mais tempo para que a bomba de vácuo atuasse e retirasse uma maior quantidade de gases antes da consolidação. Além disso, o patamar de 4 minutos pode ter sido efetivo na eliminação de pequenas bolhas formadas. A figura 6.16 mostra a peça livre de bolhas obtida e o gráfico da figura 6.17 mostra como variaram os parâmetros temperatura, contração axial e pressão na câmara desta experiência. $O$ tempo entre o início do segundo pico de liberação e o início da consolidação do material foi identificado pela letra 'd'.

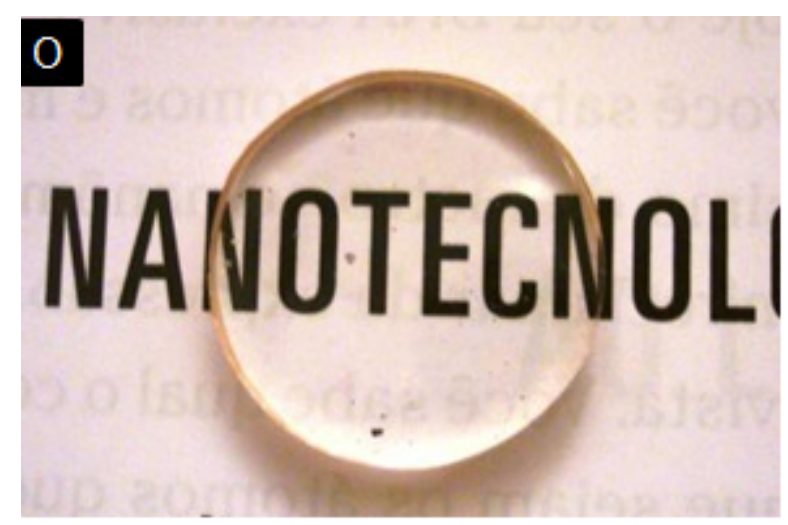

Figura 6. 16 - Amostra livre de bolhas produzida com o nanopó amorfo. 


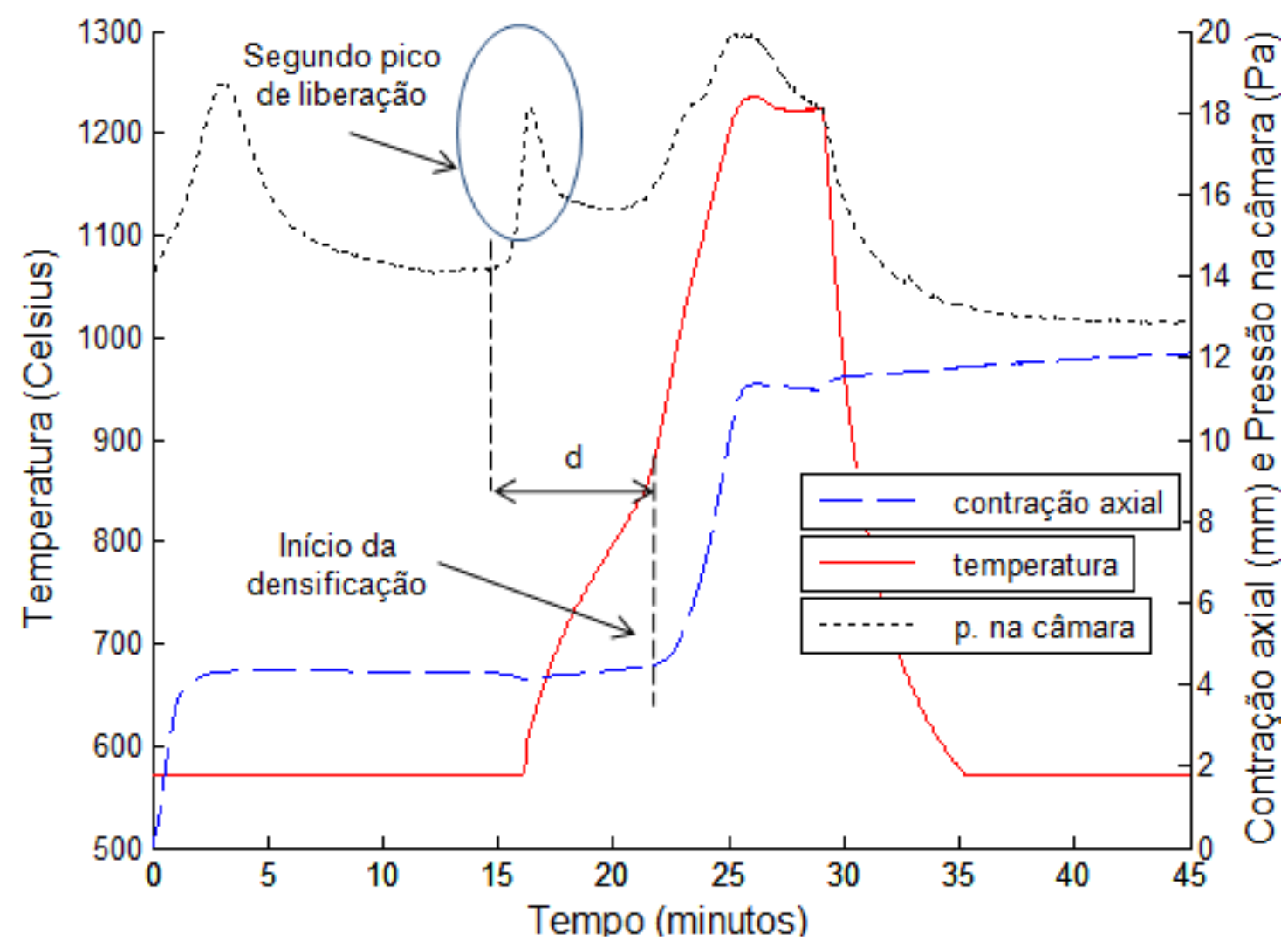

Figura 6. 17 - Parâmetros de processo em experimento que gerou amostra sem bolhas.

A tabela 6.2 a seguir resume e relaciona os principais parâmetros de processo testados na sinterização de 2,5 g do nanopó amorfo e a aparência da amostra em razão quantidade de bolhas.

Tabela 6. 2 - Aparência das amostras em função dos parâmetros de processo.

\begin{tabular}{|c|c|c|c|c|}
\hline $\begin{array}{l}\text { Taxa de aquec. } \\
\qquad\left({ }^{\circ} \mathrm{C} / \mathrm{min} .\right)\end{array}$ & $\begin{array}{l}\text { Temp. final } \\
\left({ }^{\circ} \mathrm{C}\right)\end{array}$ & $\begin{array}{c}\text { Tempo de } \\
\text { patamar } \\
\text { (seg.) }\end{array}$ & $\begin{array}{c}\text { Tempo de } \\
\text { processo } \\
\text { (min.) }\end{array}$ & Aparência \\
\hline 60 & $\sim 1350$ & 1 & 26 & $\begin{array}{l}\text { Transparente com } \\
\text { regiões brancas }\end{array}$ \\
\hline Entre 125 e 150 & $\begin{array}{l}\text { Entre } 1200 \\
\text { e } 1400\end{array}$ & 0 & 12 a 15 & $\begin{array}{c}\text { Toda esbranquiçada } \\
\text { (aspecto leitoso) }\end{array}$ \\
\hline Entre 125 e 150 & $\begin{array}{l}\text { Entre } 1200 \\
\text { e } 1450\end{array}$ & 4 & 16 a 20 & $\begin{array}{l}\text { Transparente com } \\
\text { regiões brancas }\end{array}$ \\
\hline $\begin{array}{c}40 \text { (até } 840^{\circ} \mathrm{C} \text { ); } \\
100 \text { (após } 840^{\circ} \mathrm{C} \text { ). }\end{array}$ & 1225 & 4 & 29 & Toda transparente \\
\hline
\end{tabular}




\subsection{Sílica vítrea a partir de pó amorfo de sílica}

A obtenção de sílica fundida utilizando como matéria-prima o pó amorfo de sílica foi realizada apoiando-se no aprendizado adquirido no processamento do pó cristalino e do nanopó de $\mathrm{SiO}_{2}$.

Assim como para o nanopó, a estrutura amorfa desta matéria-prima não exige que a temperatura se eleve até a temperatura de fusão do $\mathrm{SiO}_{2}$ como ocorreu com o pó cristalino. Neste caso, bem como no caso do nanopó, o aumento da temperatura serve para diminuir a viscosidade das partículas vítreas até que elas colapsem umas nas outras formando um único sólido.

Temperaturas em torno de $1220^{\circ} \mathrm{C}$ foram suficientes para que ocorresse a densificação das partículas de nanopó e, portanto essa temperatura foi também utilizada na sinterização do pó amorfo de tamanho de partícula da ordem de $100 \mu \mathrm{m}$. A curva de temperatura com baixa taxa de aquecimento $\left(\sim 40^{\circ} \mathrm{C} / \mathrm{min}\right.$.) no início e depois com elevação dessa taxa para aproximadamente $100^{\circ} \mathrm{C} / \mathrm{min}$. foi utilizada, uma vez que a mesma programação garantiu a ausência de bolas na amostra. A figura 6.18 mostra a curva de temperatura e o sólido obtido com a matéria-prima amorfa de sílica. $\mathrm{O}$ resultado foi a obtenção de um consolidado de $\mathrm{SiO}_{2}$ vítreo livre de bolhas. 


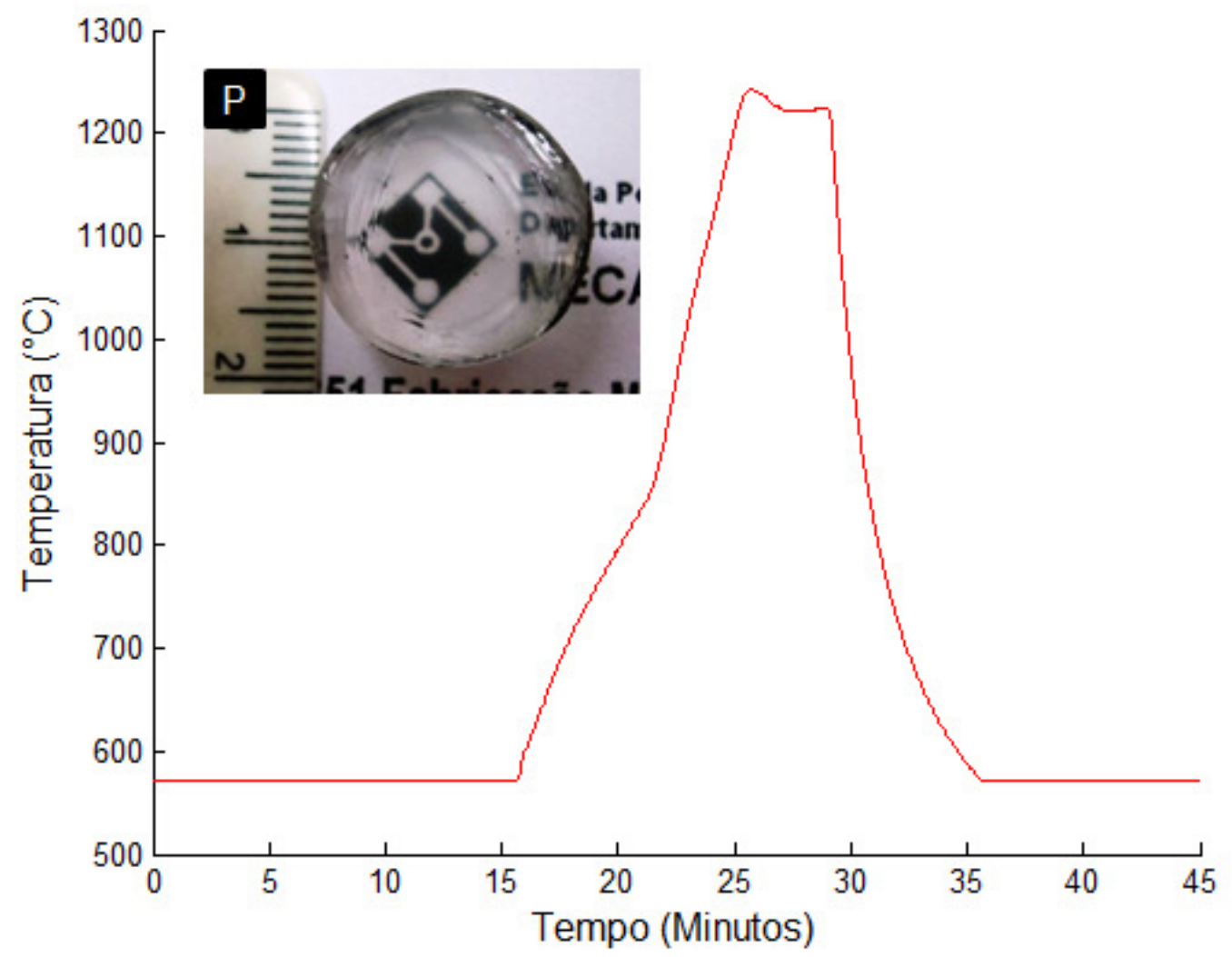

Figura 6. 18 - Variação da temperatura no tempo e amostra obtida com pó amorfo de sílica.

\subsection{Processo de densificação da matéria-prima}

A densificação ou contração axial da matéria-prima durante o processo de sinterização foi analisada e comparada para os diferentes tipos de pó de sílica utilizados neste estudo.

\subsubsection{Temperatura da contração axial}

A contração dos pós cristalinos foi sempre precedida pela fusão do material particulado e, em razão disso, o início da densificação dos pós de quartzo ocorreu em temperaturas mais elevadas do que para os pós amorfos, conforme indica o 
gráfico da figura 6.19, que compara os três tipos de pós estudados em experimentos com taxas de aquecimento menores que $100^{\circ} \mathrm{C} / \mathrm{min}$.

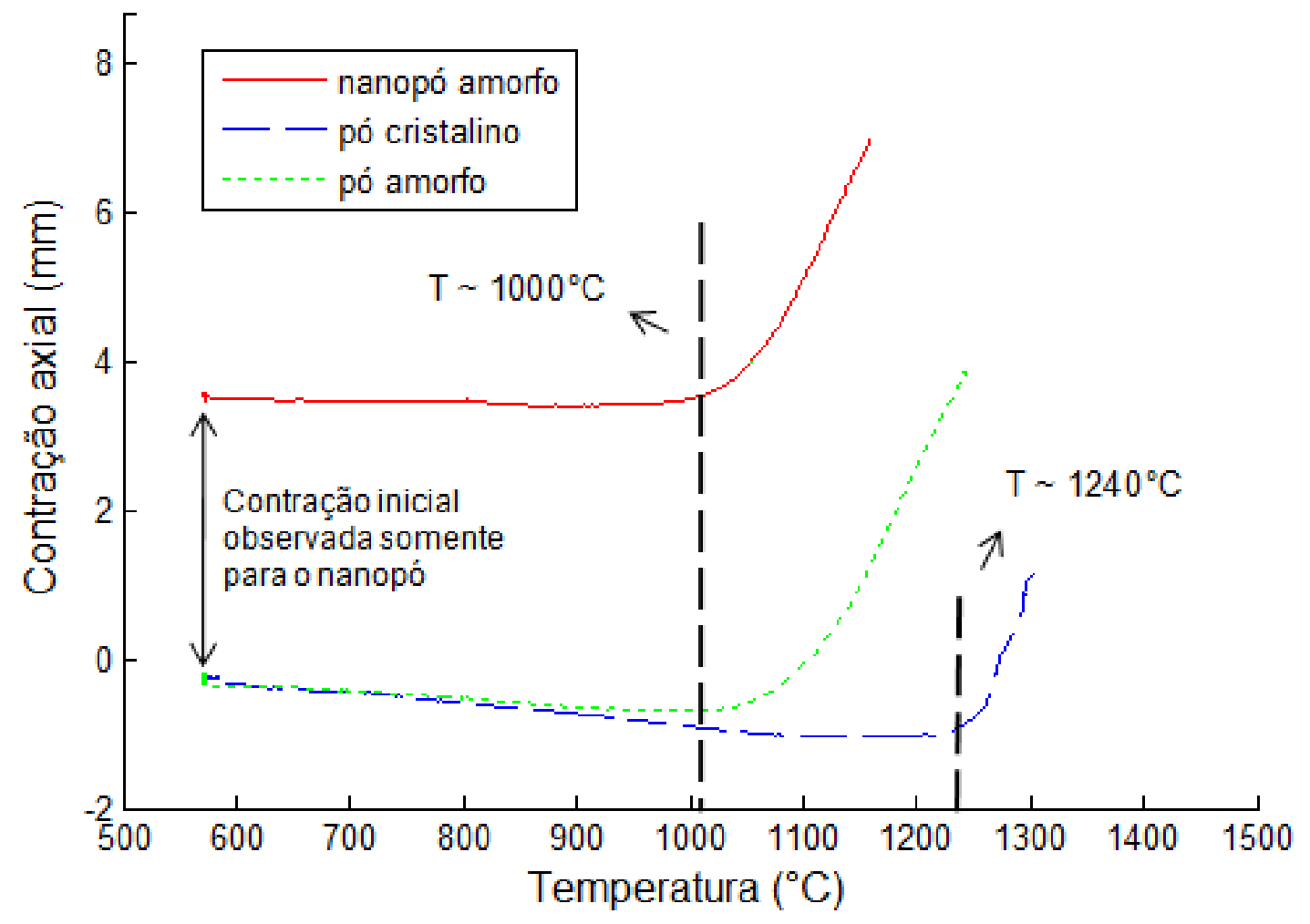

Figura 6. 19 - Contração axial em função da temperatura para os diferentes pós de sílica.

Analisando o gráfico, é possível concluir que tanto o pó amorfo como o nanopó amorfo iniciam a densificação a temperaturas próximas a $1000^{\circ} \mathrm{C}$, porém o material cristalino somente começa a contrair em torno de $1240^{\circ} \mathrm{C}$. Observa-se, também, que a curva de contração do nanopó inicia a medição já com quase $4 \mathrm{~mm}$, devido ao efeito da compressão axial exercida pelos eletrodos. Essa contração só é relevante no caso do nanopó, em razão da menor dimensão de suas partículas cerca de 1000x menor que nos outros pós - as quais aglomeram com facilidade dificultando o seu empacotamento na fase de preparação do molde quando é realizada apenas a prensagem manual do pó dentro da matriz.

Comparando-se o efeito da taxa de aquecimento sobre o início da compactação para o nanopó e para o pó cristalino, observou-se que taxas de aquecimento maiores exigem uma maior temperatura para a densificação do pó cristalino, ao passo que para o nanopó essa temperatura decai (Figura 6.20). Conforme discutido anteriormente, a sílica não é boa condutora de calor e, portanto, 
leva mais tempo para a temperatura entrar em equilíbrio em todo o grão ou partícula retardando, assim, o início da consolidação quando se utiliza altas taxas de aquecimento. Contudo, no caso do nanopó, esse efeito não se mostra relevante devido à pequena dimensão dos grãos. $O$ efeito que se mostra relevante nesse caso é o do gradiente de temperatura entre a parede do molde e a amostra que é maior quanto maior for a taxa de aquecimento. Desse modo, o aumento da velocidade do aquecimento faz a temperatura na amostra atingir valores maiores para as mesmas temperaturas medidas na parede do molde e, portanto, a consolidação inicia-se a uma temperatura medida menor.

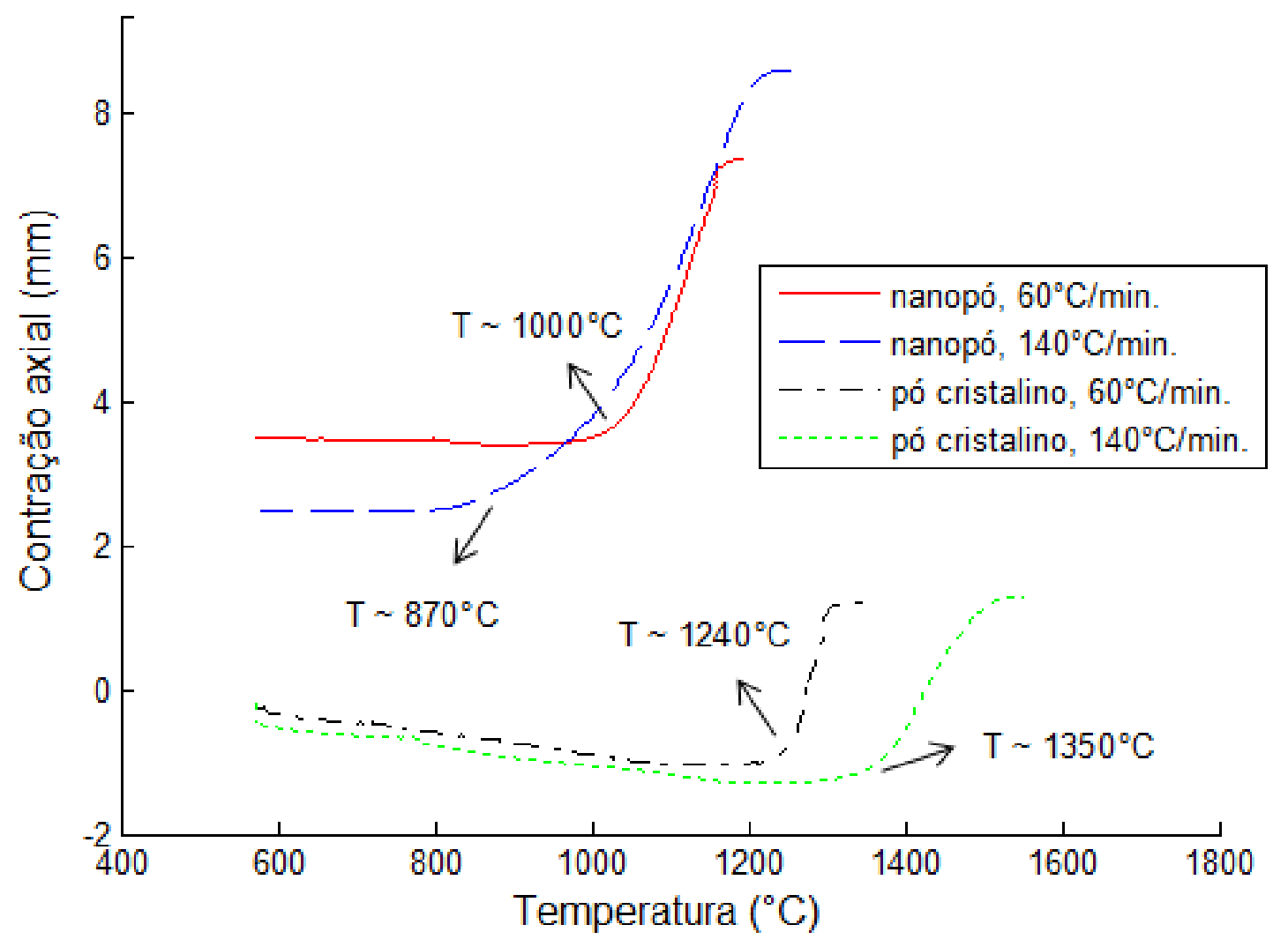

Figura 6. 20 - Efeito da taxa de aquecimento na temperatura de início da consolidação.

\subsubsection{Duração e valor da contração axial}

O valor da contração axial mostrou, como esperado, depender da granulometria - tamanho da partícula ou grãos - das matérias-primas trabalhadas. As 
partículas de nanopó, de dimensões entre 20 e 300 nm, apresentaram uma contração axial média de $5 \mathrm{~mm}$ para aproximadamente $2,5 \mathrm{~g}$ de matéria-prima, enquanto que o pó cristalino, de tamanho médio de partícula de $100 \mu \mathrm{m}$, contraiu por volta de 1,3 $\mathrm{mm}$ para aproximadamente $5,7 \mathrm{~g}$ de massa. Como a contração é proporcional à massa de sílica utilizada no experimento, caso as massas dos dois pós fossem igualadas a diferença entre as contrações seriam ainda maiores.

A duração do processo de densificação não indicou ser influenciada pela estrutura cristalina ou pela granulometria das matérias-primas. Esse parâmetro sempre teve valores entre 2 e 4 minutos, tendendo a ser menor para altas taxas de aquecimento.

$\mathrm{Na}$ curva de contração tanto do pó cristalino como dos pós amorfos, observou-se o efeito da dilatação térmica do material particulado, devido ao aumento da temperatura, empurrando o punção inferior para baixo e consequentemente diminuindo o valor da contração antes do início da densificação.

Na sinterização do nanopó, logo no início do processo, ocorre uma contração de 2 a $4 \mathrm{~mm}$ em razão do esforço de compressão axial, conforme explicado na seção anterior.

Os gráficos das figuras 6.21 e 6.22 mostram a curva de contração axial da amostra em função do tempo para o pó cristalino e para o nanopó, respectivamente, em experimentos com taxas de aquecimento próximas a $60^{\circ} \mathrm{C} / \mathrm{min}$.

Diferentemente da temperatura de consolidação que mostrou ser influenciada pelo valor da taxa de aquecimento, a duração e a contração do processo de densificação da amostra não sofreram mudanças consideráveis com a alteração desse parâmetro.

A tabela 6.3 mostra como se comportaram os parâmetros de densificação dependendo da matéria-prima e das condições de processamento. 


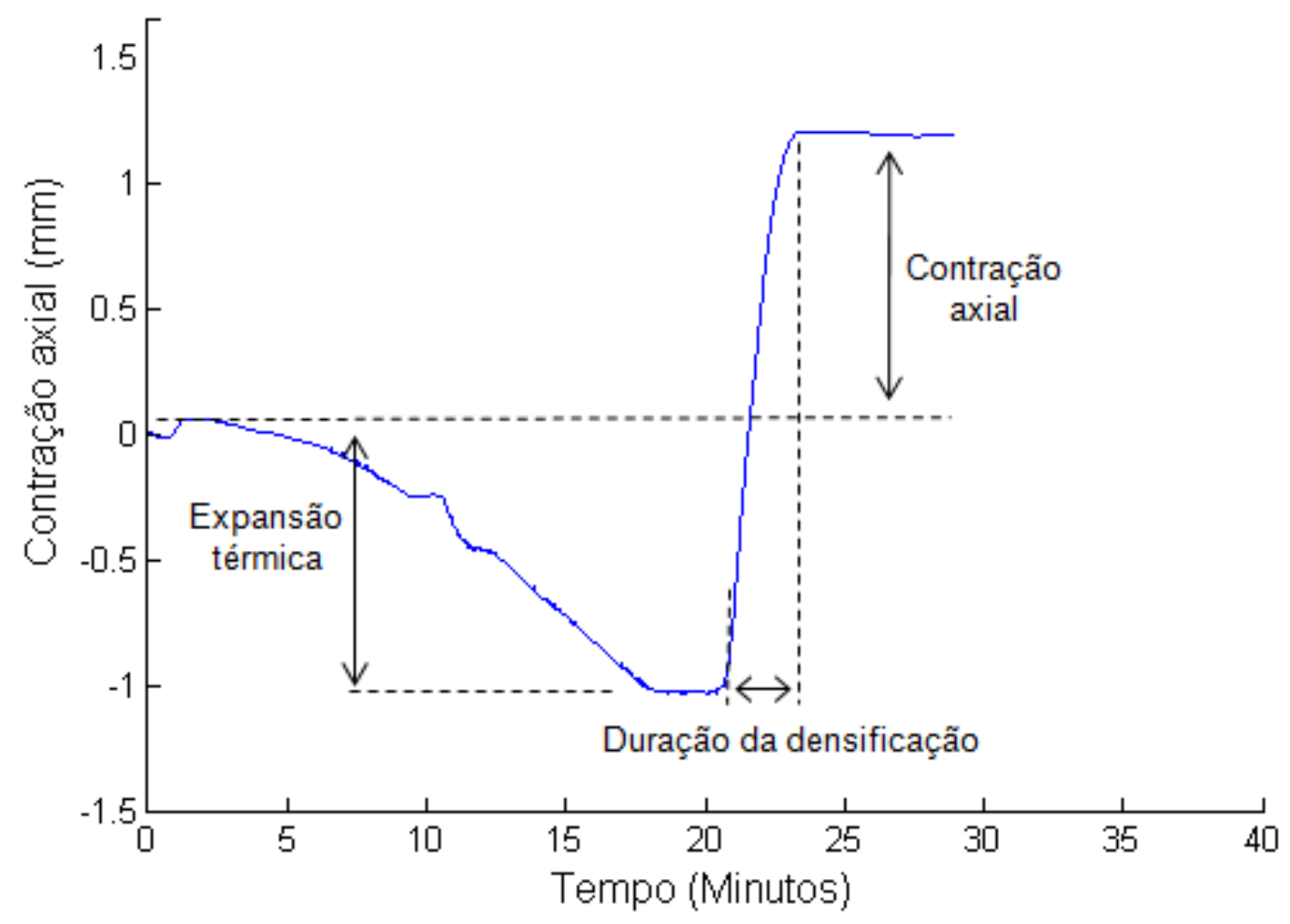

Figura 6. 21 - Curva de contração axial para a sinterização do pó de sílica cristalina.

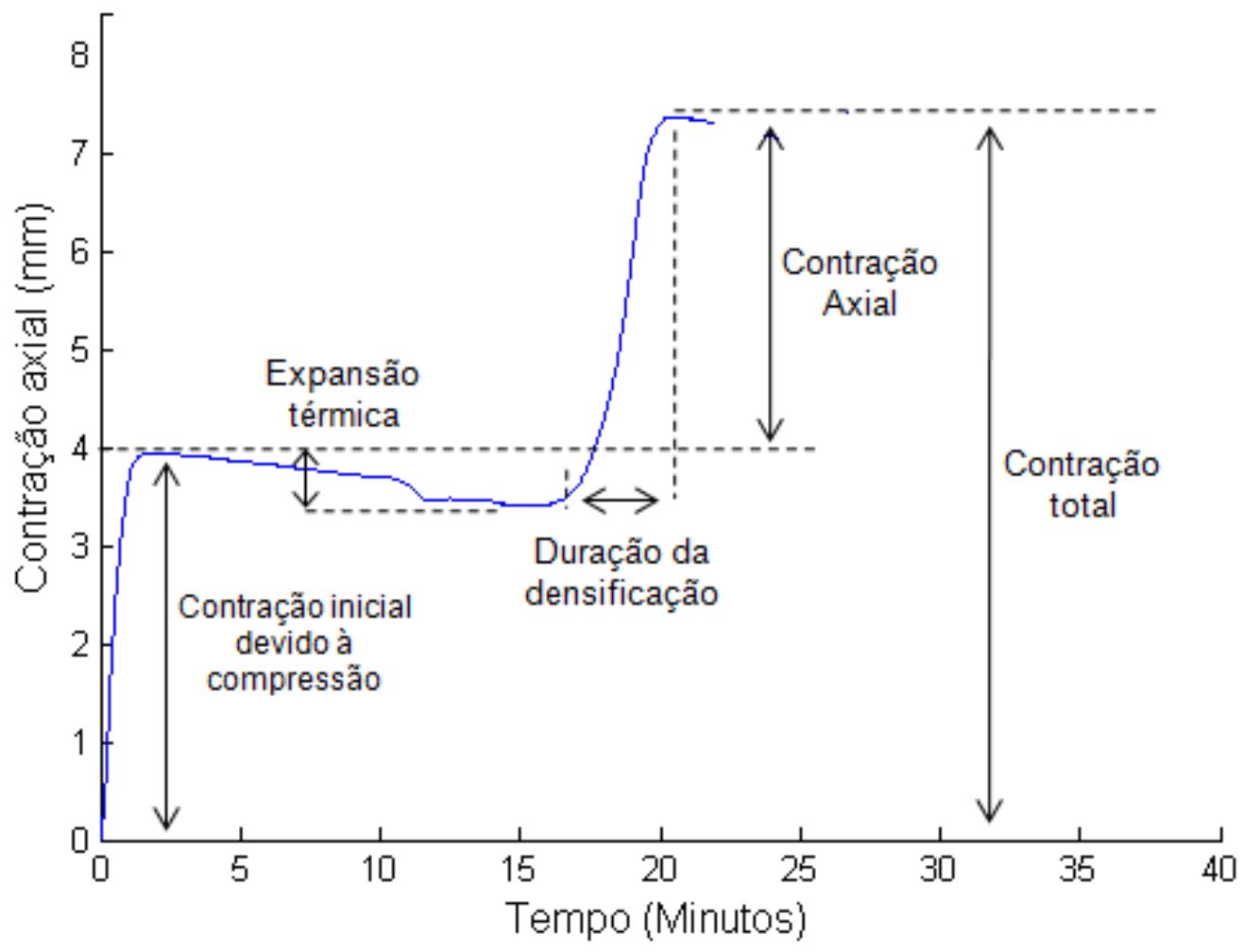

Figura 6. 22 - Curva de contração axial para a sinterização do nanopó de sílica. 
Tabela 6. 3 - Densificação em função do tipo de pó e das condições da sinterização.

\begin{tabular}{|c|c|c|c|c|c|}
\hline Tipo de pó & $\begin{array}{c}\text { Massa } \\
\text { (g) }\end{array}$ & $\begin{array}{c}\text { Taxa de } \\
\text { aquecimento } \\
\left({ }^{\circ} \mathrm{C} / \mathrm{min} .\right)\end{array}$ & $\begin{array}{c}\text { Temp. de } \\
\text { início da } \\
\text { densificação } \\
\left({ }^{\circ} \mathrm{C}\right)\end{array}$ & $\begin{array}{l}\text { Contração axial } \\
\text { média }(\mathrm{mm})\end{array}$ & $\begin{array}{c}\text { Duração da } \\
\text { contração } \\
\text { (min.) }\end{array}$ \\
\hline Cristalino & 5,7 & Entre 50 e 60 & $\begin{array}{c}\text { Entre } 1210 \\
\text { e } 1270\end{array}$ & 1,3 & 2 a 3 \\
\hline Cristalino & 5,7 & 140 & $\begin{array}{c}\text { Entre } 1250 \\
\text { e } 1350\end{array}$ & 1,5 & 2 a 3 \\
\hline Nanopó & 2,5 & 60 & $\begin{array}{c}\text { Entre } 950 \text { e } \\
1050\end{array}$ & 5,4 & 2,5 a 4 \\
\hline Nanopó & 2,5 & Entre 125 e 150 & $\begin{array}{c}\text { Entre } 870 \text { e } \\
930\end{array}$ & 5,7 & 2,5 a 3,5 \\
\hline Nanopó & 2,5 & $\begin{array}{l}40 \text { até } 840 \\
100 \text { até } 840 .\end{array}$ & $\begin{array}{c}\text { Entre } 950 \text { e } \\
1000\end{array}$ & 6,5 & 3 a 4 \\
\hline Amorfo & 5,7 & $\begin{array}{c}40 \text { até } 840 ; \\
100 \text { após } 840 .\end{array}$ & $\begin{array}{c}\text { Entre } 980 \text { e } \\
1070\end{array}$ & 3,7 & 2 a 3 \\
\hline
\end{tabular}

\subsubsection{Efeito da granulometria na densificação dos pós de quartzo}

O efeito do tamanho da partícula é bem evidente quando comparados o pó cristalino e o nanopó uma vez que a razão entre suas respectivas dimensões é da ordem de 0,001.

Em uma série de experimentos com pós de quartzo com pequena variação no tamanho de partícula também se observou a influência da granulometria na temperatura de início da densificação e no valor da contração de volume da amostra. Os pós de grãos maiores iniciaram a consolidação a temperaturas ligeiramente maiores, bem como contraíram menos que os pós de menor dimensão de partícula, como pode ser visualizado no gráfico da figura 6.23. Os experimentos exibidos ocorreram com a mesma curva de temperatura: taxa de aquecimento próxima de $50^{\circ} \mathrm{C} / \mathrm{min}$. e temperatura final de $1550^{\circ} \mathrm{C}$. 


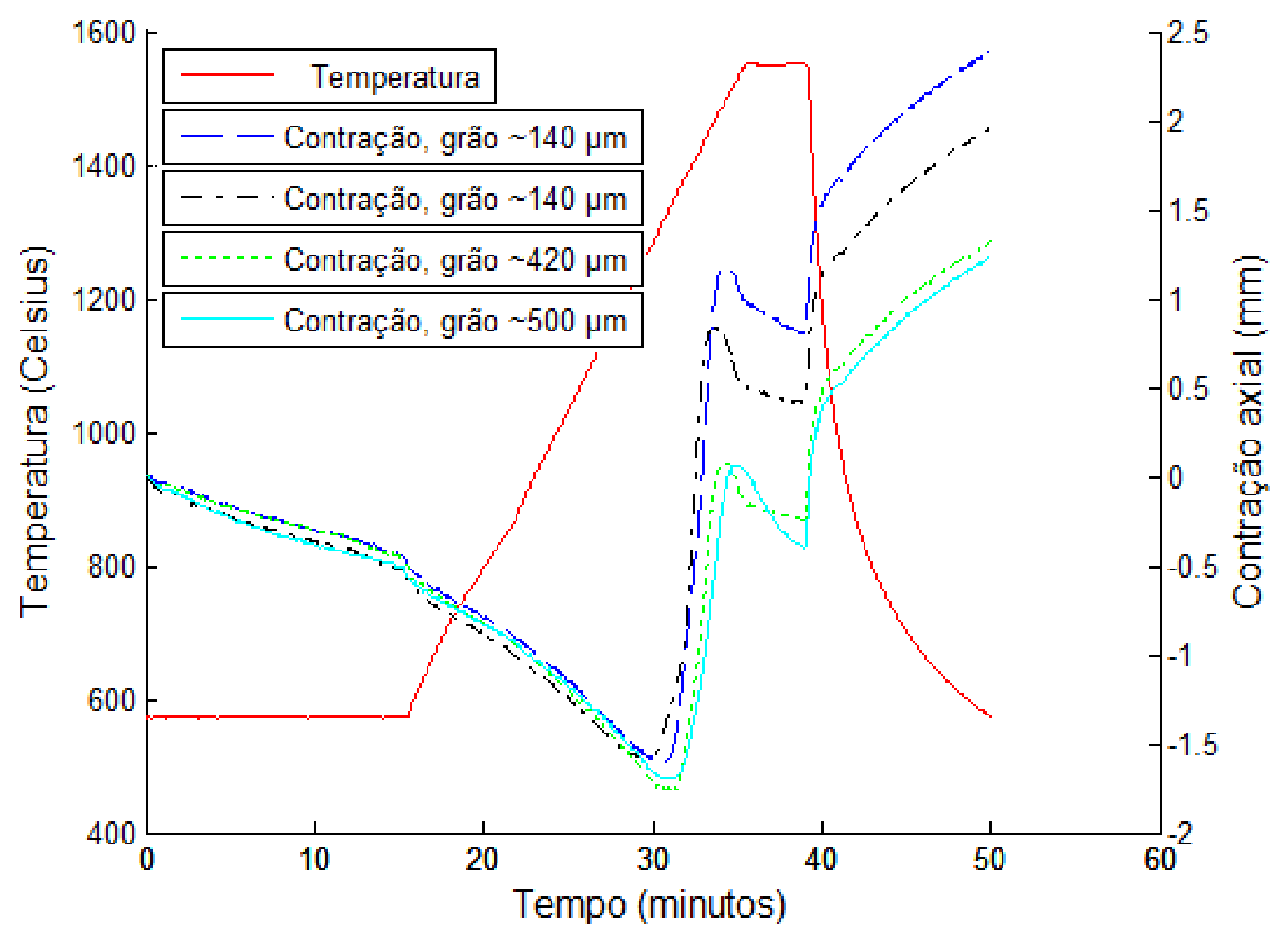

Figura 6. 23 - Contração de 4 pós cristalinos de tamanhos variados sob a mesma temperatura.

\subsection{Liberação de gases dos pós de sílica no processo SPS}

A liberação de gases da amostra durante o processo SPS está relacionada com a variação de pressão dentro da câmara de sinterização. A diminuição da pressão de vácuo ou o aumento da pressão atmosférica na câmara corresponde à liberação de gases pela amostra. Esse fenômeno já foi discutido neste texto quando se analisou a sinterização do pó cristalino e do nanopó amorfo. No caso do nanopó, esse efeito se mostrou crítico, uma vez que, dependendo dos parâmetros de processo, a liberação de gases pode comprometer seriamente a transparência das amostras devido à grande quantidade de bolhas formadas. Uma análise mais detalhada sobre esse tema comparando os diferentes tipos de pós trabalhados é feita agora nesta seção. 


\subsubsection{Liberação de gás do $\mathrm{SiO}_{2}$ e origem da matéria-prima}

Os diferentes processos de produção dos pós de sílica utilizados neste trabalho influenciaram o desprendimento de gases dos mesmos durante o processo SPS na fabricação de sílica vítrea. No entanto, independentemente da origem, todos os pós apresentaram aumento na liberação de gases durante a densificação, uma vez que, nesta etapa, todos os vazios ou poros, são fechados expulsando os gases que, por ventura, estejam aprisionados nestas lacunas. $O$ pó cristalino foi o que mais liberou gases durante essa fase.

Além da liberação devido à contração axial, o nanopó, produzido por processo sintético conhecido como VAD, apresentou dois outros picos acentuados de liberação de gás (Figura 6.24) a temperaturas próximas a $100^{\circ} \mathrm{C}$ e $700^{\circ} \mathrm{C}$. Esses picos ocorrem devido a grande presença de água no processo de fabricação da matéria-prima, classificada como sílica vítrea tipo 3 [30]. A liberação de vapor d'água ocorre com maior intensidade a temperaturas próximas de $100^{\circ} \mathrm{C}$, enquanto em torno de $700^{\circ} \mathrm{C}$ há grande liberação de $\mathrm{H}_{2}$ [59].

O pó cristalino, produzido por pulverização de lascas de quartzo, bem como o pó amorfo, fabricado por processo Sol-gel, não apresentaram picos de liberação, tão acentuados como os do nanopó antes da densificação (Figura 6.24). 


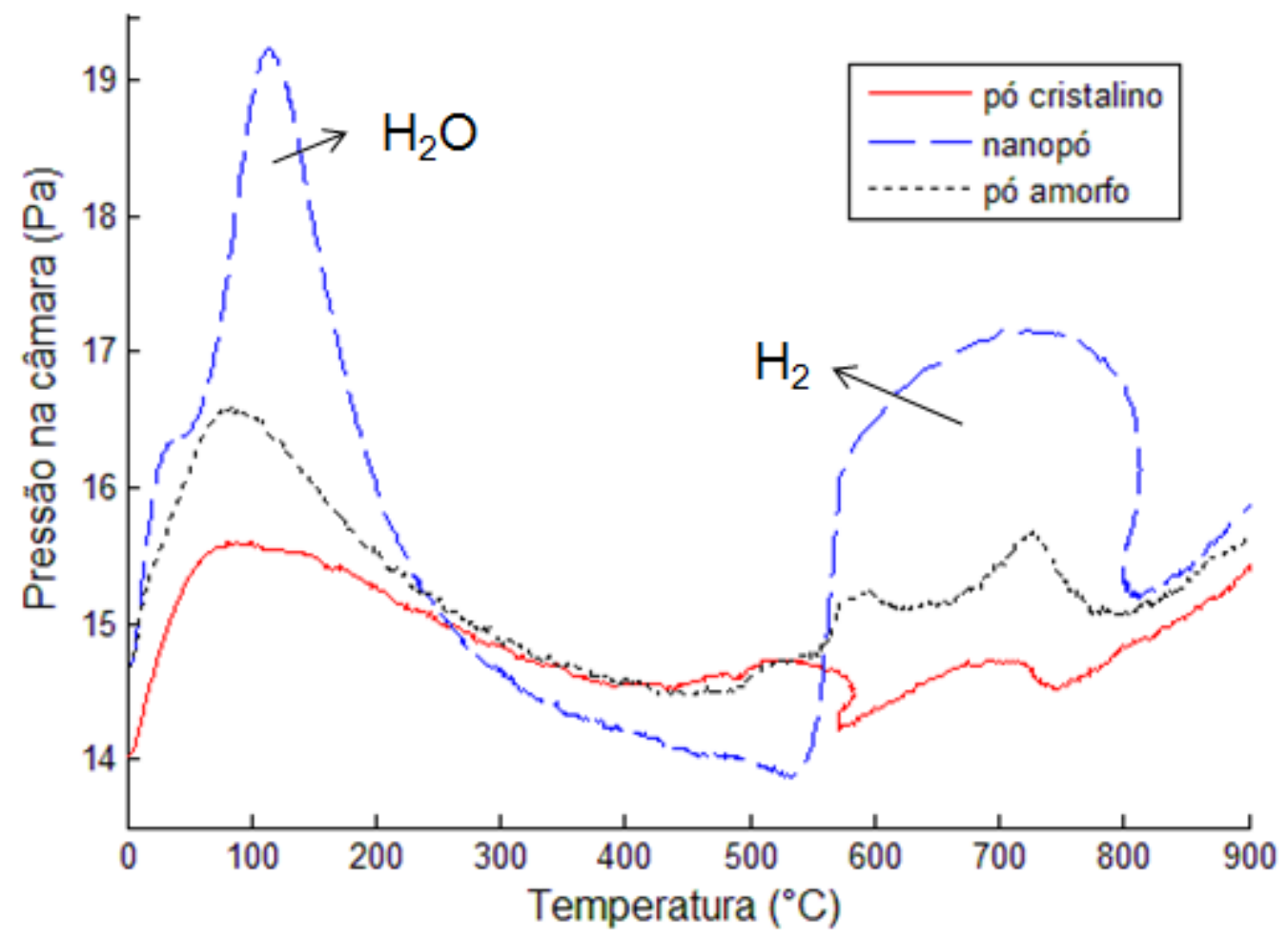

Figura 6. 24 - Liberação de gases do nanopó, do pó cristalino e do pó amorfo para temperaturas menores que as de consolidação.

\subsubsection{Liberação de gás do $\mathrm{SiO}_{2}$ e taxa de aquecimento}

Conforme discutido anteriormente, altas taxas de aquecimento podem, indiretamente, limitar a liberação de gases pela amostra na medida em que reduzem o tempo de atuação da bomba de vácuo. Caso a densificação do material ocorra muito rapidamente ou próxima a um pico de liberação de gases, pode ocorrer a prisão de gases no material consolidado, originando bolhas no mesmo. Esse efeito é mais intenso no processamento do nanopó amorfo, já que esta matéria-prima possui picos de liberação de gases mais acentuados antes da densificação.

Como já observado anteriormente, o segundo pico de liberação de gás do nanopó ocorre a uma temperatura muito próxima da do início da consolidação, causando a formação de bolhas na amostra. Ainda sobre o processamento do nanopó, notou-se que o uso de altas taxas de aquecimento, além de diminuir o tempo de atuação da bomba de vácuo, aumenta a temperatura correspondente ao segundo pico de liberação e diminui a temperatura de início da densificação, 
aproximando ainda mais os dois fenômenos (Figura 6.25), intensificando o aprisionamneto de bolhas. Conforme explicado, utilizou-se, então, uma menor taxa de aquecimento para aumentar a "distância" entre o segundo pico de liberação e o início da consolidação (Figura 6.26). Assim, a bomba de vácuo teve mais tempo para extrair os gases liberados e impedir o aprisionamento de bolhas na amostra.

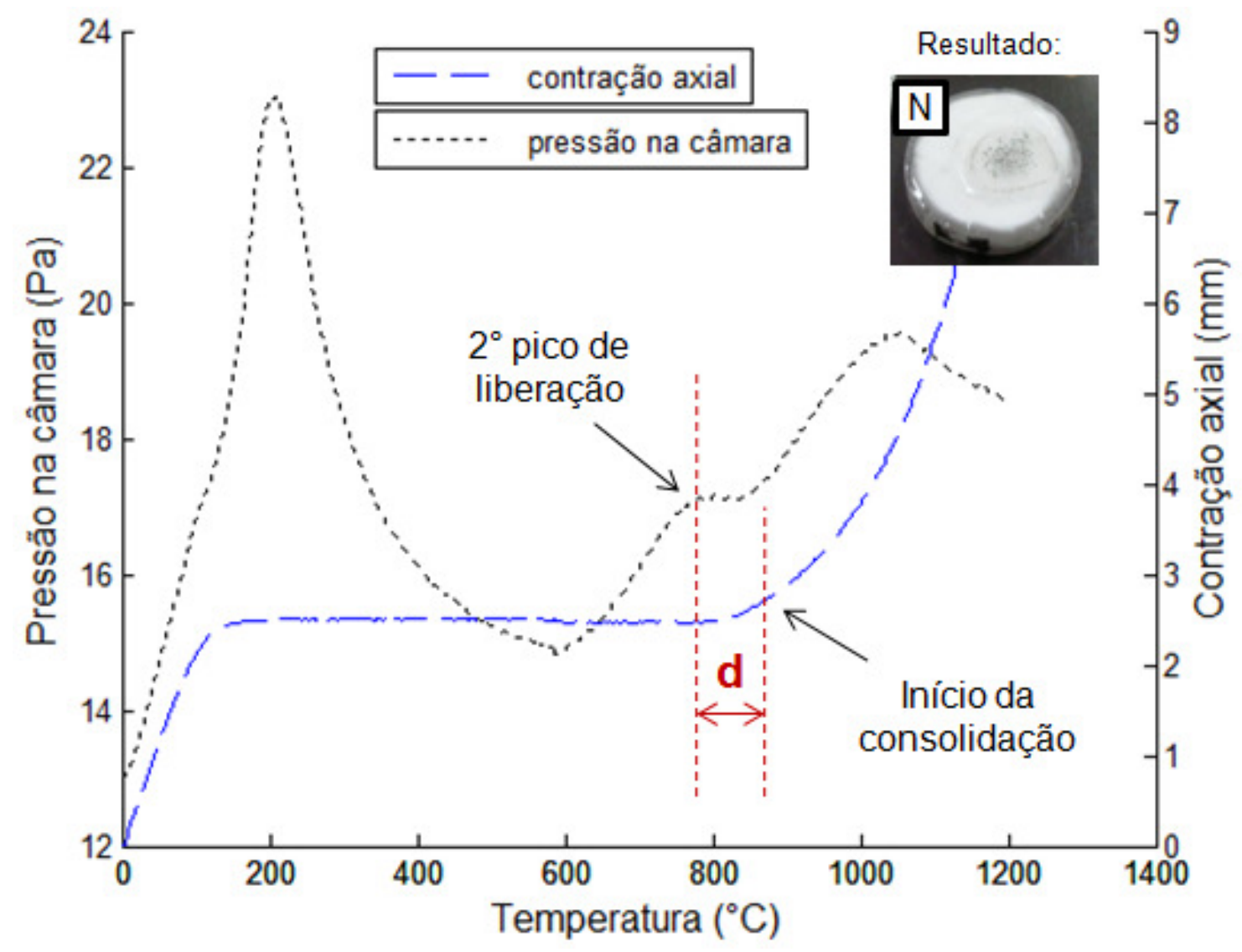

Figura 6. 25 - Pressão na câmara e contração axial em função da temperatura em experimento com o nanopó realizado com alta taxa de aquecimento. 


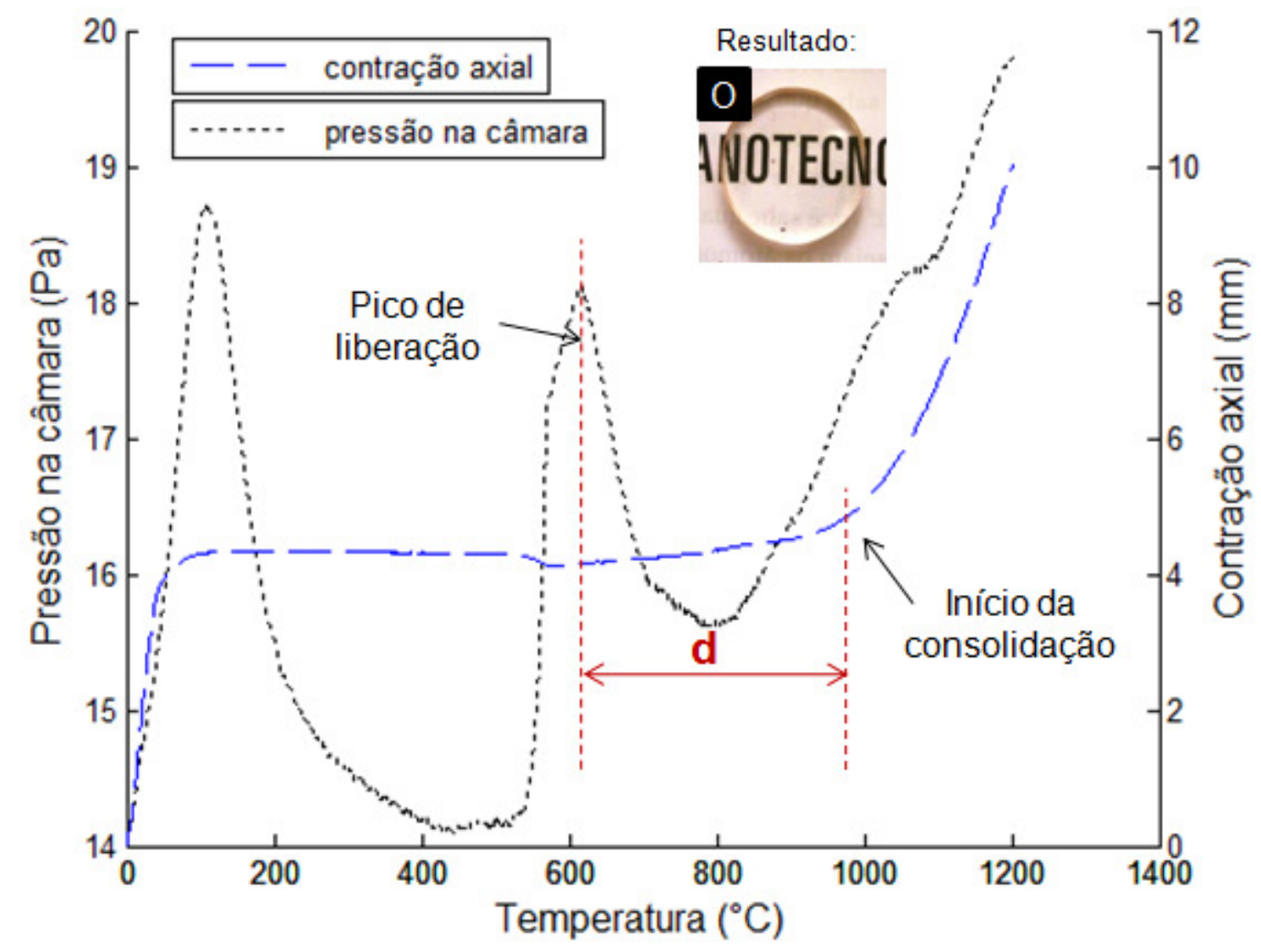

Figura 6. 26 - Experimento com maior "distanciamento" entre o pico de liberação de gás e o início da consolidação que resultou em amostra livre de bolhas.

\subsubsection{Liberação de gás e impurezas}

A sinterização do pó cristalino fabricado pela empresa lota liberou grandes quantidades de gases detectadas pelo sensor de pressão interno à câmara (Figura 6.27) que chegou a medir $80 \mathrm{~Pa}$. Isso ocorreu devido ao grande volume de impurezas presente nesta matéria-prima comparada com os pós cristalinos e amorfos testados com maior freqüência neste trabalho, os quais têm níveis de impureza desprezíveis. Durante o aquecimento, as impurezas se tornam líquidas e podem se transformar em gases evaporando ou reagindo para formar substâncias gasosas. 


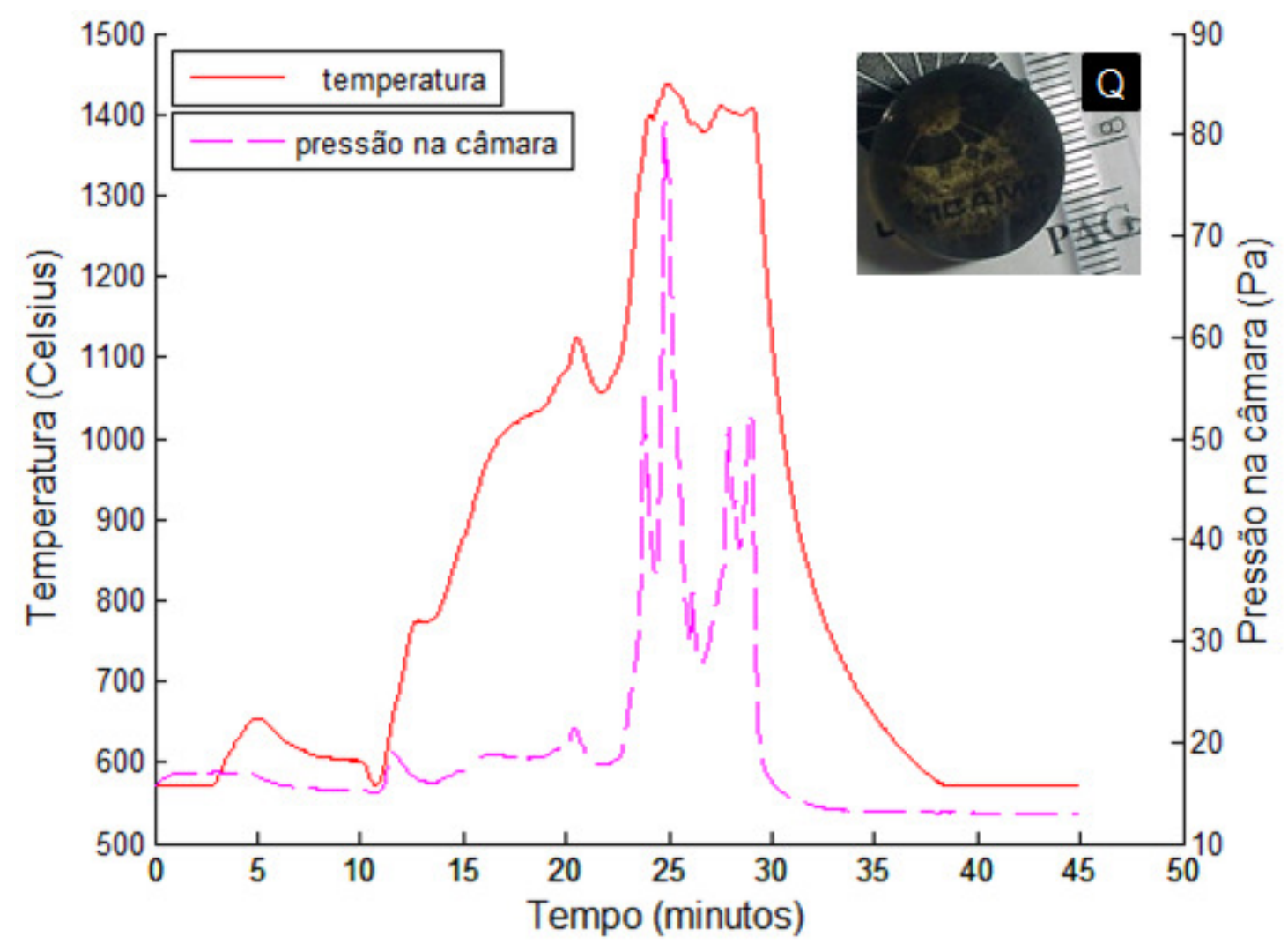

Figura 6. 27 - Temperatura e pressão no processamento de pó mais impuro de sílica.

\subsection{Difração de raios $X$}

A difração de raios $x$ foi importante para confirmar a estrutura amorfa da sílica vítrea fabricada pelo processo SPS. O resultados dos difratogramas das amostras transparentes produzidas a partir dos pós cristalinos e amorfos foram semelhantes (Figuras 6.28, 6.29, 6.30) e todos indicaram a estrutura amorfa do material uma vez que não há picos de difração e verifica-se a presença de um halo ou espalhamento característico de materiais amorfos - de intensidade máxima em aproximadamente $2 \theta=22^{\circ}$. 


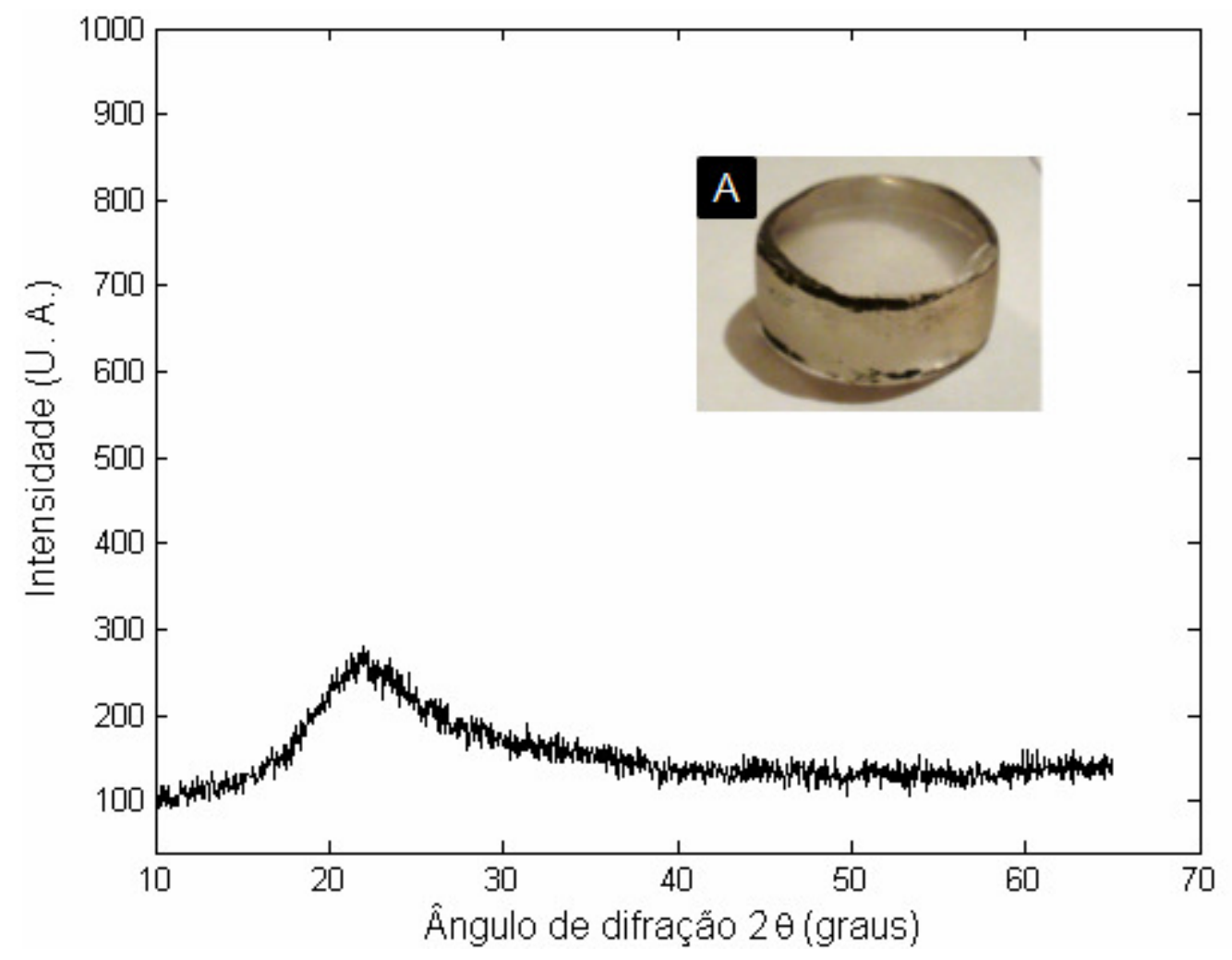

Figura 6. 28 - Difratograma da sílica vítrea obtida a partir do pó cristalino.

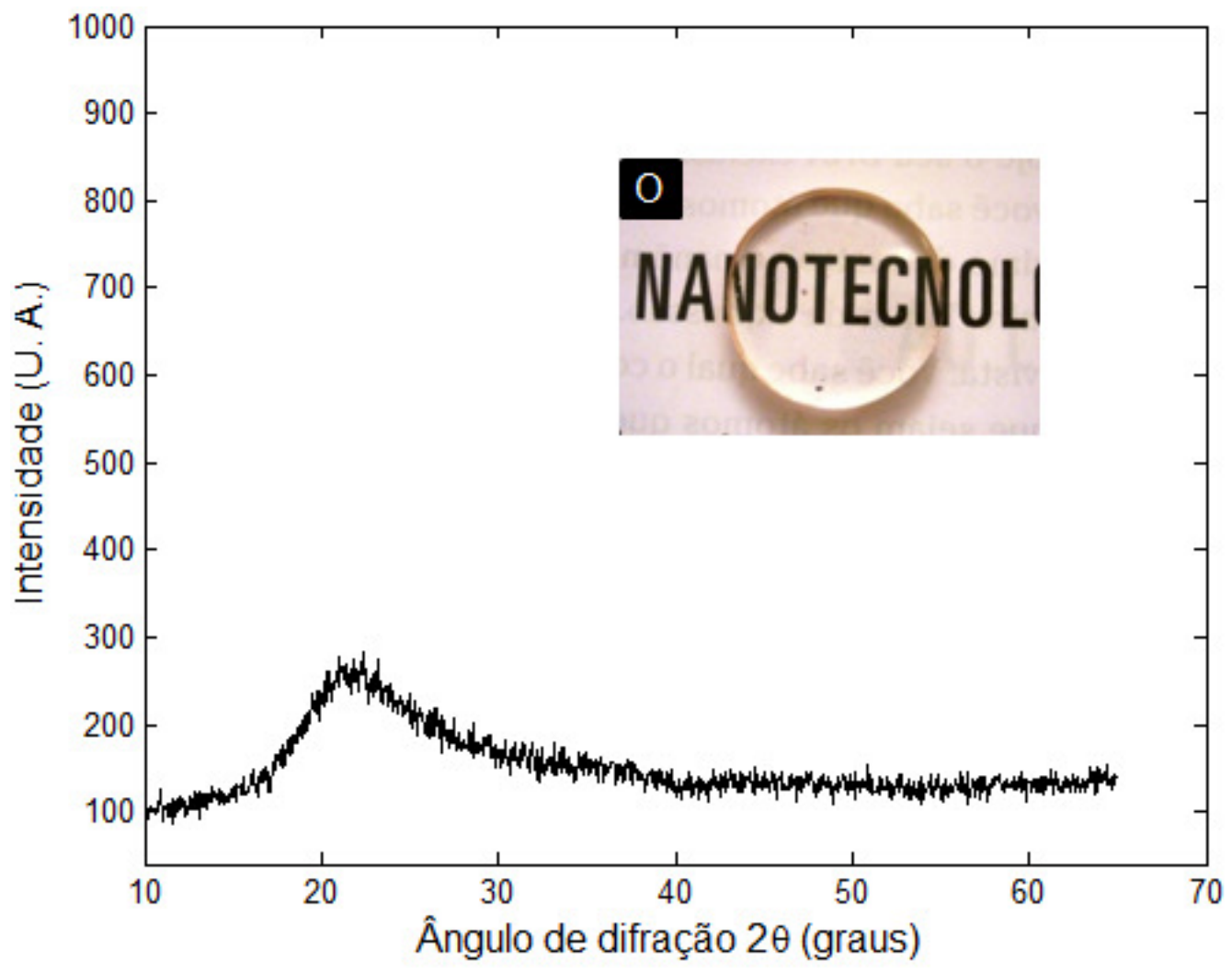

Figura 6. 29 - Difratograma da sílica vítrea obtida a partir do nanopó amorfo. 


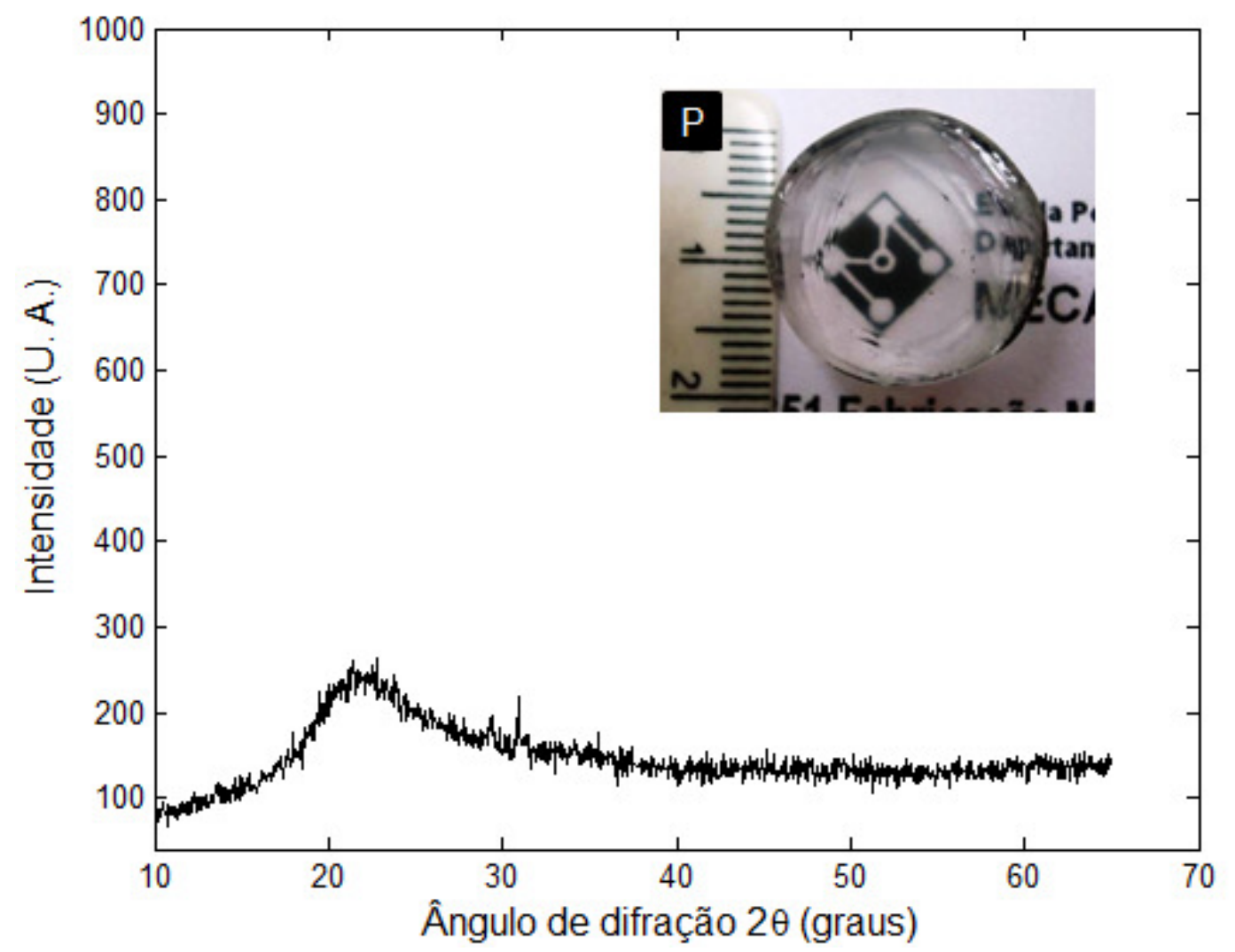

Figura 6. 30 - Difratograma da sílica vítrea obtida a partir do pó amorfo.

A difração de raios $X$ serviu também para excluir as suspeitas de que as regiões esbranquiçadas presentes em algumas amostras produzidas a partir do nanopó fossem cristais de sílica (cristobalita ou quartzo) crescidos em razão do aquecimento, conforme mostrou o resultado do difratograma (Figura 6.31) o qual não apresentou picos de difração. Essas regiões eram, na verdade, aglomerações de micro-bolhas. 


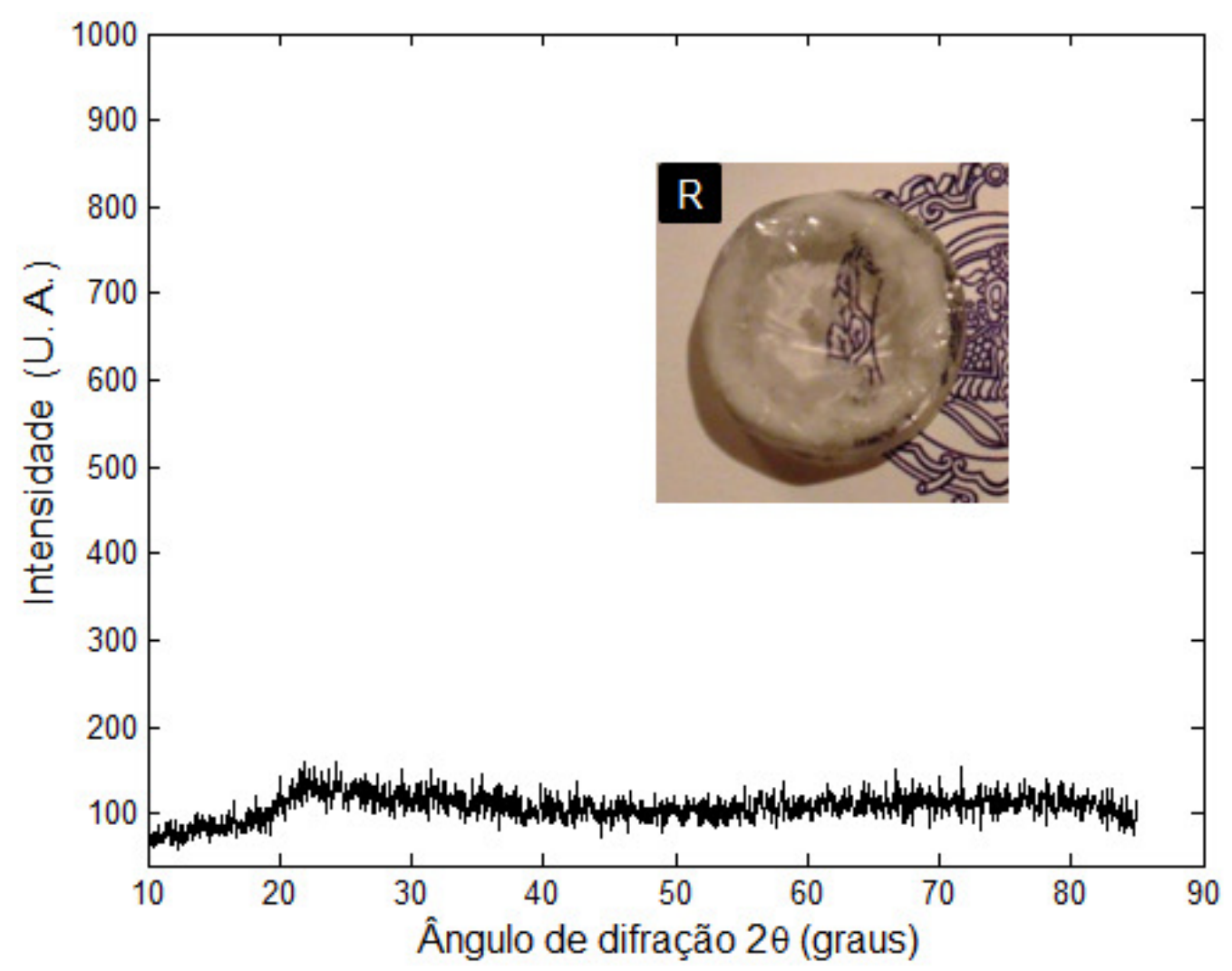

Figura 6. 31 - Difratograma comprovando a ausência de cristais em peça com regiões esbranquiçadas devido à presença de bolhas.

\subsection{Análise da densidade}

A medição da densidade das amostras completamente vítreas e transparentes produzidas indicou, independentemente da matéria-prima utilizada, um valor próximo de $2,200 \mathrm{~g} / \mathrm{cm}^{3}$, densidade da sílica vítrea encontrada na bibliografia [5].

Já os consolidados fabricados a partir de pó cristalino que não foram totalmente fundidos apresentaram uma densidade ligeiramente maior, da ordem de $2,260 \mathrm{~g} / \mathrm{cm}^{3}$, uma vez que a presença de cristais de quartzo cuja densidade é de aproximadamente $2,65 \mathrm{~g} / \mathrm{cm}^{3}$ [5] elevaram o valor da densidade do sólido obtido.

Um valor de densidade pouco menor que $2,200 \mathrm{~g} / \mathrm{cm}^{3}$ foi medido para as amostras de nanopó obtidas a altas taxas de aquecimento, as quais se 
apresentaram opacas e esbranquiçadas com aspecto leitoso devido à grande quantidade de bolhas, as quais causaram da redução da densidade do compacto.

A tabela 6.4 expõe os valores de densidade medidos de acordo com as características das amostras obtidas e suas matérias-primas.

Tabela 6. 4 - Características da matéria-prima, do material sinterizado e sua densidade.

\begin{tabular}{|c|c|c|c|}
\hline Matéria-prima & $\begin{array}{c}\text { Estrutura } \\
\text { cristalina do } \\
\text { consolidado }\end{array}$ & Características visuais & $\begin{array}{l}\text { Densidade } \\
\text { média } \\
\left(\mathrm{g} / \mathrm{cm}^{3}\right)\end{array}$ \\
\hline Cristalina & Amorfa & $\begin{array}{l}\text { Completamente } \\
\text { transparente }\end{array}$ & 2,207 \\
\hline Cristalina & $\begin{array}{l}\text { Parcialmente } \\
\text { amorfa }\end{array}$ & $\begin{array}{c}\text { Regiões transparentes } \\
\text { e regiões opacas } \\
\text { brancas e porosas }\end{array}$ & 2,263 \\
\hline $\begin{array}{c}\text { Amorfa } \\
\text { (nanométrica) }\end{array}$ & Amorfa & $\begin{array}{l}\text { Completamente } \\
\text { transparente }\end{array}$ & 2,200 \\
\hline $\begin{array}{c}\text { Amorfa } \\
\text { (nanométrica) }\end{array}$ & Amorfa & $\begin{array}{l}\text { Opaca esbranquiçada } \\
\text { de aspecto leitoso }\end{array}$ & 2,176 \\
\hline Amorfa & Amorfa & $\begin{array}{l}\text { Completamente } \\
\text { transparente }\end{array}$ & 2,203 \\
\hline
\end{tabular}

\subsection{Análise da transmitância óptica}

Até o momento, este texto classificou as amostras sinterizadas entre transparentes, parcialmente transparentes ou opacas. O critério para essa classificação foi simplesmente visual e, como visto, influenciado pela presença de bolhas ou de material não fundido nas amostras. Outro critério de análise de materiais transparentes é a medição da sua transmitância óptica. Algumas amostras de sílica vítrea obtidas neste estudo foram submetidas à análise de transmitância do espectro luminoso no UV - Vis - NIR.

As sílicas vítreas produzidas com os pós cristalinos e amorfo, de purezas 99,99 e 99,9999\% respectivamente, apresentaram transmitância elevada (próxima ou maior que 90\%) em todo o espectro de luz visível e em boa parte do infravermelho próximo (Figuras 6.32 e 6. 33).

A transmitância da amostra produzida a partir do pó cristalino (Figura 6.32) foi superior a $90 \%$ entre 300 e $2820 \mathrm{~nm}$ de comprimento de onda e sofreu leve aumento 
da absorção a partir $2900 \mathrm{~nm}$. Como não há queda da transmitância em 2700 nm de comprimento de onda, ou seja, a diferença entre ' $T_{b}$ ' e ' $T_{2,72}$ ' (Eq. 1) é próxima de zero, sua concentração de $\mathrm{OH}$ é praticamente nula.

Por outro lado, o consolidado fabricado com o pó amorfo de sílica (obtido por processo Sol-Gel) apresentou uma diminuição da transmitância para valores próximos a $69 \%$ em torno de $2700 \mathrm{~nm}$ (Figura 6.33). Se for ajustada uma reta entre as transmitâncias em 2,52 $\mu \mathrm{m}$ e 2,92 $\mu \mathrm{m}$ (Figura 6.34), pode-se estimar o valor de ' $T_{b}$ ' no ponto médio $(2,72 \mu \mathrm{m})$ e substituir os valores de ' $T_{b}$ ' $\mathrm{e}$ ' $T_{2,72}$ ' na Eq. 1, para se obter um valor aproximado da concentração de $\mathrm{OH}$ na amostra, como feito a seguir:

$$
\begin{aligned}
& T_{b}=\frac{T_{2,52}+T_{2,92}}{2}=\frac{0,92+0,88}{2}=0,90 ; \\
& T_{2,72} \approx 0,69 ; \\
& t=5,9 \mathrm{~mm} ; \\
& {[O H]=\frac{1000}{t} \log \left(\frac{T_{b}}{T_{2,72}}\right)=19,6 \mathrm{ppm}}
\end{aligned}
$$

O valor da concentração de $\mathrm{OH}$ calculado (19,6 ppm) é baixo se comparado aos compactos obtidos a partir do pó de sílica amorfa fabricado por processo Solgel. Rabinovich, E. M. et al [34] reportaram uma quantidade de grupos hidroxila maior que 600 ppm presente na sílica vítrea de origem Sol-gel consolidada em atmosfera de He puro. 


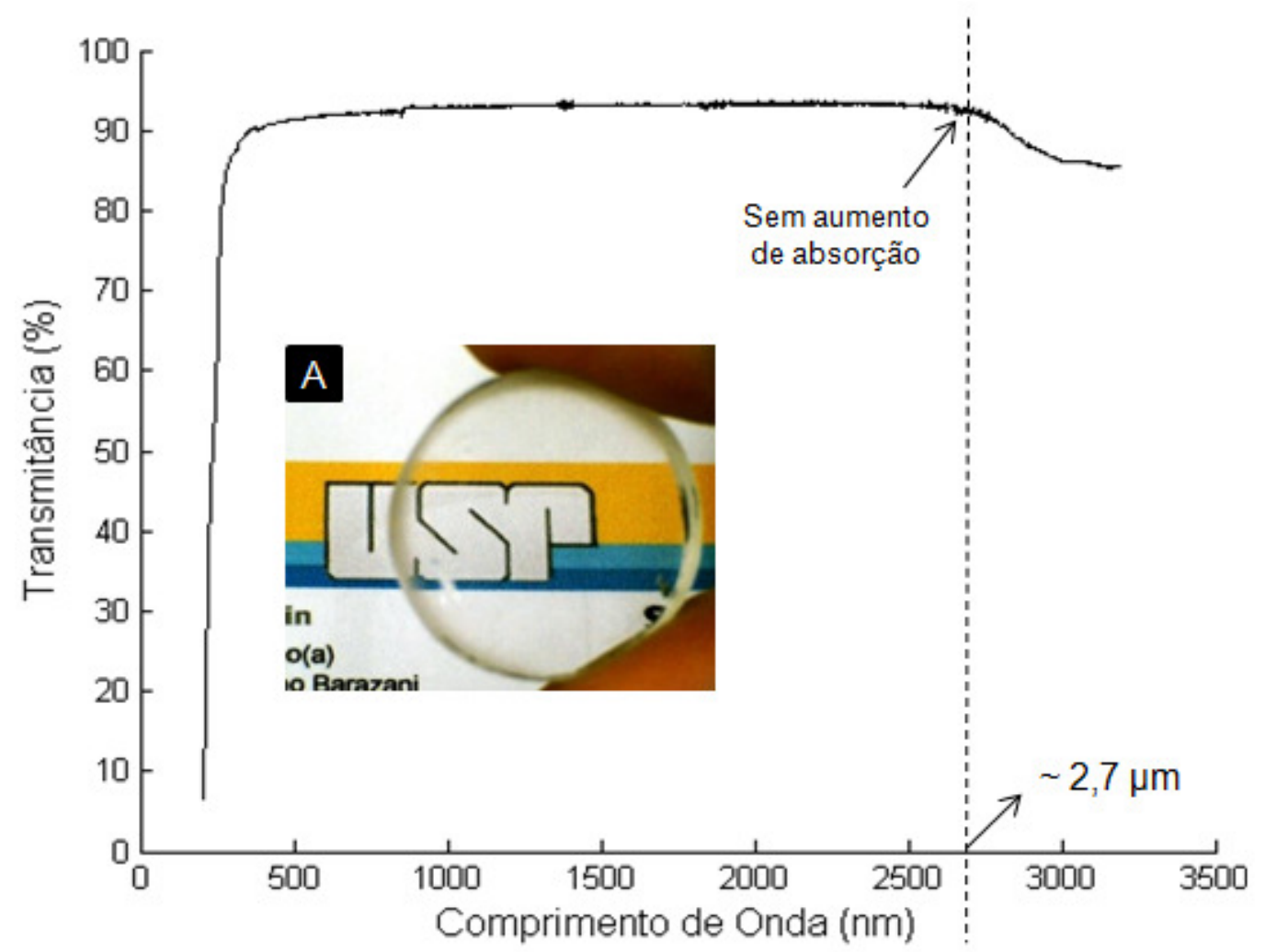

Figura 6. 32 - Transmitância no UV - VIS - NIR de $\mathrm{SiO}_{2}$ vítreo fabricado com pó cristalino.

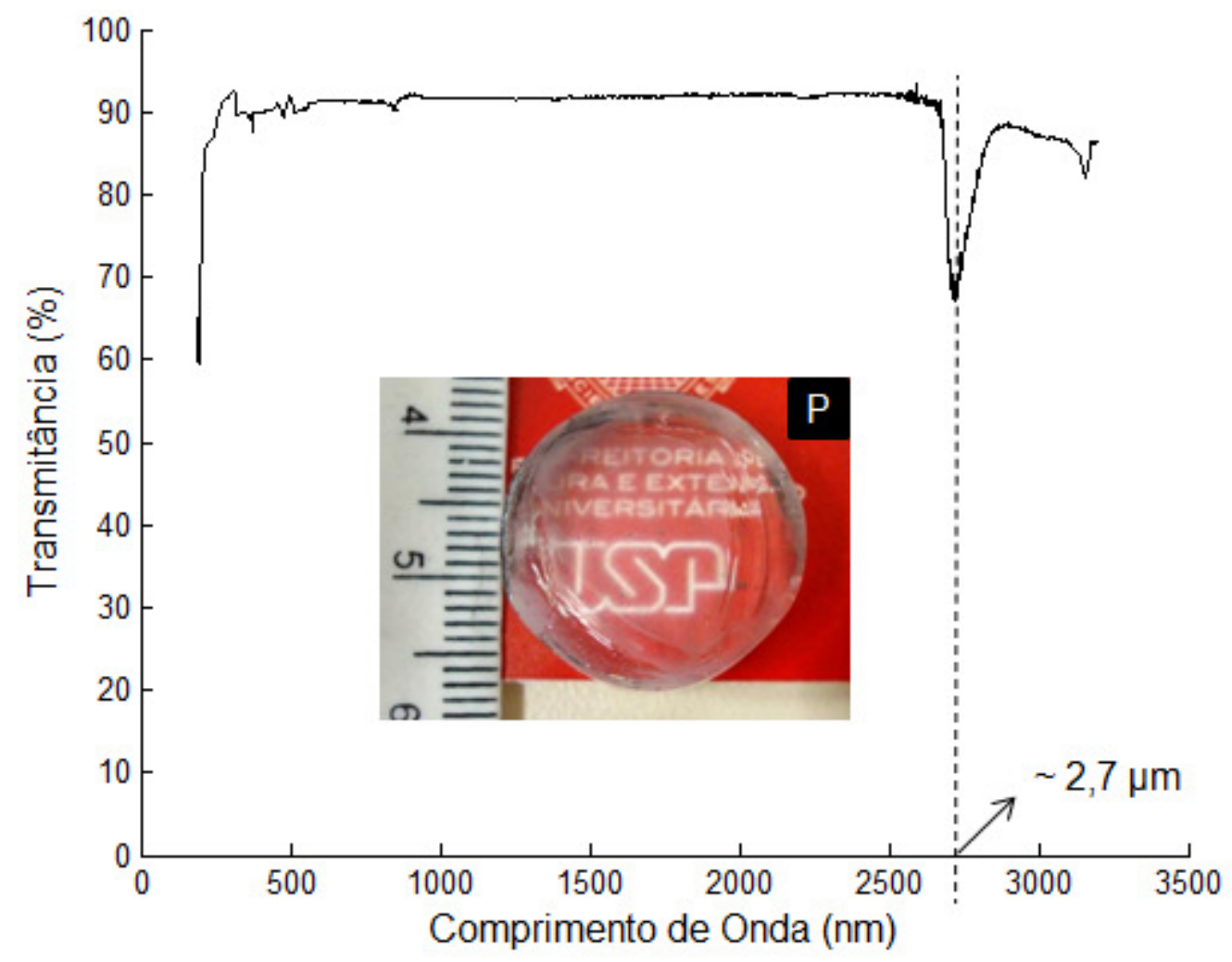

Figura 6. 33 - Transmitância no UV - VIS - NIR de $\mathrm{SiO}_{2}$ vítreo fabricado com pó amorfo. 


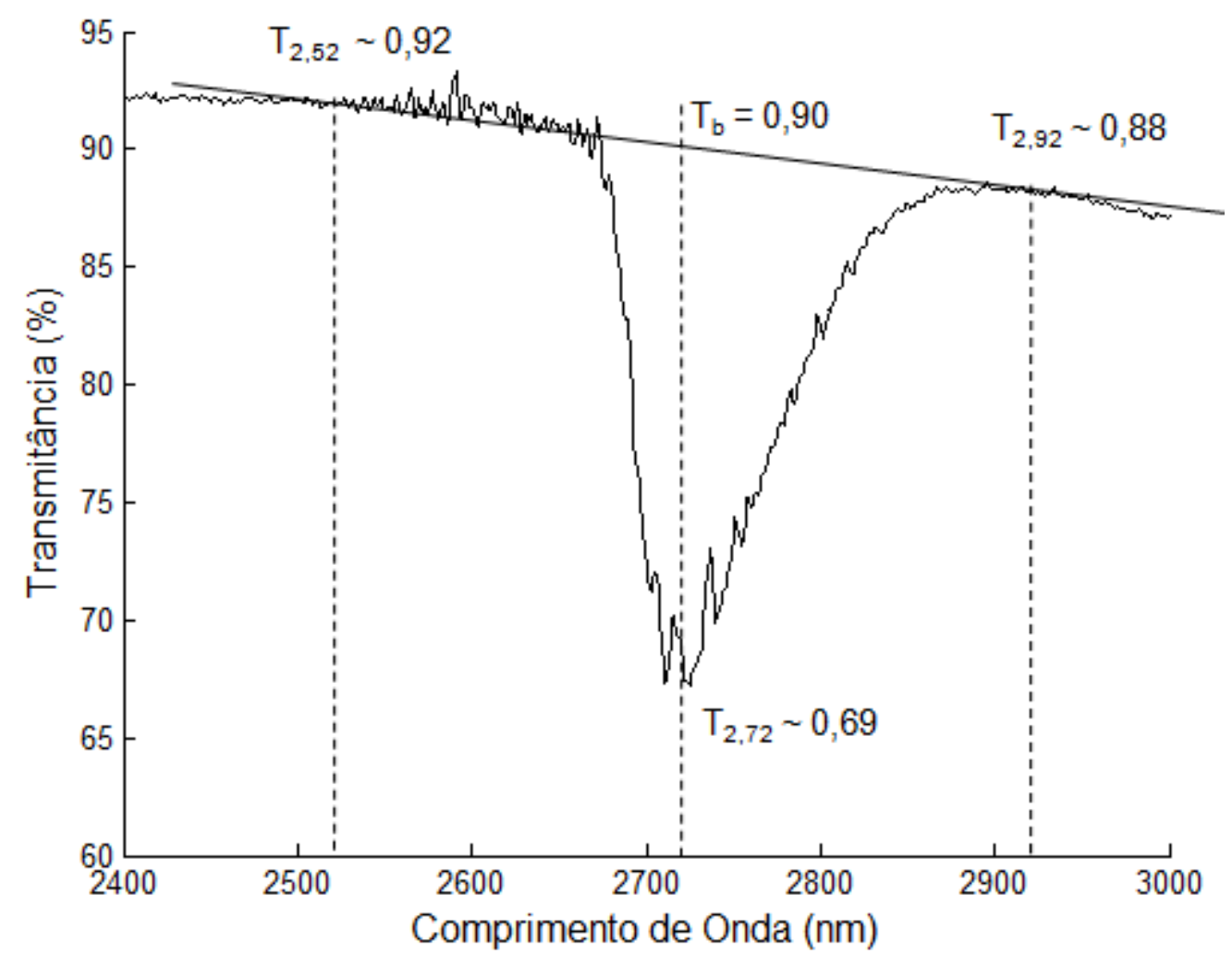

Figura 6. 34 - Aproximação do valor de $T_{b}$ como ponto médio dos pontos $T_{2,52}$ e $T_{2,92}$.

Amostras vítreas produzidas com pó cristalino de pureza inferior tiveram maior absorção em todo no espectro luminoso avaliado, sendo esse aumento maior no espectro visível (Figura 6.35). Essa menor transmitância foi causada pela presença de impurezas e, eventualmente, de bolhas nos consolidados.

Sílica vítrea parcialmente fundida, originada da sinterização de pó cristalino de maior granulometria, apresentou transmitância inferior a 40\% em todo espectro luminoso analisado (Figura 6.36) em razão dos cristais remanescentes na estrutura consolidada.

Apesar de possuírem diferentes espectros de transmitância, as amostras fabricadas a partir dos pós cristalinos (Figuras 6.32, 6.35, e 6.36) não apresentaram aumento de absorção no comprimento de onda próximo de 2,7 $\mu \mathrm{m}$. Essa característica confere ao material uma viscosidade superior à da sílica fundida convencional devido aos grupos $\mathrm{OH}$ existentes nela [30]. 


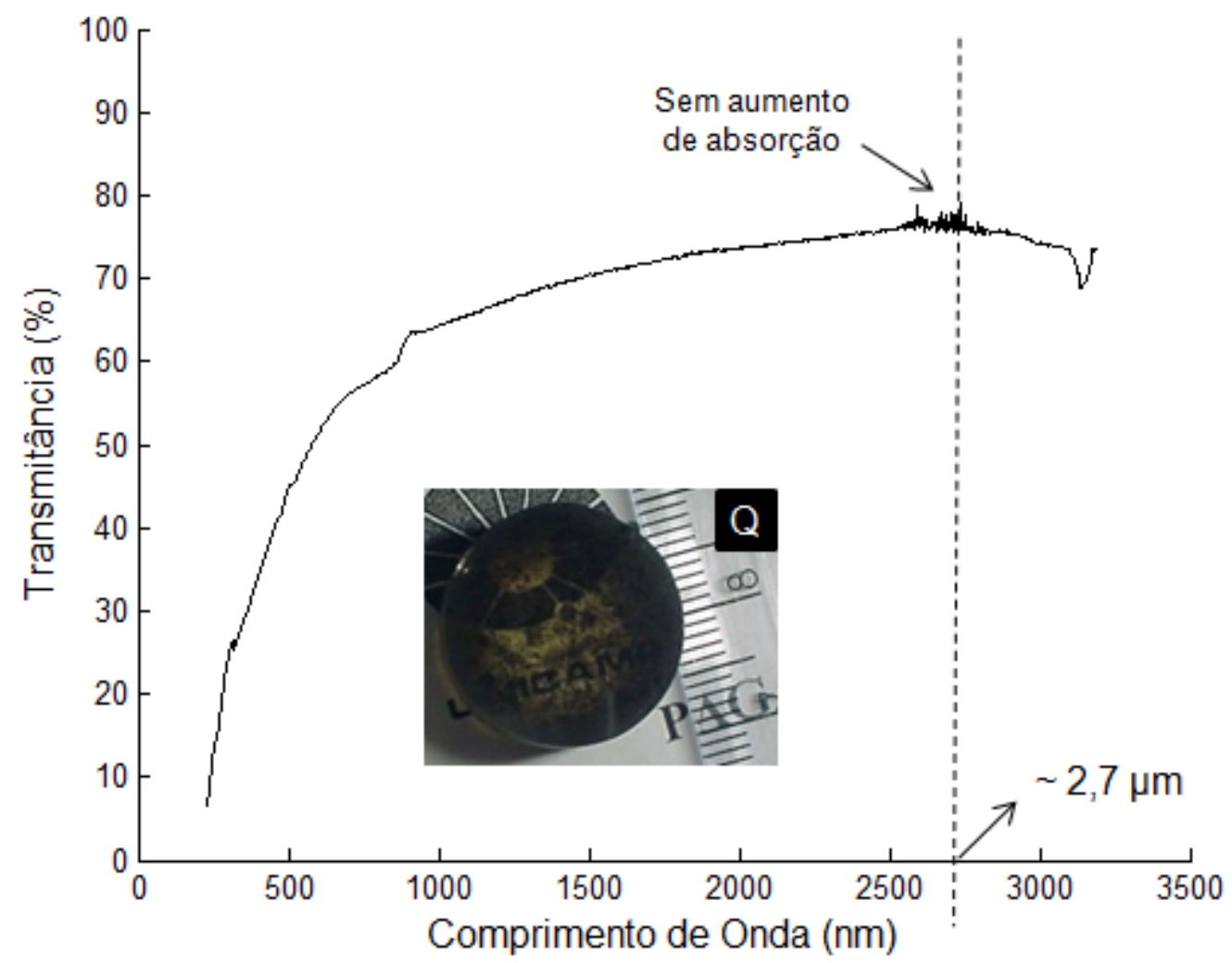

Figura 6. 35 - Transmitância de $\mathrm{SiO}_{2}$ vítreo obtido com pó cristalino de baixa pureza.

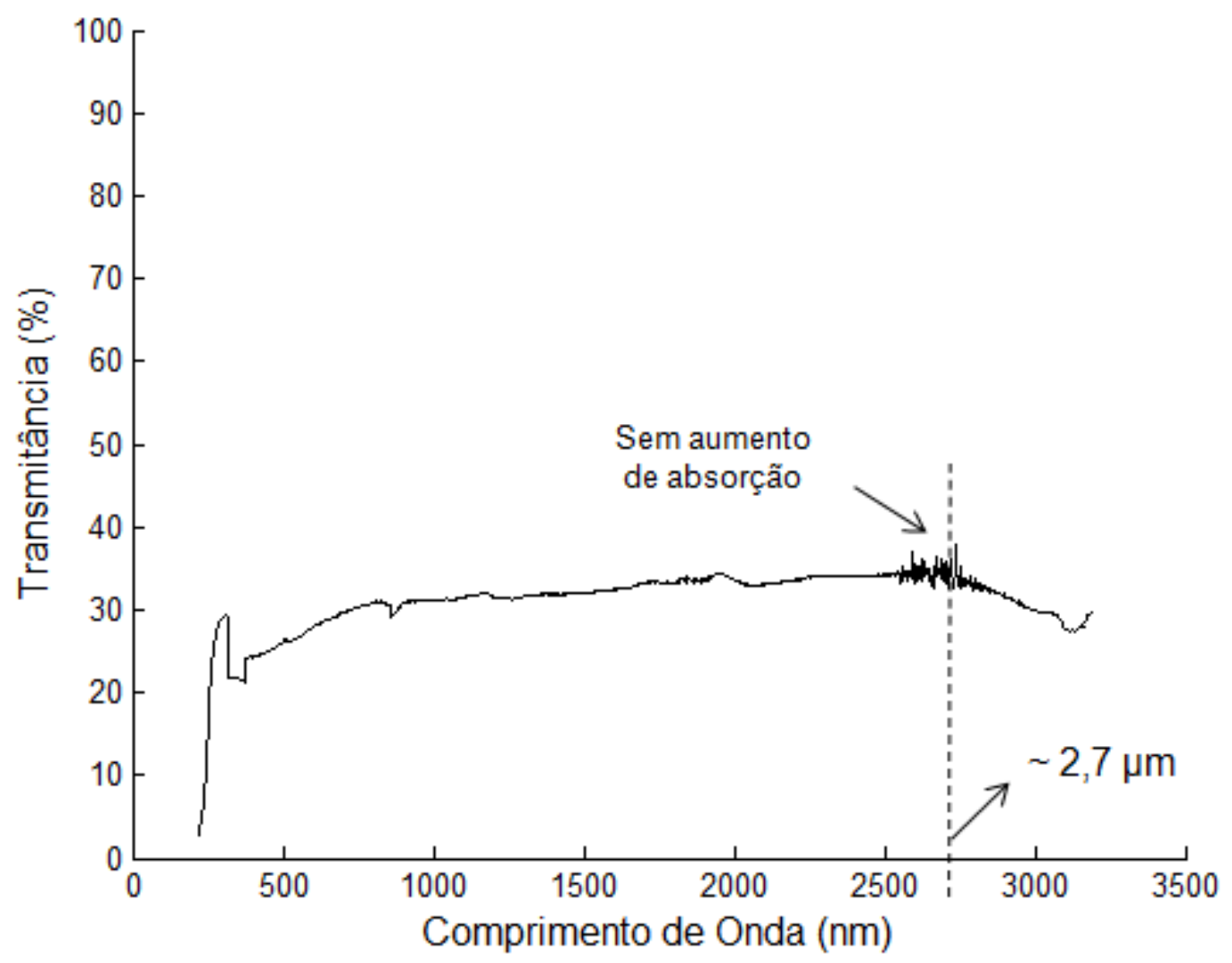

Figura 6. 36 - Transmitância de $\mathrm{SiO}_{2}$ parcialmente fundido fabricado com pó cristalino. 


\subsection{Fabricação de sílica titânia pela técnica SPS}

A sinterização do pó de sílica titânia resultou em compactos opacos de coloração azulada ou preta com pigmentação esbranquiçada.

$\mathrm{Na}$ sinterização do pó de sílica dopada com titânia anatase atingiu-se uma temperatura final próxima de $1200^{\circ} \mathrm{C}$ e como resultado foi obtida uma amostra completamente consolidada de coloração azul (Figura 6.37). A análise do difratograma revelou a presença somente da forma cristalina rutilo, indicando que transição anatase-rutilo ocorreu de forma completa apesar do breve tempo de manutenção da temperatura elevada (cerca de 4 minutos). Esse efeito pode ser justificado pela ação da atmosfera redutora do processo que acelera essa mudança de fase $[49,50]$

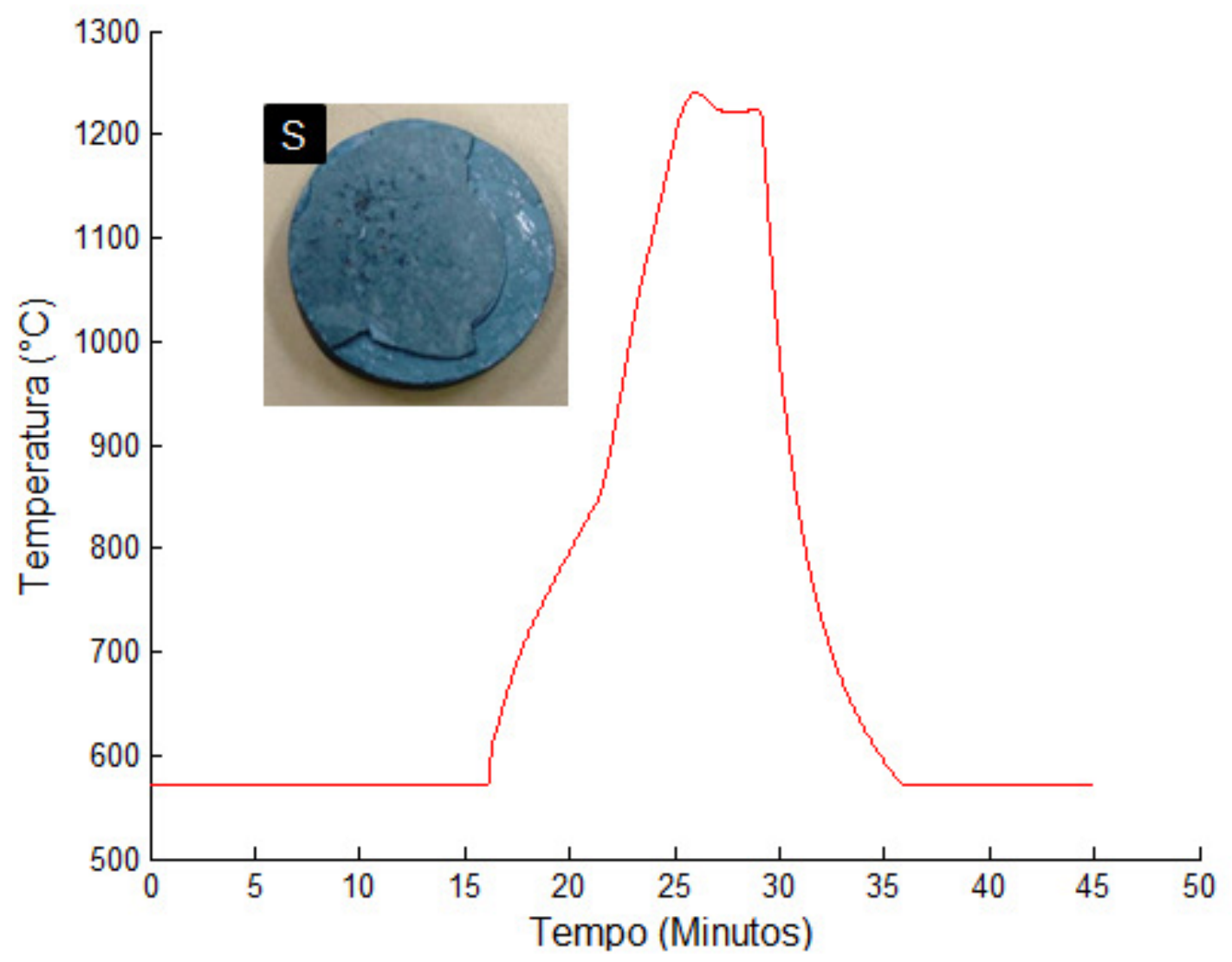

Figura 6. 37 - Curva de temperatura de amostra obtida a partir de sílica dopada titânia anatase. 
A sinterização do pó dopado com titânia na fase rutilo foi realizada com temperaturas máximas próximas de $1220^{\circ} \mathrm{C}$ e $1450^{\circ} \mathrm{C}$ (Figura 6.38). No processo de temperatura mais baixa a amostra resultante apresentou coloração azul claro enquanto que no caso de maior temperatura a coloração da peça foi preta. Ambas as amostras apresentaram pigmentos esbranquiçados, contudo esses pigmentos eram maiores e mais facilmente observados na amostra de cor preta.

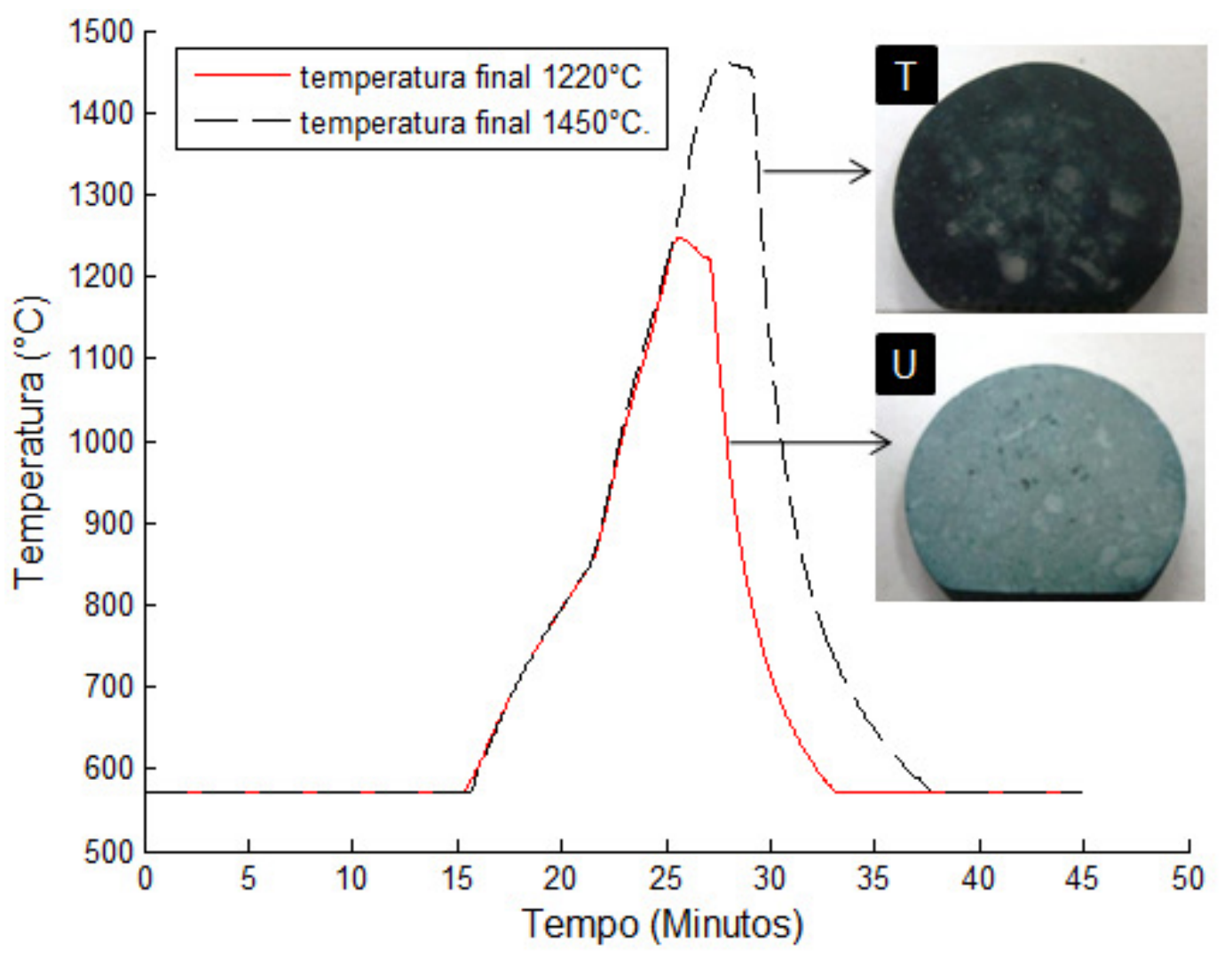

Figura 6. 38 - Amostras de sílica titânia e as respectivas curvas de temperatura.

A análise das duas amostras realizada utilizando um microscópio de varredura eletrônica permitiu concluir que o aumento da temperatura de processo causou uma maior precipitação de titânia devido ao aumento do tamanho dos clusters deste material na matriz de sílica. As figuras 6.39 e 6.40 mostram imagens ampliadas da superfície das amostras de cor azul e preta respectivamente. Nas regiões mais brancas foi detectada uma maior quantidade do elemento químico titânio, identificando esses locais como clusters de titânia. Como as ampliações são iguais nas duas imagens conclui-se que houve maior precipitação de titânia na amostra que atingiu temperaturas mais altas, a de cor preta. 


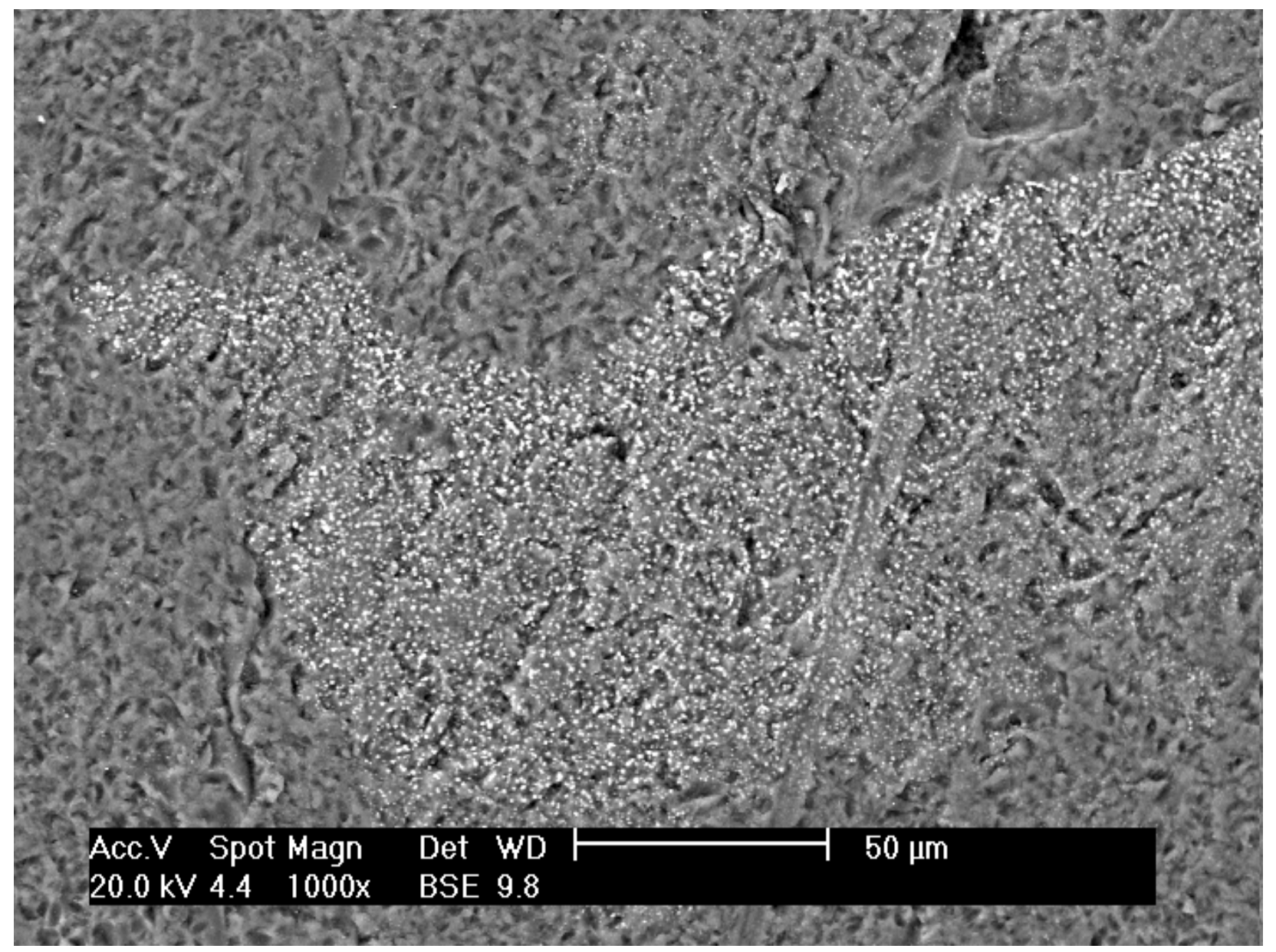

Figura 6. 39 - Superfície da sílica titânia processada a $1220^{\circ} \mathrm{C}$ com ampliação de 1000x.

A coloração apresentada pelas amostras pode ser resultado da geração de centros de cor causados por defeitos presentes na estrutura da titânia [49]. Esses defeitos podem ser, por exemplo, vacâncias de oxigênio causadas pela atmosfera quimicamente redutora do processo devido à utilização de molde e punções de grafite.

Outra explicação para o fato da sílica titânia adquirir cor é a presença do íon $\mathrm{Ti}^{3+}$ também justificada pela ação da atmosfera redutora [60] e pela redução da quantidade de água (grupos $\mathrm{OH}$ ) na composição do vidro [61]. 


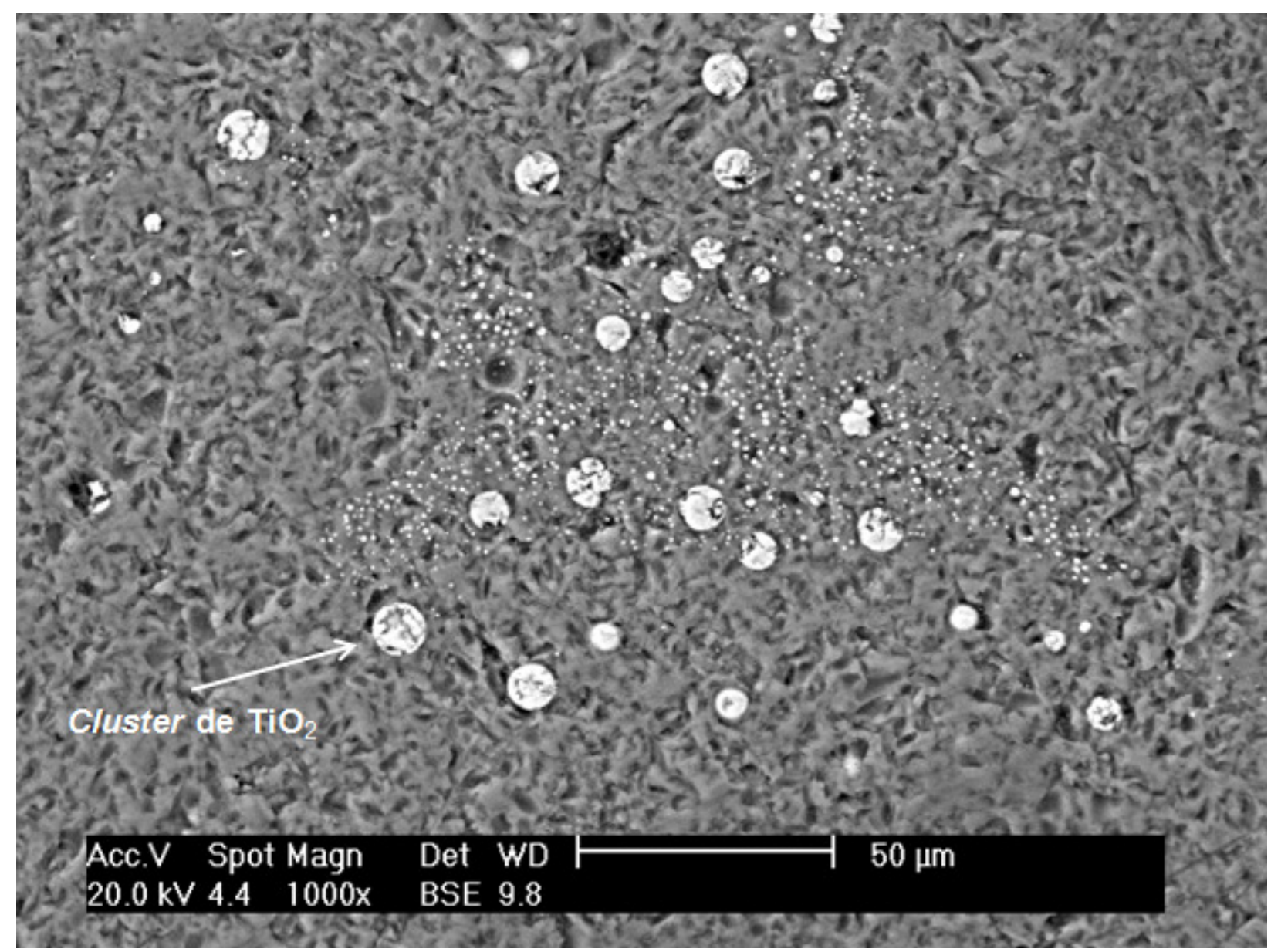

Figura 6. 40 - Superfície da sílica titânia processada a $1450^{\circ} \mathrm{C}$ com ampliação de $1000 x$. 


\section{Conclusões}

O estudo realizado permitiu concluir a viabilidade da produção de compactos de sílica vítrea transparente por meio da técnica de sinterização por plasma pulsado a partir de diferentes tipos de matérias-primas de $\mathrm{SiO}_{2}$.

Sobre as características de processamento, conclui-se que é possível obter consolidados de sílica fundida transparente em experimentos com durações máximas menores que 40 minutos, tempos de consolidação entre 2 e 4 minutos e taxas de aquecimento entre $40^{\circ} \mathrm{C} / \mathrm{min}$. e $160^{\circ} \mathrm{C} / \mathrm{min}$. Temperaturas próximas a $1450^{\circ} \mathrm{C}$ foram suficientes para a fusão e densificação completa do pó cristalino a uma taxa de aquecimento de $60^{\circ} \mathrm{C} / \mathrm{min}$., enquanto que para uma taxa de $140^{\circ} \mathrm{C} / \mathrm{min}$. foi necessária uma temperatura final próxima de $1600^{\circ} \mathrm{C}$ devido à baixa condutividade térmica da sílica. Nanopó e pó amorfo de sílica foram compactados a uma temperatura mínima próxima de $1220^{\circ} \mathrm{C}$. Na sinterização do nanopó, a redução da taxa de aquecimento foi necessária para aumentar o tempo de ação da bomba de vácuo na retirada de gases liberados pela matéria-prima antes do início da consolidação, evitando, assim, a presença de bolhas na amostra.

No processamento do pó cristalino, temperaturas finais menores em 50 a $100^{\circ} \mathrm{C}$ das temperaturas necessárias para a fusão completa do material deram origem a amostras com regiões transparentes e opacas (regiões que não chegaram a fundir), permitindo concluir que a temperatura na amostra, durante o processo de sinterização, decresce na direção radial no sentido do centro para as bordas da amostra devido ao formato côncavo da frente de fusão observada.

Dentre as diferentes caracterizações realizadas, a difração de raios $X$ confirmou a estrutura amorfa dos compactos transparentes e com bolhas enquanto a medição da densidade indicou valores maiores que $2,200 \mathrm{~g} / \mathrm{cm}^{3}$ - densidade da sílica vítrea - para as amostras parcialmente fundidas e valores menores que isso para as amostras esbranquiçadas devido à presença de bolhas. Além disso, a análise da transmitância indicou o não aumento da absorção em comprimentos de onda próximos de $2,7 \mu \mathrm{m}$ na sílica vítrea produzida a partir de pós cristalinos, sugerindo uma quantidade praticamente nula de grupos $\mathrm{OH}$ no material sinterizado a partir deste pó. Já no caso dos consolidados obtidos a partir do pó amorfo, 
produzido por processo sol-gel, estimou-se uma quantidade de grupos $\mathrm{OH}$ da ordem de 20 ppm.

Apesar do êxito na produção de sílica vítrea pura transparente, os compactos de sílica titânia fabricados apresentaram opacidade, muito provavelmente, devido à atmosfera redutora do processo. Conclui-se, então, que a obtenção de compactos transparentes de sílica titânia pela técnica SPS pode ser dificultosa, uma vez que a utilização de molde e punções de grafite (característico do método) torna a atmosfera da câmara de sinterização quimicamente redutora. 


\section{Sugestões para trabalhos futuros}

Uma vez adquirido o conhecimento necessário para a produção de sílica vítrea pura pelo processo SPS, um próximo passo seria a obtenção de sílica vítrea dopada com outros compostos. A rapidez desse tipo de sinterização pode permitir uma maior concentração de dopantes sem tornar o material heterogêneo, melhorando as propriedades do mesmo, além de possibilitar a conservação dos dopantes conforme a etapa de preparação do molde, permitindo a fabricação de materiais com gradação funcional, como, por exemplo, lentes planas com índices de refração variando ao longo da espessura.

Um material de particular interesse é a vitro-cerâmica de sílica pura constituída por uma matriz de sílica amorfa reforçada com cristais de sílica. Este composto tem potencial para servir como ferramenta de corte, bem como para ser utilizado como cadinho de sílica no processo de crescimento de cristais de silício.

A produção de sílica titânia transparente também é uma sugestão para trabalhos futuros. A substituição do molde de grafite por um de outro material ou alguma outra solução para que a sinterização por plasma pulsado ocorra em uma atmosfera oxidante ou neutra pode ser uma saída para a obtenção do vidro de sílica titânia transparente. 


\section{Referências Bibliográficas}

[1] - RAHAMAN, M. N. Sintering of Ceramics. Boca Raton, United States.:Ed. CRC Press, 2008, $388 \mathrm{p}$.

[2] - PORTER, D. A., EASTERLING, K. E.; SHERIF, M. Y. Phase Transformations in Metals and Alloys. Boca Raton, United States.: Ed. CRC Press, 2009, 500 p.

[3] - GARAY, J. E. Current-Activated, Pressure-Assisted Densification of Materials. Annual Review Material Research, v. 40, p. 445 - 468, 2010.

[4] - TOKITA, M. Mechanism of Spark Plasma Sintering. In: 2000 Powder Metallurgy World Congress. November, 2000. Japan, Kyoto. Proceedings of 2000 Powder Metallurgy World Congress, Kyoto, 2000, p.729 - 732.

[5] - SOSMAN, R. B. The phases of silica. New Brunswick, N.J.: Rutgers University Press, 1965, $388 \mathrm{p}$.

[6] - BANSAL, N. P. AND DOREMUS, R. H. Handbook of Glass Properties. San Diego, United States. Ed. Academic Press, 1986, 686 p.

[7] - YEH, C. Handbook of Fiber Optics: Theory and Applications. San Diego: Academic Press, 1990, 382 p.

[8] - PRAMOD, R. W., SEONGMIN J., AND WON-TAEK H. A Nd-YAG LaserPumped Tm-Doped Silica Glass Optical Fiber Amplifier at $840 \mathrm{~nm}$. IEEE photonics technology letters, v. 18, $n^{\circ} .15$, p. $1651-1653,2006$.

[9] - HERAEUS, 2011. Suprasil( 501 ArF / 502 ArF. <http://optik.heraeusquarzglas.de/en/productsapplications/productdetail_14592.aspx?psMarketld=13 12\&psApplicationld=762756> , 03 Mar. 2011.

[10] - HUANG, X., KOH, S, WU, K., CHEN, M., HOSHIKAWA, T, HOSHIKAWA, K. AND UDA, S. Reaction at the interface between Si melt and a Ba-doped silica crucible. Journal of Crystal Growth, v. 277, p. 154 - 161, 2005.

[11] - MIZOSHIRI, M., NISHIYAMA, H.; KAWAHARA, T., NISHII, J., AND HIRATA, Y. $\mathrm{SiO}_{2}$-Based Hybrid Diffractive-Refractive Lenses Fabricated by Femtosecond 
Laser-Assisted Micromachining. Applied Physics Express, $\mathrm{n}^{\circ} 1$, p. 127001$127003,2008$.

[12] - FENG, J., ZHOU, C. ZHENG, J., CAO, H., AND LV, P. Design and fabrication of a polarization-independent two-port beam splitter. Applied Optics, v. 48, $n^{\circ}$. 29, p. 5636 - 5641, 2009.

[13] - DAVIS, C. L. J.; HIRDINA, K. E.; SABIA, R.; STEVENS, H. Extreme ultraviolet soft $x$-ray projection lithographicmethod and mask devices. US IP 6,576,380, 10 Jun. 2003.

[14] - MURATA, H. Handbook of Optical Fibers and Cables. New York, United States.: Marcel Dekker, 1988.

[15] - lota High Purity Quartz, <http://www.iotaquartz.com/world.html>, 22 Ago. 2011.

[16] - SONG, L., Kasho Corporation-China, Comunicação particular, Osaka, Março 2011.

[17] - Patury, S. R. Cristal de rocha na região de sento-sé, Bahia. Mineração \& Metalurgia,. v. 8, n. 43, p. 41 - 44, 1944.

[18] - KAWAHARA, M.; KIM, H.; TOKITA, M. Fabrication of Nanomaterials by the Spark Plasma Sintering (SPS) Method. In: 2000 Powder Metallurgy World Congress. November, 2000. Japan, Kyoto. Proceedings of 2000 Powder Metallurgy World Congress, Kyoto, 2000 p. 741-744.

[19] - INOUE, K. Apparatus for eletrically sintering discret bodies. US IP 3,250,892, 10 May 1962.

[20] - INOUE, K. Electric-discharge sintering. US IP 3,241,956, 22 Mar. 1966.

[21] - OMORI, M. Sintering, consolidation, reaction and crystal growth by the spark plasma system (SPS). Materials Science and Engineering. v. 287, p. 183 188, 2000.

[22] - ANSELMI-TAMBURINI, U.; GENNARI, S.; GARAY, J. E.; MUNIR,, Z. A. A. Fundamental Investigations on the Spark Plasma Sintering/synthesis Process II. 
Modeling of Current and Temperature Distributions. Materials Science and Engineering. v. 394, p. 139-148, 2004.

[23] - TOKITA M. Industrial applications for functionally graded materials fabricated by spark plasma sintering (SPS) systems. In: Proceedings KORUS 2000. The 4th Korea-Russia international symposium on science and technology, 2000. Proceedings of the 4th Korea-Russia international symposium on science and technology, 2000, v.3, p. 251 - 256.

[24] - OLEVISKY, E. A.; KANDUKURI, S.; FROYEN, L. Consolidation enhancement in spark-plasma sintering: Impact of high heating hates. Journal of Applied Physics. n. 102, 114913, p. 1 - 12, 2007.

[25] - WANG, X.; CASOLCO, S.R.; XU, G.; GARAY, J.E. Finite element modeling of electric current-activated sintering: The effect of coupled electrical potential, temperature and stress. Acta Materialia. N55, p. 3611 - 3622, 2007.

[26] - CINCOTTI, A.; LOCCI, A. M.; ORRÙ, R. CAO, G. Modeling of SPS apparatus: Temperature, current and strain distribution with no powders. American Institute of Chemical Engineers, v. 53, n. 3, p. 703 - 719, 2007.

[27] - TIWARI D.; BASU, B.; BISWAS, K. Simulation of thermal and electric field evolution during spark plasma sintering. Ceramics International, N³5, p. 699 - 708, 2009.

[28] - CALLISTER, W. D. Ciência e engenharia de materiais: uma introdução. $5^{a}$ Edição. Rio de Janeiro: Livros Técnicos e Científicos, 2002, 589 p.

[29] - BECHMANN, R. Elastic and Piezoelectric Constants of Alpha-Quartz. Physical Review, v. 110, n. 5, 1958.

[30] - BROCKNER, R. Properties and structure of vitreous silica. Journal of NonCrystalline Solids, v. 5, p. 123-175,1970.

[31] - SAITOA, K.; IKUSHIMA, A. J. Reduction of light-scattering loss in silica glass by the structural relaxation of "frozen-in" density fluctuations. Applied Physics Letters, v. 70, n. 26, p 3504 - 3506, 1997. 
[32] - ZACHARIASEN, W. K. The atomic arrangement in glass. Journal of the American Chemical Society, v. 54, p. 3841 - 3851, 1932.

[33] - SUZUKI, C. K.; TORIKAI, D. Vitreous silica processing by vapor phase deposition for optical fiber preform. Radiation Effects and Defects in Solids, v. 147, p. $55-63,1998$.

[34] - RABINOVICH E.M.; MACCHESNE, J.B. JOHNSON Jr, D. W.; SIMPSON, J.R.; MEAGHER, B.W.; DIMARCELLO, F.V.; WOOD, D.L.; SIGETY, E. A. Sol-gel Preparation of Transparent Silica Glass. Journal of Non-Crystalline Solids, n. 63, p. $155-161,1984$.

[35] - SUZUKI, C. K.; TORIKAI, D.; NAGAI, E. Y.; ISHIZUKA, T. Fabricação de Silica Glass por Fusão em Chama - Verneuille. In: $39^{\circ}$ Congresso Brasileiro de Cerâmica, 1996, águas de Lindóia. Anais do $39^{\circ}$ Congresso Brasileiro de Cerâmica. São Paulo: Associação Brasileira de Cerâmica, 1996. v. 2. p. 10311037.

[36] - KIKUCHI, Y. SUDO, H. KUZUU, N. OH contente Dependence of Viscosity of Vitreous Silica. Journal of the Ceramic Society of Japan, v. 105, n. 8, p. 645 649, 1997.

[37] - KUSHIBIKI, J.; WEI, OHASHI, Y.; TADA, A. Ultrasonic microspectroscopy characterization of silica glass. Journal of Applied Physics, v. 87, n. 6, p.3113 - 3121, 2000.

[38] - KITAMURA, R.; PILON, L.; MIROSLAW, J. Optical constants of silica glass from extreme ultraviolet to far infrared at near room temperature. Applied Optics, v. 46, n. 33, p. $8118-8133,2007$.

[39] - HETHERINGTON, G.; JACK, K. H. Water in Vitreous Silica: Part I. Influence of "water" content on the properties of vitreous silica. Physics and Ceramics of Glasses, v. 3, n. 4, p. 129 - 133, 1962)

[40] - SCHULTZ, P. C. Binary Titania-Silica Glasses Containing 10 to $20 \mathrm{wt} \% \mathrm{TiO}_{2}$. Journal of the American Ceramic Society, v. 59, p. 214-219, 1976.

[41] - NORDBERG, M. E. Glass having an expansion lower than that of silica. US IP 2,326,059, 3 Aug. 1943. 
[42] - CZANDERNA, A. W.; RAO, C. N. R.; HONIG, J. M. The anatase-rutile transition part I. - kinetics of the transformation of pure anatase. Transactions of the Faraday Society, n. 54, p 1069 - 1073, 1958.

[43] - GOUMA, P. L. MILLS, M. J. Anatase-to-Rutile Transformation in Titania Powders. Journal of the American Ceramic Society, v. 84, n. 3, p. 619-622, 2001.

[44] - BYUN, C. JANG, J. W.; KIM, I. T.; HONG, K. S.; LEE, B. W. Anatase-to-rutile Transition of Titania Thin Films Prepared by MOCVD. Materials Research Bulletin, v. 32, n. 4, p. 431 - 440, 1997.

[45] - RAO, C.N.R.; TURNER, A. HONIG, J.M. Some observations concerning the effect of impurities on the anatase-rutile transition. Journal of Physics and Chemistry of Solids, v. 11, n. 1-2, p. 173-175, 1959.

[46] - YOGANARASIMHAN, S. R.; RAO, C. N. R. Mechanism of Crystal Structure Transformations Part 3. Factors Affecting the Anatase-Rutile Transformation. Transactions of the Faraday Society, n. 58, p. 1579 - 1589, 1962.

[47] - SHANNON, R. D.; PASK, J.A. Kinetics of the Anatase-Rutile Transformation. Journal of the American Ceramic Society, v.48, n.8, p.391-398, 1965.

[48] - MANFRIN, T.; ONO, E.; FUJIWARA, E.; SANTOS, M.; BOERY, M.; SANTOS, J.; SUZUKI, C. influência da temperatura e tempo de tratamento térmico no crescimento e transição de fase de nanocristais de titânia embebidos em matriz de sílica amorfa. In: 19을 Congresso Brasileiro de Engenharia e Ciência dos Materiais, novembro de 2010, Campos do Jordão. Anais do 19 Congresso Brasileiro de Engenharia e Ciência dos Materiais, 2010 p. 1445 - 1452.

[49] - SHANNON, R. D. Phase Transformation Studies in $\mathrm{TiO}_{2}$ Supporting Different Defect Mechanisms in Vacuum-Reduced and Hydrogen-Reduced Rutile. Journal of Applied Physics, v. 11, n. 35, p. 3414 - 1416, 1964.

[50] - HANAOR, D. A. H.; SORRELL, C. C. Review of the anatase to rutile phase transformation. Journal of Material Science, n 46, p. 855 - 874, 2011.

[51] - KUWABARA, M.; WADA, T.; KOMURA, Y. Apparatus for producing an optical fiber porous glass preform. US IP 6,012,305, 11 Jan. 2000. 
[52] - SADANA, K.; SHIOTA, T.; INADA, K. Studies of the chemical kinetics on the vapor phase axial deposition method. Journal of Non-Crystalline Solids, $n$. 188 , p. 275 - 284, 1995.

[53] - HASSANI, A. SERAJI, G. N.; ZABIHI, F. E. Evolution of glass bubbles in VAD sintering process. In: 5th Laser and Fiber-Optical Networks Modeling (LFNM) 2003. September 2003. Alushta, Crimea, Ucrânia. Proceedings of 5th Laser and Fiber-Optical Networks Modeling (LFNM), 2003.

[54] - YONG-TAEG, O.; FUJINO, S.; MORINAGA, K. Fabrication of transparent silica glass by powder sintering. Science and Technology of Advanced Materials, v. 3, p. 297 - 301, 2002.

[55] - CARDOSO, A.V.; ABREU, W. M. The sintering of $\mathrm{v}-\mathrm{SiO}_{2}$ and quartz. Journal of Non-Crystalline Solids, v. 247, p. 103-107, 1999.

[56] - KOIDE, M.; TAKEI, S.; SATO, T.;MATUSITA, K. Preparation of Silica Glass by Electric Current Method. Journal of the Ceramic Society of Japan, v. 110 [9], p. $867-869,2002$.

[57] - MAYERHOFER, T. G.; SHEN, Z.; LEONOVA, E.; EDÉN, M.; KRILTZ, A.; POPP, J. Consolidated silica glass from nanopartcles. Journal of Solid State Chemistry, v. 181, p. 2442 - 2447, 2008.

[58] - RAHAMAN, M. N. Ceramic Processing and Sintering. New York, United States.: Marcel. Dekker, 1995, 770 p.

[59] - MORIMOTO, Y.; IGARASHI, T.; SUGAHARA, H.; MORIMOTO, S. N. Analysis of gas release from vitreous sílica. Journal of Non-Crystalline Solids, n. 139, p. 354 - 46, 1992.

[60] - BIHUNIAK, P. P.; CONDRATE, R. A. Structures, Spectra and Related Properties of Group IVB-doped Vitreous Silica. Journal of Non-Crystalline Solids, n. 44, p. 331 - 343, 1981.

[61] - CARSON, D. S.; MAURER, R. D. Optical Attenuation in Titania-silica Glasses. Journal of Non-Crystalline solids, n. 11, p. 368 - 380, 1973. 